Portland State University

PDXScholar

7-11-1996

\title{
The Dangers of Nuclear Proliferation: Five Reasons More May Not Be Better
}

Matthew MacArthur

Portland State University

Follow this and additional works at: https://pdxscholar.library.pdx.edu/open_access_etds

Part of the Political Science Commons

Let us know how access to this document benefits you.

\section{Recommended Citation}

MacArthur, Matthew, "The Dangers of Nuclear Proliferation: Five Reasons More May Not Be Better" (1996). Dissertations and Theses. Paper 5239.

https://doi.org/10.15760/etd.7112

This Thesis is brought to you for free and open access. It has been accepted for inclusion in Dissertations and Theses by an authorized administrator of PDXScholar. Please contact us if we can make this document more accessible: pdxscholar@pdx.edu. 


\section{THESIS APPROVAL}

The abstract and thesis of Matthew MacArthur for the Master of Science degree in Political Science were presented July 11, 1996 and accepted by the thesis committee and the department.

COMMITTEE APPROVALS:
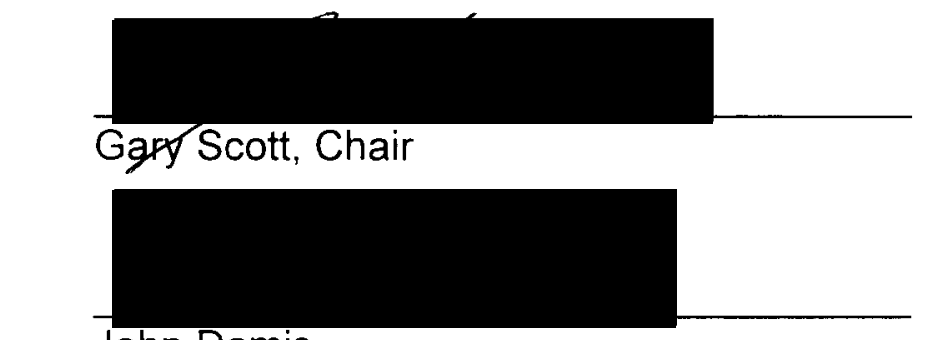

John Damis

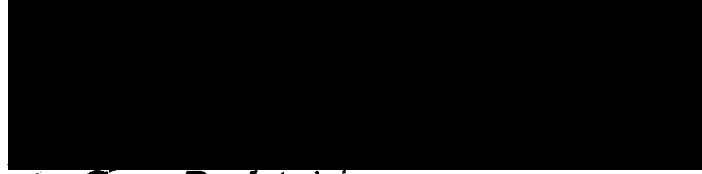

- Gary Peristein

Representative of the Office of Graduate Studies

DEPARTMENT APPROVAL:

Gary Scott, Chair

Department of Political Science

ACCEPTED FOR PORTLAND STATE UNIVERSITY BY THE LIBRARY

by on 29 Cenguet 1996 


\begin{abstract}
An abstract of the thesis of Matthew MacArthur for the Master of Science in Political Science presented July 11, 1996.
\end{abstract}

Title: The Dangers of Nuclear Proliferation: Five Reasons More May Not Be Better

Though many international relations theorists have speculated that the spread of nuclear weapons may diminish the frequency - if not the severity - of military conflict among states, there are five reasons to expect that increased proliferation will increase the likelihood that nuclear weapons will be employed for coercive or destructive purposes. These dangers are independent of one another; that is, they are not interconnected as causes and effects.

First, as nuclear weapons spread, the notion that these weapons are useful for purposes other than deterrence will spread concomitantly. Those who argue that the spread of nuclear weapons will diminish conflict wrongly assume that the leaders of new nuclear states will consider nuclear weapons useful only for deterrence.

Second, actors within states may support policies that undermine deterrence stability. Specifically, such actors could support the deployment of 
weaponry and other technologies that could - in certain strategic contexts provide incentives for pre-emptive attacks by one side or the other.

Third, one side of an inter-state rivalry may acquire nuclear weapons long in advance of its vulnerable adversary. Often, the leaders of states that enjoy such advantages contemplate attacking their rival before it can acquire nuclear weapons, too.

Fourth, though new nuclear states will be assumed to be as careful with their weapons as the older nuclear states, proliferation may nevertheless cause the probability of such accidents to grow at an accelerating rate. As the number of nuclear states increases, the distances between these states decrease, and some of them may assume dangerous launch-on-warning force postures to compensate for their perceived vulnerability to sudden attack. Launch-on-warning increases the danger that accidents could escalate into nuclear violence.

Fifth, surreptitious attempts may be made by third parties to instigate nuclear war between other states. The likelihood that the provocateur of such an incident would remain undiscovered increases as the number of nuclear states grows - as does the temptation to instigate such an event. 
THE DANGERS OF NUCLEAR PROLIFERATION: FIVE REASONS MORE MAY NOT BE BETTER

by

MATTHEW MACARTHUR

A Thes is Submitted in Partial Fulfillment of the Requirements For the Degree of

\section{MASTER OF SCIENCE \\ in \\ POLITICAL SCIENCE}

Portland State University

1996 


\section{ACKNOWLEDGMENTS}

Thanks are due to Gary Scott, for igniting in me the spark of wonder; to Howard and Frances Zoet, for their eternal love; and finally to my wife Lori, for enriching my life in ways too numerous to list here. 


\section{TABLE OF CONTENTS}

PAGE

ACKNOWLEDGMENTS

LIST OF TABLES

vi

CHAPTER

I THE ROOTS OF THE PROLIFERATION DEBATE

1

The Purpose of This Chapter

6

THE REALISTIC ORIGINS OF OPTIMISM $\quad 7$

Realism and the Causes of War $\quad 7$

Realism and Classicism $\quad 9$

Realism, Order and Nuclear Weapons 12

Why Worry? $\quad 16$

PESSIMISM AND ITS ORIGINS 17

Pessimists as Critics of Realism 18

Pessimists as Critics of Classicism $\quad 19$

Pessimists, Order and Nuclear Weapons 21

Why Be Complacent? 23

$\begin{array}{ll}\text { A THIRD PERSPECTIVE } & 25\end{array}$

Nuclear Weapons and International Political

Order

Dual-Level Explanation 
THE STRATEGY OF THIS THESIS

WHAT IS DETERRENCE?

THE COMMITMENT PROBLEM

Rationality and Credibility

Reputation and Credibility

48

DETERRENCE THEORIES

50

NERVE AND PAIN

53

Mutually Assured Destruction

55

MAD and the Commitment Problem

62

Nuclear Utilization Target Selection

71

CONCLUSION

77

III FIVE REASONS FOR PESSIMISM

79

CREEPING ANTI-CLASSICAL THOUGHT

81

The Instinctual Appeal of Anti-Classical Thought

Soviet Resistance to MAD

Anti-Classical Thought and New Nuclear States

Revisionism, Desperation, and the Utility of Nuclear Weapons

The Interaction Between Doctrine and Capabilities 
The Interaction Between Doctrine and Adversary Capabilities

MAD in a Nuclearized World

PAROCHIALISM AND MYOPIA

A Note on Myopia and Anticipation

ASSYMETRICAL PROLIFERATION AND PREVENTATIVE WAR

CASCADING ACCIDENTS AND CRISES

A Brief History of Nuclear Weapons Accidents and Near Accidents

The Implications of "Close Calls" for New Nuclear States

CATALYTIC WAR

SUMMARY

CAN PROLIFERATION BE REVERSED, STOPPED OR SLOWED?

The Problem With Hierarchical Measures

Anarchical Supply-Oriented Measures

Anarchical Demand-Oriented Measures

How Far Will Nuclear Weapons Spread?

CAN PROLIFERATION-RELATED PROBLEMS BE SOLVED ANYWAY? 
Assymetrical Proliferation and Preventative War

Nuclear Use and the Result of a Cascading Accident

Catalytic War 


\section{LIST OF TABLES}

PAGE

TABLE 3-1 Weapons Preferences 85 


\section{CHAPTER ONE:}

\section{THE ROOTS OF THE PROLIFERATION DEBATE}

It is well that war is so terrible, or we should grow too fond of it.

Robert E. Lee

There are only two alternatives for mankind: world government or nuclear holocaust.

Albert Einstein

It would probably come as a surprise to most that anyone would challenge the received wisdom that nuclear proliferation is dangerous. Since the 1960 s, however, the threat posed by the proliferation of nuclear technology has been a hotly-debated issue in the field of international relations. On one side, the Optimists advance a counter-intuitive but nonetheless persuasive argument: in the case of nuclear weapons "more may be better." According to this view, the same factors that prevented direct, large-scale war between the superpowers during the Cold War may also

${ }^{1}$ This is the title of an article by a prominent Optimist. See Kenneth N. Waltz, "More May Be Better," in The Spread of Nuclear Weapons: A Debate, ed: Scott D. Sagan and Kenneth N. Waltz (New York: W.W. Norton \& Company, Inc., 1995), pp. 1-46. 
prevent war among an increasing number of fledgling nuclear states. ${ }^{2}$ On the

other side, the Pessimists make the more familiar argument that as the

number of nuclear-armed states grows, so too does the likelihood that these

weapons might be used. ${ }^{3}$

Bruce Berkowitz — himself an Optimist — points out that the logic of both arguments is unassailable. ${ }^{4}$ However, each argument proceeds from

${ }^{2}$ As Waltz points out, "Nuclear weapons have never been used in a world in which two or more states had them." Waltz, "More May Be Better," p. 15. For other examples of Optimistic literature, see Michael D. Intriligator and Dagobert L. Brito, "Nuclear Proliferation and the Problem of War," Public Choice 37 (1981): 247-260; Bruce Bueno de Mesquita and William H. Riker, "An Assessment of the Relative Merits of Selective Nuclear Proliferation," Journal of Conflict Resolution 26 (June 1982): 293-306; Pierre Marie Gallois, The Balance of Terror (Boston: Houghton-Mifflin, 1961); Walter B. Wentz, Nuclear Proliferation (Washington: Public Affairs Press, 1968).

Berkowitz Optimistically believes that a completely nuclearized world would be the safest, but he Pessimistically doubts that this point is attainable. See Bruce Berkowitz, "Proliferation, Deterrence, and the Likelihood of War," Journal of Conflict Resolution 29 (March 1985): 112-136. Berkowitz's argument will be taken up in the final chapter.

${ }^{3}$ As Rhodes puts it, "the probability of some sort of irrational behavior increases as the number of independent nuclear decision centers suffering the effects of situational stress increases." See Edward J. Rhodes, Power and MADness: The Logic of Nuclear Coercion (New York: Columbia University Press, 1989), p. 190. For more on the "n-th country problem," see Leonard Beaton and John Maddox, The Spread of Nuclear Weapons (New York:

Frederick A. Praeger, Inc., 1962); Joseph S. Nye, Jr., "The Long-Term Future of Deterrence," in The Logic of Nuclear Terror, ed: Roman Kolkowicz (Winchester, MA: Allen \& Unwin, Inc., 1987); Joseph S. Nye, Jr., "NPT: The Logic of Inequality," Foreign Policy 59 (Summer 1985): 127; Albert Wohlstetter, "Technology, Prediction and Disorder," in The Dispersion of Nuclear Weapons, ed: R.N. Rosecrance (New York: Columbia University Press, 1964), p. 289; Arnold Kramish, "The Emergent Genie," in The Dispersion of Nuclear Weapons, ed: R.N. Rosecrance (New York: Columbia University Press, 1964), p. 271; Berkowitz, "Likelihood of War," pp. 11415.

${ }^{4}$ Berkowitz, "Likelihood of War," p. 117. 
incompatible assumptions regarding deterrence, state decision-making, and the likelihood that the spread can be halted or reversed. ${ }^{5}$

Though both arguments are cogent, well-represented, and merit thoughtful consideration, it is the central proposition of this thesis that the proliferation of nuclear weapons will be more dangerous than the Optimists concede. The proliferation of nuclear weapons increases the probability of their use - either as a result of informed deliberation or misperceptions and accidents.

In this thesis I concentrate on five specific dangers. These dangers are independent of one another; that is, they are not interconnected as causes and effects. These dangers may grow at differential rates with respect to the proliferation of nuclear weapons. The first three dangers can be imagined to be additive: with each addition to the "Nuclear Club," the likelihood of use increases by some fixed amount. The fourth and fifth dangers grow at a exponential rate: with each additional increase in the number of nuclear states, the probability of use grows at an increasing rate.

1. Creeping Anti-Classical Thought ${ }^{6}$ The first danger is that as nuclear weapons spread, the notion that these weapons are useful for purposes other than deterrence will

${ }^{5}$ Ibid., p. 113.

${ }^{6}$ Admittedly, the names of these problems - particularly the first - may seem arcane at this point. The terms used here will be defined in the next two chapters. 
spread concomitantly. (As we will see, the Optimistic argument rests on the assumption that most new nuclear states will consider nuclear weapons useful only for deterrence.)

2. Parochialism and Myopia

The second danger is that actors within states may support policies contrary to the avowed objectives of the state as a whole.

Specifically, such actors could support the deployment of weaponry and other technologies that could - in certain strategic contexts prove destabilizing.

3. Asymmetrical Proliferation and Preventative War

The third danger is that of asymmetrical proliferation: one side of an inter-state rivalry may acquire nuclear weapons long in advance of its vulnerable adversary. Often, the leaders of states that enjoy such advantages contemplate attacking their rival before it can acquire nuclear weapons, too.

4. Nuclear Use as a Result of a "Cascading Accident" The fourth danger is that a major nuclear accident during a crisis might result in escalation to a nuclear exchange. Though new nuclear states will be assumed to be as careful with their weapons as the older nuclear states, proliferation may nevertheless cause the probability of such accidents to grow at an accelerating rate. As the number of nuclear states increases, the distances between these states decrease, and some of them may assume dangerous launch-on-warning force postures to compensate for their perceived vulnerability to sudden attack: Launch-on-warning increases the danger that accidents could escalate into nuclear violence.

${ }^{7}$ I borrow this term from Milton Leitenberg, "Nuclear Weapons and 50 Years of International Political History: Risks, Dangers, Threats, Crises, Proposals and Considerations of Use," (Unpublished manuscript, 7 August, 1995). 
5. Catalytic War

The fifth danger is the possibility of a surreptitious attempt by a third party to instigate nuclear war between other states. The likelihood that the provocateur of such an incident would remain undiscovered increases as the number of nuclear states grows - as does the temptation to instigate such an event.

Two terminological points ought to be made before proceeding. First, by "use" of nuclear weapons, I am referring to any use of nuclear weapons other than for deterrence. Nuclear blackmail for the purpose of shifting the status quo - even when the blackmailer has no intention of actually using the weapons as threatened - constitutes use by my reckoning.

Second, I borrow the Department of Defense definition of accident:

An unexpected event involving nuclear weapons or nuclear weapons components that results in any of the following: accidental or unauthorized launching, firing, or use by U.S. forces or supported allied forces, of a nuclear-capable weapon system which could create the risk of an outbreak of war; nuclear detonation; non-nuclear detonation or burning of a nuclear weapon or radioactive weapon component, including a fully assembled nuclear weapon, an unassembled nuclear weapon, or a radioactive nuclear weapon component; radioactive contamination; seizure, theft, or loss of a nuclear weapon, or radioactive nuclear weapon component, including jettisoning; public hazard, actual or implied. ${ }^{8}$

At the risk of sounding callous, my interest in accidents is confined only to those events that could provoke nuclear hostilities. Such cases would (May 1981): 2

8 "U.S. Nuclear Weapons Accidents: Danger in Our Midst," The Defense Monitor 10 
presumably involve either false warnings of attack or accidental detonations, and these accidents could spiral into nuclear violence only if they occurred during intense international crises.

\section{The Purpose of This Chapter}

In the sections below, I will examine what I consider to be the most significant difference between Optimists and Pessimists. Optimists are Realists who are comfortable with the assumption that states are unitary rational actors, and that their behavior is determined mostly by exogenous, "structural" forces. Pessimists reject this assumption, and instead assume that the primary determinants of state behavior are endogenous. These divergent predispositions have led Optimists and Pessimists to radically opposed conclusions about the danger of nuclear proliferation.

The remainder of this chapter will be devoted to an examination of this rift and its ramifications. I will also develop an alternative "Pessimistic" perspective on proliferation. Obviously, the need for an alternative approach implies that each of the present choices are inadequate in some way. My alternative perspective will be constructed by retaining some of the Pessimists' assumptions, while rejecting those I consider indefensible. 


\section{THE REALISTIC ORIGINS OF OPTIMISM}

As Berkowitz explains, theories about the danger of proliferation are based on theories of deterrence. If one is confident that deterrence has succeeded and will continue to be successful in the future, then one would likely be an Optimist. However, if one believes other factors - including perhaps good fortune - have prevented nuclear war in the past, then one would likely be a Pessimist.

Robert Powell points out a deeper linkage: deterrence theories are in turn based on theories of the causes of war. ${ }^{9}$ Without a theory of the causes of war to supplement it, a deterrence theory alone provides no basis for estimations of the likelihood of war. ${ }^{10}$

I argue below that Optimism is founded upon Classical deterrence theory, which is based on Realism - a theory of the causes of war.

\section{Realism and the Causes of War}

In Man, the State, and War, Kenneth Waltz identifies three "images" or levels of analysis - in the study of the causes of war. First-image, or individual-level analyses seek explanations of war within humans themselves.

\footnotetext{
${ }^{9}$ Powell, "Theoretical Foundations," p. 96.

${ }^{10}$ Ibid., p. 93.
} 
Second-image, or state-level explanations of war focus on factors within the state. Finally, third-image, or system-level explanations of war focus on the environment within which states operate as the cause of war. ${ }^{11}$

The Realists emphasize the structural causes of war. Regardless of the individual idiosyncrasies of leaders, or the uniqueness of the states they lead, Realists expect that states will operate in a roughly similar manner by virtue of the fact that they all must meet the demands of survival in an anarchical environment. States must seek security through either selfimprovement or strategic alliance. For Realists, peace is not so much the product of good intentions as it is a fortuitous and often unintended byproduct of the distribution of power.

Therefore, the advent and spread of nuclear weapons alone does not cause the Optimists to be hopeful that the probability of war will diminish. Rather, it is the Optimists' Realistic, structural focus that produces this expectation. The balance of power becomes far easier to maintain when it is evident that all states are capable of inflicting intolerable damage upon one another with nuclear weapons. ${ }^{12}$

${ }^{11}$ For a good suvey of the various theories on the cause of war, and the evidence supporting them, see J. David Singer, "The Political Origins of International War: A

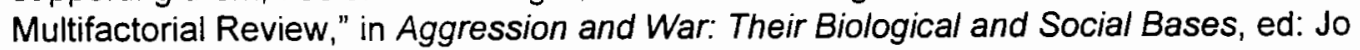
Groebel and Robert A. Hinde (Cambridge, U.K.: Cambrige University Press, 1989), pp. 202219.

${ }^{12}$ Nye, "Future of Deterrence," p. 234. 


\section{Realism and Classicism}

The Optimists are also Classicals - adherents of Classical deterrence theory and proponents of the doctrine of Mutually Assured Destruction (MAD). ${ }^{13}$ The Classicals expect that the possession of nuclear weapons by rival states will have an irenic effect when three tenets of MAD are fulfilled: first, a portion of the nuclear arsenals of both rival states must be able to survive a first-strike; ${ }^{14}$ second, the survival of either side's weapons cannot depend on a launch-on-warning force posture $;^{15}$ and third, the probability of accidental or unauthorized launches from either state must be minimized.

When these tenets are adhered to, states contemplating first-strikes would quickly realize that they would be better off not launching such an attack, given the expected utility of such an action. ${ }^{16}$ This assumption that

${ }^{13}$ MAD will receive greater attention in Chapter Two. The Optimists do deviate from Classicism occasionally. For example, Waltz, though mostly Classical, seems to expect that nuclear war would be a methodical, deliberate "bargaining" process of attack and counterattack rather than a spasm of uncontrolled violence. As we will see in the next chapter, this expectation accords better with the views of the Anti-Classicals than those of the Classicals.

${ }^{14}$ James DeNardo, The Amateur Strategist: Intuitive Deterrence Theories and the Politics of the Nuclear Arms Race (New York: Cambridge University Press, 1995), pp. 22-23.

${ }^{15}$ Stated another way, some of the weapons must be made invulnerable - through point-defense techniques, mobility, hardening of silos, or other techniques.

${ }^{16}$ Waltz, "More May Be Better," p. 20. 
states are utility maximizing entities is the tie that binds Classicals and Realists together.

When MAD conditions do not obtain, however, Classicals admit that deterrence may be unstable. If one state's nuclear arsenal is vulnerable to a first-strike, the danger of preventative war increases, especially during crises. ${ }^{17}$ If a state's weapons must be launched on detection to survive, the likelihood of launch on the basis of misperception or technical malfunction increases, and again makes preventative war more attractive for the adversary.

Classicals and Optimists do not worry too much about these possibilities, however, because they are confident that state leaders will recognize that MAD is not only a valid policy doctrine, but an inescapable condition of the modern world. According to such Classicals, resistance to MAD is futile, and obviously so. States will strive to ensure that the doctrine's basic tenets are maintained. Furthermore, the Optimists consider these tenets easily adhered to. ${ }^{18}$

${ }^{17}$ Robert Jervis, "Arms Control, Stability and Causes of War," Political Science Quarterly 108 (Summer 1993): 248.

${ }^{18}$ Kenneth N. Waltz, "Waltz Responds to Sagan," in The Spread of Nuclear Weapons: A Debate, ed: Scott D. Sagan and Kenneth N. Waltz (New York: W.W. Norton \& Company, Inc., 1995), pp. 108-110. 
They also regard the threat of nuclear-armed "mad colonels" as greatly exaggerated, and argue that as long as leaders are "sensitive to costs" even the irrational would be deterred from launching a first-strike. ${ }^{19}$ In the age of $M A D$, what states should do and what states will do are no longer separate issues. Given the stark choices of survival and destruction, no leader — smart or stupid, sane or mad - is likely to use nuclear weapons. ${ }^{20}$

For Optimists, it is understandable that states without nuclear weapons would seek them. These weapons offer weak and poor states a number of advantages, not the least of which being an alleviation of the pressure to enhance their security through territorial expansion and military spending. ${ }^{21}$

${ }^{19}$ Waltz, "Waltz Responds," pp. 98, 113. The assumption of rationality used in this text is modified from Strotz's: "An individual is imagined to choose a plan of [action] for a future period of time so as to maximize the utility of the plan as evaluated at the present moment." $R$. $\mathrm{H}$. Strotz, "Myopia and Inconsistency in Dynamic Utility Maximization," Review of Economic Studies 23 (1955-56): 165. I have simply substituted "action" for "consumption."

Many have noted that nuclear deterrence does not require sanity. Waltz speculates that even Hitler would have been deterred had the Axis and Allied powers been armed with weapons of mass destruction. Even if he had not been deterred, his generals would be reluctant to carry out orders that would result in national suicide. Waltz claims that historical evidence that Hitler's orders to use gas weapons late in the war were ignored lend support to this view. Waltz, "More May Be Better," pp. 28-29. See also Robert Jervis, "Deterrence Theory Revisited," World Politics 31 (January 1979): 300; Waltz, "Waltz Responds," p. 98; John J. Weltman, "On the Obsolescence of War: An Essay in Policy and Theory," International Studies Quarterly 18 (December 1974): 190.

${ }^{20}$ As Waltz puts it, "War becomes less likely as the costs of war rise in relation to possible gains." Waltz, "More May Be Better," p. 3. See also Steinbruner, "Beyond Rational Deterrence," p. 227.

${ }^{21}$ Waltz, "More May Be Better," pp. 29-33. On the various benefits of nuclear weapons, from their affordability to their prestige value, see Hedley Bull, The Control of the Arms Race (New York: Praeger, 1961), p. 152; Aaron Karp, "Ballistic Missiles in the Third World," International Security 9 (Winter 1984-85): 194; Steve Fetter, "Ballistic Missiles and Weapons of Mass Destruction," International Security 16 (Summer 1991): 12; Weltman, 
To deny states the ability to acquire these weapons would not only needlessly heighten animosity between the nuclear "Haves" and "Have Nots," but would impede the expansion of the "nuclear peace."22

\section{Realism, Order and Nuclear Weapons}

There are thought to be two principal types of order in international politics, which result from different distributions of power among states. ${ }^{23}$ First and most obviously, a hierarchical order can be imposed by a powerful state, or group of allies, on the less powerful. Second, when there are no states sufficiently powerful to impose a hierarchical order, states may ally with one another to form two or more equally powerful poles. An anarchical order of

"Obsolescence of War," International Studies Quarterly 18 (December 1974): 175; R. N. Rosecrance, "Stability and Nuclear Diffusion," in The Dispersion of Nuclear Weapons, ed: R. N. Rosecrance (New York: Columbia University Press, 1964), p. 301; Robert Gilpin, War and Change in Worid Politics (New York: Cambridge University Press, 1981), pp. 215-216; Daniel Ellsberg, "Manhattan Project II: To End the Threat of Nuclear War," Harvard Journal of World Affairs (Summer 1992): 6.

The new Russia is today experiencing the pressures felt by weak, non-nuclear states, and is strengthening its nuclear posture. Technologically, U.S. conventional forces surpass Russia's, and Moscow can ill-afford to devote resources to conventional military modernization and research and development. See Bruce G. Blair, Global Zero Alert for Nuclear Forces (Washington, D.C.: The Brookings Institution, 1995), p. 4; Ellsberg, "Manhattan Project II," pp. 6-7.

${ }^{22}$ As Karp explains, "By trying to deny the Third World countries the technologies they earnestly see as necessary to their own national interests, restraint will earn their enmity in direct proportion to the program's success." See Karp, "Ballistic Missiles," p. 192.

${ }^{23}$ Jon Elster, Nuts and Bolts for the Social Sciences (Cambridge: Cambridge University Press, 1989), p. 101. 
this sort has prevailed in international society since the dawn of the state system. $^{24}$

For a variety of reasons, Realists prefer anarchical order. First, Realists regard states as rational, power-maximizing, unitary actors. Seen as such, states can be expected to be capable of maintaining the balances of power necessary to prevent large-scale or "hegemonic" war. Second, assuming that a hierarchical international order would be desirable, the transition to it would be a bloody and costly affair. ${ }^{25}$ Third, assuming that an anarchical order could peacefully yield to hierarchy, many Realists subscribe to a "pluralist" or "power corrupts" belief that it is preferable that no single actor dominate all others. Instead, they argue that security ought to be achieved by pitting states against one another to prevent global tyranny. ${ }^{26}$ Finally, many argue that despite advances, plans to unite the world under one authority remain technically unfeasible. ${ }^{27}$

${ }^{24}$ Hedley Bull, Arms Race, p. 37. On anarchical orders, see also Raymond Aron, "The Anarchical Order of Power," Daedalus 124 (Summer 1995): 27-52.

${ }^{25}$ Gilpin, War and Change, pp. 228-229.

${ }^{26}$ See for example Kenneth N. Waltz, "Anarchic Orders and Balances of Power," in Neorealism and Its Critics, ed: Robert Keohane (New York: Columbia, 1986), pp. 108-112.

${ }^{27}$ Albert Wohlstetter, "Technology, Prediction and Disorder," p. 281. R. N. Rosecrance, "Bipolarity, Multipolarity and the Future," Journal of Conflict Resolution 10 (September 1966): 314. 
For the Realists, the advent of nuclear weapons has not ushered in a new international political era. They consider nuclear weapons merely another in a long series of functionally-related technologies stretching back to antiquity. ${ }^{28}$ Thomas Schelling makes the macabre observation that, "Against defenseless people there is not much that nuclear weapons can do that cannot be done with an ice pick" - emphasizing the essential similarity of all weapons and crystallizing Realist and Optimist thought on the matter. ${ }^{29}$

The implication of the Optimists' conclusion that nuclear weapons are not a qualitatively novel development is that these weapons do not necessitate the transformation of the present anarchical international order, which has endured since the Peace of Westphalia. They point out that past predictions that nuclear weapons would precipitate the demise of the state system have so far proven incorrect. Despite hopes and fears that the

${ }^{28}$ Pipes points out, for example, that the atomic bombing of Hiroshima killed 72,000 , whereas the conventional bombing of Dresden claimed the lives of 135,000 . Richard Pipes, "Why the Soviet Union Thinks It Could Fight and Win a Nuclear War," Commentary 64 (July 1977): 22.

Despite the Optimists protestations to the contrary, Bull charges that Optimists consider nuclear weapons as "wholly novel" as do Pessimists. To Optimists, they represent the promise of "Pax Atomica," while Pessimists consider them the greatest threat yet to civilization. Bull, Arms Race, p. 95. He later claims that, "Both views arise from what is the bane of much thinking about politics: the conviction of the uniqueness of present problems." Ibid, p. 46.

${ }^{29}$ Thomas C. Schelling, Arms and Influence (New Haven: Yale University Press, 1966), p. 19. Rapoport makes a very similar point when he explains that with nothing but nooses, the Thugs may have killed more people than any other group in world history. See David C. Rapoport, "Fear and Trembling: Terrorism in Three Religious Traditions," American Political Science Review 78 (September 1984): 658-677. 
traditional structures of world politics might be transcended, "this system has survived the introduction of the weaponry intact, and indeed without catastrophe." ${ }^{30}$

Furthermore, Realists consider themselves "realistic" because they attempt to view international politics as it is, rather than as it ought to be. Because they are Realists, Optimists accept as a given that nuclear technology cannot be un-invented, and that the spread of nuclear weapons is inevitable so long as they remain in demand. ${ }^{31}$ Beginning with this assumption, Optimists try simply to make the best of an admittedly bad situation by expounding upon the potential benefits of managed proliferation rather than concocting utopian solutions. ${ }^{32}$

${ }^{30}$ John J. Weltman, "Obsolescence of War," pp. 171-172.

${ }^{31}$ For statements on the inevitablity of proliferation and the impossibility of forever eliminating nuclear weapons, see Steve Fetter, "Ballistic Missiles and Weapons of Mass Destruction," International Security 16 (Summer 1991): 40; Berkowitz, "Likelihood of War," p. 115; Ellsberg, "Manhattan Project II," p. 4.

Ironically, it may be the Pessimists who provide the more compelling evidence that the spread cannot be halted. See, for example, Blair, Global Zero Alert, pp. 33-35, on the possibility of smuggling weapons-grade plutonium out of Russia, Ukraine and Kazakhstan. Blair also points out that weapons-grade plutionium may not even be necessary to build nuclear bombs, and that the belief that only weapons-grade plutonium is useful for bombmaking has led the Russians to be lax in its security of its nonweapons nuclear sites. He points out that in the early 1960 s, the U.S. itself conducted tests of nuclear weapons using merely reactor-grade plutonium. Ibid, p. 38, n. 56 .

${ }^{32}$ For instance, Mearsheimer seems fully cognizant of the potential dangers of proliferation. Nevertheless, he argues that, "Well-managed proliferation would reduce the danger that states might miscalculate the relative strength of coalitions, since nuclear weapons clarify the relative power of all states, and diminish the importance of unforeseen additions and defections from alliances." See John J. Mearsheimer, "Back to the Future: Instability in Europe After the Cold War," in The Cold War and After: Prospects for Peace, ed: Sean M. Lynn-Jones and Steven E. Miller (Cambridge: MIT Press, 1993), pp. 173-175. 


\section{Why Worry?}

If the correctness of MAD doctrine is patently obvious, how do

Classicals and Optimists explain the prevalence of Pessimism? They dismiss their critics as victims two related fears. First, Optimists charge that apprehension regarding the spread of nuclear weapons is rooted in a fear of the limitations it would impose on older nuclear states. ${ }^{33}$ States traditionally considered powerful, having invested heavily in conventional military forces, would see their advantages evaporate, and would consequently be less capable of imposing their will on erstwhile weak states now armed with nuclear weapons. ${ }^{34}$

Second, Optimists contend that Pessimism may be rooted in ethnocentrism. ${ }^{35}$ According to Optimists, the Pessimists are anxious about

Similarly Realistic views can be seen in Bruce Berkowitz, "Technological Progress, Strategic Weapons, and American Nuclear Policy," Orbis 29 (Summer 1985): 258.

${ }^{33}$ Waltz, "Waltz Responds," p. 111. Had North Korea, North Vietnam or Iraq possessed nuclear weapons, the recent history of U.S. interventionism would certainly be very different. On this point, see Fetter, "Ballistic Missiles," p. 28; Ellsberg, "Manhattan Project II," p. 9.

34 "Certainty about the relative strength of adversaries . . makes war less likely," claims Waltz. Nuclear weapons increase that certainty. Waltz, "More May Be Better," p. 6.

${ }^{35}$ For example, Wohlstetter worries that, "While more responsible powers would be hard put to it to find a use for their nuclear capability, diffusion is likely to bring some less responsible recruits into the club." Wohlstetter, "Nuclear Sharing," p. 203. Statements such as these have provided the Optimists ammunition for use against the Pessimists. 
what "lesser breeds without the law" may do with nuclear weapons. ${ }^{36}$ John

Weltman, for example, argues that

any assertion that regional nuclear balances would, as a general rule, be unstable for political reasons - the absence of those patterns of behavior and modes of thought that produced prudence in the SovietAmerican relationship - must be regarded to be of questionable validity. Such an assertion would assume that the capacity for political rationality is a narrow, culturally-based attribute ... . It must instead flow from a belief that these states are somehow incapable of making the correct instrumental inferences as to the means to effectuate goals of self-preservation. Is there any basis for such a view - beyond that Western conceit which would hold rationality to be an attribute confined to ourselves? ${ }^{37}$

In sum, because the possession of nuclear weapons tends to foster wariness, the Optimists argue that the ultimately unstoppable spread of nuclear weapons among states is something that probably should not be feared — and certainly should not be hindered — by older nuclear states.

\section{PESSIMISM AND ITS ORIGINS}

If Optimism finds its origins in Realism and Classical deterrence theory, then where do the roots of Pessimism lie? Though Pessimists have a more diverse background than the Optimists, they usually proceed from first- and

\footnotetext{
${ }^{36}$ Waltz, "More May Be Better," p. 13.

${ }^{37}$ Weltman, "On the Obsolescence of War," pp. 189-190.
} 
second-images of the causes of war. By looking within the state rather than at the international political structure for explanations, the Pessimists find two problematic data. First, states are not unitary rational actors, as they are imagined to be by the Realists. Second, states do not always follow the tenets of MAD doctrine as Classicals suggest. ${ }^{38}$ So while Pessimism has a wide range of origins, the Pessimists usually have two things in common: they are critical of Realism, and they are critical of those Classicals who consider their doctrine's merit to be evident to all.

\section{Pessimists as Critics of Realism}

The Pessimists look for first- or second-image explanations of war, and seek explanations at the agent-level of international politics. They reject structuralism, and expect that agents may behave differently under similar circumstances. ${ }^{39}$ They also dispense with the unitary depiction of states, bringing into focus a range of agent-level explanations of state behavior: "the internal politics and bureaucracy of government, ... the chain of command

${ }^{38}$ Examples of departures from MAD doctrine by the U.S. and the Soviets will be examined in Chapter Two. Deviations by other states will be explored in Chapter Three.

${ }^{39}$ See Barry Buzan, Charles Jones and Richard Little, The Logic of Anarchy: Neorealism to Structural Realism (New York: Columbia University Press, 1993), p. 244; Stephen Haggard, "Structuralism and Its Critics: Recent Progress in International Relations Theory," in Progress in Postwar International Relations, ed: Emanuel Adler and Beverly Crawford (New York: Columbia University Press, 1991), pp. 418-419. 
and on lines of communication, ... party structures and pressure groups, as well as . . . individual values and careers. ${ }^{40}$

Given their agent-level focus, the Pessimists have less reason to expect that the spread of nuclear weapons will diminish the frequency of war in international society. Some leaders may become cautious once they acquire nuclear weapons; others may become reckless or bold. The effects of possession on leaders will likely vary depending upon a host of factors, from their personal idiosyncrasies, to the relative capabilities of their adversaries. ${ }^{41}$

\section{Pessimists as Critics of Classicism}

Because they focus on individual state leaders and governments, Pessimists are more open to the possibility that these entities may - correctly or incorrectly - come to conclusions divergent to the Classicals with regard to the utility of nuclear weapons.

How and why would nuclear weapons ever be used? Pessimists offer a variety of answers to this question. "Accidental" use of nuclear weapons is 1966), p. 86.

${ }^{40}$ Thomas C. Schelling, Arms and Influence (New Haven: Yale University Press,

${ }^{41}$ A variety of analysts argue that the effects of proliferation to the " $n$-th country" depend upon the identify of the $n$-th state and its leaders. See Rosecrance, "Nuclear Diffusion," p. 311; Berkowitz, "Likelihood of War," pp. 124-130; Intriligator and Brito, "Nuclear Proliferation," p. 248. 
possible, and though such an event would not necessarily precipitate an uncontrollable escalatory spiral of violence, it might. ${ }^{42}$ Psychologically unstable leaders may also use nuclear weapons to realize some objective. ${ }^{43}$ Pessimists also do not discount the possibility of deliberate, rational use of nuclear weapons. Robert Gilpin reminds us that "it is far too early to conclude that there will not be a Gaius Marius, Alexander, or Napoleon who will develop tactics and strategy to make nuclear weapons and the nuclear threat effective instruments of national policy." ${ }^{44}$

Even rational leaders who never intended to use nuclear weapons for anything other than deterrence might be forced to consider such options by the limiting effects of their prior decisions. ${ }^{45}$ While a rational leader may be unlikely to decide to annihilate an adversary - especially when the intended

42 Though many argue that there is no such thing as an accidental war, Sagan cites three examples: the Japanese invasion of Manchuria in 1931 (an unauthorized attack), the French and Indian War (sparked in 1754 by an erroneous report of a French invasion of Maine) and the Battle of Wounded Knee in 1890 (a tense standoff led to a firefight desired by neither side). See Sagan, Limits of Safety, p. 263.

${ }^{43}$ Rhodes explains that "while individuals with different, 'nonsensible' values or with irrational decision-making processes are presumably no more likely to exist now than in the past, they now have the power to inflict more damage ..." Rhodes, Power and MADness, $p$. 139.

${ }^{44}$ Gilpin, War and Change, p. 217.

${ }^{45}$ This problem - also refered to as "stepwise irrationality" or the "penny-wise, poundfoolish" problem - is described well by Rhodes. "[A]fter the first step is taken, the expected marginal benefit of the second step outweighs its expected marginal cost, even though the total cost of the two steps together outweighs their total benefit," he explains. Rhodes, Power and MADness, p. 118. 
victim could retaliate - past choices regarding weapons acquisitions, deployment, and even issues only tangentially related to deterrence could dangerously narrow a leader's range of options in the present. ${ }^{46}$

\section{Pessimists, Order and Nuclear Weapons}

Most Pessimists consider nuclear weapons to be novel, "absolute" weapons, and they subscribe to the belief that the present anarchical international order must be transformed so that the horrors of nuclear use can be averted. ${ }^{47}$ The Pessimists seem to subscribe to what Albert Wohlstetter has dubbed the "Small World" perspective: the view that new technologies "enable us from any one point on earth to affect any other point and to do this with increasing speed and effectiveness. ${ }^{.48}$ Small Worlders often assume that

${ }^{46}$ This problem is particularly acute in the case of organizations, in which individual members wrangle over definitions of collective interests, often trying to hijack the organization so as to secure short-term personal interests at the expense of long-term organizational interests. For example, though a leader may understand the need for a secure second-strike force, organizational pressures (e.g., interservice rivalries, defense industry influence) could make it difficult to achieve this objective. On these difficulties, see Jervis, "Deterrence Theory Revisited," pp. 312-314.

${ }^{47}$ On the absolute nature of nuclear weapons, see Kenneth N. Waltz, "The Origins of War in Neorealist Theory," in The Origin and Prevention of Major Wars, ed: Robert I. Rotberg and Theodore K. Rabb (Cambridge, U.K.: Cambridge University Press, 1988), p. 51. See also Bernard Brodie, The Absolute Weapon: Atomic Power and World Order (New York: Harcourt Brace, 1946), pp. 75-76.

${ }^{48}$ Wohlstetter, "Technology, Prediction and Disorder," p. 279. 
far-reaching technologies will be used simply because they can be used, ${ }^{49}$ and conclude that there is an "immediate necessity for world-wide agreement in controlling the technology of destruction - a control that amounts to organizing the separate sovereignties into one world - simply because the destructive implications of technology are so awful." ${ }^{\text {. }}$

Some Pessimists propose as an intermediate step the centralization of control of nuclear weapons within the states that possess them, and express the ultimate hope that all nuclear weapons will eventually be placed in the custody of a supreme international authority. ${ }^{51}$ To accomplish this task, it would be necessary to transform the international order from anarchy to hierarchy, so that a central authority could either monopolize nuclear weapons, or somehow enforce a ban on these (and presumably other) weapons.

${ }^{49}$ For example, Von Neumann claims that "once such possibilities become actual, they will be exploited." John Von Neumann, "Can We Survive Technology?", Fortune, June 1955, p. 152. See also Wohlstetter, "Technology, Prediction and Disorder," p. 285.

${ }^{50}$ Wohlstetter, "Technology, Prediction and Disorder," p. 279.

${ }^{51}$ For example, Iklé expresses the hope that, "By exerting sustained leadership, the United States can - again with some good luck — organize a project that would succeed where the Baruch and Acheson-Lilienthal plans of 1946 . . . were destined to fail." Iklé rejects the idea of world government, which he thinks "would either degenerate into global tyranny or - far more likely - prove totally ineffective." See Fred Charles Iklé, "The Second Coming of the Nuclear Age," Foreign Affairs 75 (January-February 1996): 127-128.

For a notable exception to this trend, see Sagan, The Limits of Safety, pp. 274-75. 


\section{Why Be Complacent?}

If the Pessimists are correct, then how do they explain the relative complacency with which the Optimists regard proliferation? First, the Pessimists accuse the Optimists of having "confused prescriptions of what rational states should do with predictions of what real states will do." ${ }^{52}$ The Pessimists have little faith that the leaders of new nuclear states will embrace MAD doctrine or will be able to adhere to its tenets.

Second, the Pessimists accuse the Optimists of misusing the U.S.Soviet model of deterrence, by exaggerating its stability and by overgeneralizing from the single specific case. ${ }^{53}$ Authors including Scott Sagan and Bruce Blair cite numerous instances in which both states deviated from Classicals' prescriptions and Optimists' expectations. Also, the level of hostility between the superpowers may never have been as great as it is along other dyads of potential nuclear conflict. ${ }^{54}$ Finally, one cannot

${ }^{52}$ Scott D. Sagan, "More Will Be Worse," in The Spread of Nuclear Weapons: A Debate, ed: Scott D. Sagan and Kenneth N. Waltz (New York: W.W. Norton \& Company, Inc., 1995), p. 86.

Snyder levels this criticism against the Optimists and Pessimists alike: "Most discussions of the dynamics of nuclear confrontations have tended to telescope these two questions - 'which strategy should logically be adopted?' and 'which strategy will in fact be adopted?' - into a single issue." Jack L. Snyder, "Rationality at the Brink: The Role of Cognitive Processes in Failures of Deterrence," World Politics 30 (April 1978): 346.

${ }^{53}$ Bull, Arms Race, p. 148. Unique rules may have developed in the case of U.S.Soviet deterrence that may not be generalizable. See Nye, "Future of Deterrence," p. 243.

${ }^{54}$ As Beaton and Maddox explain, "Where none of the political conflicts between Russia and the United States are matters of life and death, those between Israel and her Arab 
confidently identify the U.S.-Soviet model as an example of successful deterrence. To make the claim that deterrence was successful, one would have to demonstrate conclusively that at some point one side or the other intended to attack the other, and was prevented from doing so by their adversary's threats. ${ }^{55}$

Finally, the Pessimists speculate that the very unthinkablility of nuclear war may impel Optimists to optimism. Hedley Bull, for example, suggests that Optimism may stem partly from "metaphysical" reasoning: nuclear war will not occur because it must not. "This is a view that is not often made explicit, but which lurks unstated in much of our thinking. .." he warns. "However, history is littered with catastrophe unthinkable and unimaginable to its victims, who placed their trust in a logic of history which deserted them in their hour of need." 56

neighbours, Pakistan and India, South Africa and black Africa . . might appear to some governments as an issue for which anything must be risked." Beaton and Maddox, The Spread of Nuclear Weapons, p. 202. Also see Gilpin, War and Change, p. 218.

${ }^{55}$ Patrick M. Morgan, Deterrence: A Conceptual Analysis (Beverley Hills: Sage Publications, 1977), p. 35.

${ }^{56}$ Bull, Arms Race, p. 48. Pipes also remarks on the "metaphysical" aspects of Classicism. See Pipes, "Fight and Win," p. 30. 


\section{A THIRD PERSPECTIVE}

Before one determines whether proliferation will be safe or dangerous, one must ask, "Safe or dangerous for whom?" In a sense, the Optimists and Pessimists are both correct. The Optimists are hopeful that the structure of international politics will endure despite the advent of nuclear weapons. There may be some unfortunate nuclear "balancing" here or there, but the balance will be quickly reestablished, and structural stability will be enhanced because the proliferation of nuclear weapons will reduce the frequency - if not the severity - of balancing wars. ${ }^{57}$

The Pessimists are apprehensive about the ramifications of nuclear imbalances - perceived or real, temporary or enduring. As Bull explains, "Military balances have contributed to the avoidance of particular wars, but they are not a guarantee against war: on the contrary, war is one of the instruments by which the balance is maintained. ${ }^{158}$ The Pessimists care less about the structural durability of international politics than preventing nuclear balancing and avoiding the uncontrollable frenzies of nuclear violence balancing wars might precipitate.

${ }^{57}$ A tension between Classicism and Realism becomes apparent here. Though the two theories regard states as unitary rational actors, Classicals expect that even limited use of nuclear weapons could escalate into all-out nuclear war. The Optimists, who are both Realists and Classicals, dismiss this danger of escalation. This tension will be examined more fully in Chapter Two.

${ }^{58}$ Bull, Arms Race, pp. 38-39. 
In the remainder of this chapter I stake out a new position in the proliferation controversy that, while pessimistic, is founded upon more solid assumptions than is either the Optimists' or the Pessimists'. First, I reject both the exclusive structure- and agent-orientations of the Optimists' and the Pessimists' in favor of a dual-level approach. Second, I accept the Realist's preference for anarchical international order.

By rejecting some elements of Optimism and Pessimism and embracing others, 1 inevitably reveal my own normative bias. This ought not be regarded as an unscientific move. As James Rosenau explains, "science is not so much a value-free enterprise as a value-explicit one. It requires observers to be clear about their presence in the research, to acknowledge biases and idiosyncratic perspectives that may skew their interpretations." ${ }^{59}$

\section{Nuclear Weapons and International Political Order}

There is much to be said for attempts to discern meaningful continuities amidst something as ostensibly chaotic as world politics. Indeed, if analysts were blind to continuity - if every observation was new and unique - the

59 James N. Rosenau, Turbulence in World Politics: A Theory of Change and Continuity (Princeton: Princeton University Press, 1990), p. 33. For other discussions of the unacknowledged normative content of intenational relations literature, see Hedley Bull, "International Theory: The Case for the Classical Approach" World Politics 18 (April 1966): 361-377; Weltman, "Obsolescence of War," p. 403; Buzan, Jones and Little, Logic of Anarchy, pp. 174-199. 
study of international relations (or anything else) would quickly degenerate into aimlessly cataloging unrelated events over time.

However, there is also the countervailing danger that a preoccupation with continuity could blind an analyst to significant changes. Stubbornly refusing to abandon expectations based on observations of the past could lead to disastrous miscalculations in the present. Ignoring the distinctiveness of nuclear weapons may allow international relations theorists to retain the assumptions, models and theories of the past, but a continued reliance on them is likely, in my estimation, to leave theorists and policymakers surprised by and unprepared for nuclear threats in coming decades.

Therefore, it is necessary to reevaluate one's expectations in the face of significant change. Knowing when such a shift is required is too often not apparent until evidence begins to accumulate that past expectations are illsuited to coping with present circumstances. In the case of nuclear weapons proliferation, the immolation of a population may be the only indisputable evidence of the need for a fundamental re-examination of one's assumptions. Thus, it is desirable to anticipate the need to change so that the transition can be voluntary and proactive, rather than merely a thoughtless reflex.

Nuclear weapons are more than merely the latest step up the ladder of weapons technology; the numerous quantitative differences between nuclear and conventional weapons (in terms of destructiveness, range, rapidity of 
effect, etc.) are so great as to make their qualitatively different from their antecedents. ${ }^{60}$ Perhaps the most important difference between nuclear weapons and the weapons of the past is the speed with which destruction can be accomplished; they "make it possible to do monstrous violence to the enemy without first achieving victory." 61

Although ice picks and other primitive weapons could be used to butcher thousands (and, unfortunately, are), it would take fewer people to accomplish the same task with nuclear weapons. ${ }^{62}$ Nuclear homicide is also a less messy affair from the perspective of the perpetrators of the violence. ${ }^{63}$ (Even Schelling, who earlier compared nuclear weapons with ice picks,

${ }^{60}$ As Keeny and Panofsky point out, "a single modern strategic nuclear weapon could have a million times the yield of the high explosive strategic bombs of World War II, or one hundred to a thousand times the yield of the atomic bombs that destroyed Hiroshima and Nagasaki ..." Spurgeon M. Keeny, Jr. and Wolfgang K. H. Panofsky, "MAD Versus NUTS," Foreign Affairs 60 (Winter 1981-82): 291-292.

For concurring opinions on the novelty of nuclear weapons, see Kenneth E. Boulding, "What Power Do Nuclear Weapons Give Their Possessors? The Basic Instability of Deterrence," in After the Cold War: Questioning the Morality of Deterrence, ed: Charles W. Kegley, Jr. and Kenneth L. Schwab (Boulder: Westview Press, 1991), p. 103; Jan N. Lodal, "Deterrence and Nuclear Strategy," Daedalus 109 (Fall 1980): 155.

${ }^{61}$ Schelling, Arms and Influence, pp. 20-22 (quote from 20). See also Steven Kull, "Nuclear Nonsense," Foreign Policy 58 (Spring 1985): 52.

${ }^{62}$ Of course, one person could not single-handedly launch a full-blown nuclear strike from either the U.S. or Russia. However, such an attack would require far fewer participants than a conventional attack even half as destructive. Rhodes, Power and MADness, pp. 138139 .

${ }^{63}$ Rhodes, Power and MADness, p. 136. 
questions the sincerity of those who trivialize the differences between

conventional and nuclear weapons. $)^{64}$

History demonstrates that the advent of nuclear weapons would not be the first technological breakthrough to undermine an existing social order and usher in another. For example, some historians argue that the advent of the cannon made possible the transition from nomadism to agrarian civilization, and it is this impact which makes cannons more than merely an improvement of the bow. ${ }^{65}$

Though nuclear weapons represent a discontinuity, their existence is problematic precisely because deeper continuities recognized by the Realists - particularly the anarchical international political order - persist and show no signs of abating. ${ }^{66}$ Conflict will remain a central theme of international politics, whether or not it involves nuclear weapons. ${ }^{67}$ While

64 "Even those who have argued that nuclears ought to be considered just a more efficient kind of artillery will surely catch their breath when the first one goes off in anger." Schelling, Arms and Influence, p. 114.

${ }^{65}$ For example, see Andrew Bard Schmookler, The Parable of the Tribes: The Problem of Power in Social Evolution (Albany, NY: State University of New York Press, 1995), p. 58; Kenneth E. Boulding, "What Power?", p. 101.

Gary Scott has questioned this argument, pointing out that the Mayan's agrarian civilization survived without cannons - or at least did not decline as a result of not having this technology.

${ }^{66}$ As Waltz explains, "The structure of international politics has not been transformed; it remains anarachic in form." Waltz, "Origins of War," p. 50.

${ }^{67}$ On violence as an enduring theme of international politics, see Gilpin, War and Change, p. 230; Morgan, Deterrence, p. 13. As Weltman explains, "that war may have 
nuclear weapons may prevent total war, they have not precluded limited war. $^{68}$ Nuclear weapons may actually cause existing political conflicts among nuclear states to fester, since in some cases these weapons remove the credible threat of violence which often forces adversaries to the bargaining table. ${ }^{69}$

Though I am a Pessimist, I will not advocate some sort of Small Worlder, hierarchical solution to the proliferation problem. I prefer anarchical international orders for the same reasons Realists do. The formation of a hierarchical order would likely necessitate war between pro-hierarchy forces and groups reluctant to assimilate. Even the establishment of a hierarchical ordering of states would not end large-scale violence; it may in fact pave the way to a global civil war among disparate political, economic and religious factions thrown together unwillingly. There is also no guarantee that a world government would be founded on universally-accepted principles, if such principles exist.

become indecisive, and thus ineffective, is no reason to say the same for the threat of it." Weltman, "Obsolescence of War," p. 415.

${ }^{68}$ Gilpin, War and Change, p. 216.

${ }^{69}$ See Ibid., pp. 217-218; Ellsberg, "Manhattan Project II," p. 1. The concept of credibility will be introduced in Chapter Two. 


\section{Dual-Level Explanation}

International politics has often been likened to Rousseau's hypothetical Stag Hunt. ${ }^{70}$ In this parable, hungry hunters gather to ambush a stag, which would provide enough meat to feed them all. However, a rabbit, which would be enough to feed a single hunter, unexpectedly passes by. Unfortunately, catching the rabbit would surely frighten off any stags in the vicinity. How would the hunters react? Would they resist the temptation to selfishly seize the rabbit? How could the hunters be certain that their companions would not do so? This simple vignette can be used to illustrate a number of collective goods dilemmas in international politics.

Though they may be able to make better than average predictions regarding how hunters would behave, Realists could not accurately predict what would happen in any one instance without knowledge of the relative "power" of the hunters. ${ }^{71}$ By examining the hunters more closely, the first- and second-image analysts' predictions are likely to be more accurate. However, their predictions would be more labor-intensive than the Realists'. Thus, while their predictions may be better, they could make them less frequently.

${ }^{70}$ See, for example, Kenneth N. Waltz, Man the State and War: A Theoretical Analysis (Columbia Unversity Press, 1959); Jean Jacques Rousseau, The Social Contract and Discourses, trans. G.D.H. Cole (New York: E.P. Dutton and Co., 1950), p. 238. the stag.

${ }^{71}$ A powerful hunter - or a hegemon - may be able to force other hunters to wait for 
Neither singular approach is likely to be highly accurate, for different reasons. Realists' predictions would be defied by altruistic hunters, or hunters who detest rabbit. They ignore these details, gambling that over the long run they can frequently make accurate predictions based only on the relative power of the hunters. ${ }^{72}$ First- and second-image analysts' expectations would lead them astray when otherwise altruistic hunters surrender to circumstance and grab the rabbit, fearing that if they did not, another would.

Exclusively structure- or agent-oriented analyses of the Stag Hunt and international war overpredict. If human nature is to blame for war, why is there ever peace? If belligerent leaders are the culprits, then why do they often abstain from war, and why do "good" leaders sometimes start them? If particular types of states are prone to conflict, why are they not always at war? ${ }^{73}$ If the anarchical international environment is to blame, then why are strong states not continually preying on the weak $?^{74}$ Joseph Nye likens

${ }^{72}$ On the "structuralists' gamble," see Haggard, "Structuralism and Its Critics," p. 408.

${ }^{73}$ Joseph S. Nye, Jr., Understanding International Conflict: An Introduction to Theory and History (New York: HarperCollins College Publishers, 1993), p. 29.

${ }^{74}$ Seyom Brown, International Relations in a Changing Global System: Toward a Theory of the World Polity (Boulder: Westview Press, 1992), p. 62. 
overpredictive explanations to stopped clocks, which "tell us the correct time twice a day, but most of the time they mislead us." ${ }^{75}$

There are, of course, reasonable answers to these questions, but they are usually found at other levels of analysis. Belligerent leaders are not likely to start a war when the distribution of power is perceived to be unfavorable to them, though they may be tempted. Capitalist states led by pacifists may not attempt to conquer weak though resource-rich states, yet they may confront pressures to do so. Hegemonic states may not wage war on lesser powers when they share democratic governmental structures, though incentives to do so may sometimes be compelling.

Clearly, reliance on only one level of analysis is an unsatisfactory method of explaining events in international relations, as has been noted by numerous international relations theorists. ${ }^{76}$ Single level explanations are not really causal explanations at all, but are merely "assertions about

${ }^{75}$ Nye, Understanding International Conflict, pp. 28-29. Nye's analogy is a good one, but, as Gary Scott notes, he overestimates the usefulness of stopped clocks. We can never know when they are telling the right time, therefore they are never really useful.

${ }^{76}$ Levels of analysis have been widely discussed. See, for example, Graham T. Allison, Essence of Decision: Explaining the Cuban Missile Crisis (Boston: Little and Brown, 1971); Charles W. Kegley, Jr. and Eugene R. Wittkopf, American Foreign Policy: Pattern and Process, 3rd ed. (New York: St. Martin's Press, 1987), pp. 11-31; Buzan, Jones and Little, Logic of Anarchy. 
necessitation. ${ }^{77}$ In order to explain the behavior of states, and their decisions to go to war in particular, it seems necessary to look for explanations at multiple levels of analysis. ${ }^{78}$

Structural explanations of peace and war, unaccompanied by analyses of states or their leaders, have been frequently criticized for this incompleteness. As Haggard points out, "the prediction of 'balancing' is consistent with a wide range of behaviors, from mutual postures of minimal deterrence to arms races and intense competition in the periphery." ${ }^{79}$ Likewise, agent-oriented explanations usually demonstrate "too great an

${ }^{77}$ On the distinction between causal explanations and assertions about necessition, see Jon Elster, Nuts and Bolts, p. 6. With regard to the weakness of structure as a causal factor, see Stephen Haggard, "Structuralism and Its Critics," p. 404.

${ }^{78}$ Alexander E. Wendt, "Agent-Structure Problem in International Relations Theory," International Organization 41 (Summer 1987): 362. Even Waltz acknowledges that his theory of international politics is incomplete without an accompanying unit level theory, admitting that "changes in, and transformation of, systems originate not in the structure of a system but in its parts." Kenneth N. Waltz, "Reflections on Theory of International Politics: A Response to My Critics," in Neorealism and Its Critics, ed: Robert Keohane (New York: Columbia University Press, 1986), p. 343. Though characterized as a determinist by some critics, he resists rigid structural determinism by offering a "softer" depiction of the relationship between agent and structure: "Neither structure nor units determine outcomes. Each affects the other." Ibid, $p$. 328.

Haggard likens the state to the mythical Janus. "On the one hand, it is rooted in the international system; on the other hand, it is simultaneously bound by domestic constraints." Stephen Haggard, "Structuralism and Its Critics," p. 422.

${ }^{79}$ Haggard, "Structuralism and Its Critics," pp. 408-409. 
eagerness to view ... decision-makers as free agents, constrained only by the properties of their own minds." ${ }^{80}$

It is not only because they are weak that single-level explanations are incomplete. Agent- and structure-oriented analyses also differ in kind. Wendt argues that structure-oriented analyses ask "why-questions" to determine the range of possibility, whereas agent-oriented analyses ask "how-questions" to explain "the actual." ${ }^{81}$ It seems that both why- and how-questions are necessary, not just because they are weak by themselves, but also because they are complementary. As Alexander Wendt explains, "a complete explanation of state action - that is, one that explains both how that action was possible and why the possibility was actualized in a particular form at a given moment - will have to combine these methodologies . . ."

Analysts often focus on one level of analysis in the name of parsimony. Parsimony has long been held to be a worthy ideal of scientific explanation, so it is unsurprising that international relations theorists would attempt to construct "simple yet elegant" explanations of state behavior. By focusing on

${ }^{80}$ Erik Yesson, "Strategic Make-believe and Strategic Reality," International Security 14 (Winter 1989-90): 193. Yesson is criticizing Kull's psychological work, specifically, but his criticism seems appropriate for agent-oriented analyses in general.

${ }^{81}$ Wendt, "Agent-Structure Problem," pp. 362-363.

${ }^{82}$ Wendt, "The Agent-Structure Problem," p. 364. 
one level of analysis, this ideal is more easily achieved. Unfortunately, parsimony may have been realized in international relations theory at the expense of explanatory power. ${ }^{83}$

The ideal approach would seek explanations of state behavior at the agent- and structure-levels. Structuralists focus on how the opportunities of states (i.e., the structure) vary while holding state preferences constant. Agent-oriented theorists focus on state preferences while paying too little attention to the structures which circumscribe state action. As Jon Elster has noted, however, it is more likely that the preferences and opportunities of actors vary, and that not only do opportunities affect preferences, but preferences can shape opportunities. ${ }^{84}$

Hence, in this analysis a singular devotion to either structure- or agentoriented methods of explanation will be rejected in favor of a dual-level approach. Parsimony has too often posed an obstacle to what ought to be the primary goal of international political analysis: explanation.

\footnotetext{
${ }^{83}$ Haggard, "Structuralism and Its Critics," p. 417.

${ }^{84}$ Elster, Nuts and Bolts, pp. 15-19.
} 


\section{THE STRATEGY OF THIS THESIS}

My aim in this text is to demonstrate that the probability that states will use nuclear weapons will increase as these weapons proliferate. To substantiate this claim, I must demonstrate that the caution-inducing effects of nuclear weapons are more than offset by their destabilizing influence.

In Chapter Two I will examine the deterrence debate. In the course of this examination, it will be shown that MAD doctrine is a deterrent only to states of the Classical persuasion. Furthermore, I will argue that the U.S.Soviet model of deterrence provides little support to the Optimistic expectation that new nuclear states will be Classical.

Chapter Three, the heart of this thesis, examines the five dangers of nuclear proliferation. Waltz claims that the Optimists have been "called into question by those who believe that the infirmities of some new nuclear states and the delicacy of their nuclear forces will work against the preservation of peace and for the fighting of nuclear wars." ${ }^{\text {" }}$ He asks, "what new causes may bring effects different from, and worse than, those known earlier in the nuclear age?" ${ }^{86}$ As I intend to demonstrate, no new causes, "mad colonels," or any other bogeymen are necessary to justify Pessimism. Even assuming that new

\footnotetext{
${ }^{85}$ Waltz, "More May Be Better," p. 8.

${ }^{86}$ Waltz, "More May Be Better," p. 10.
} 
nuclear states and the people within them behave rationally, that they are no more prone to believing nuclear weapons are useful than others, and that they will handle these weapons with the same care as others, the five dangers loom.

Finally, Chapter Four will explore the implications of Pessimism, and outline some tentative policy suggestions for states confronting the dangers described in this text.

The topics of this thesis - proliferation and deterrence - very much determine that the methodology to be employed will be of the deductive sort, as opposed to the "large- $N$ " quantitative or the "small- $N$ " case study approaches. ${ }^{87}$ Though cases of deterrence most surely occurred, they are difficult to identify. Only cases of deterrence failures can be identified with any accuracy. Fortunately for mankind - but unfortunately for those who would study deterrence through the application to empirical methods - there are no cases of failed mutual nuclear deterrence.

\footnotetext{
${ }^{87}$ Rhodes notes, "the unavailability of empirical data for use in focused comparisons or in quantitative correlation studies has made the empirical derivation or testing of nuclear deterrence theory a dubious exercise." Rhodes, Power and MADness, p. 11. Betts also explains that, "The nature of the evidence precludes conclusions about whether peace was maintained because of nuclear threats or in spite of them ..." Richard K. Betts, Nuclear Blackmail and Nuclear Balance (Washington, D.C.: The Brookings Institution, 1987), pp. 132, 216-217; Richard Ned Lebow, "Deterrence: A Political and Psychological Critique," in Perspectives on Deterrence, ed: Paul C. Stern, Robert Axelrod, Robert Jervis and Roy Radner (New York: Oxford University Press, 1989), pp. 25-26; Jervis, "Deterrence Theory Revisited," p. 301.
} 
Even if we relied on cases of conventional deterrence failures, we can posit only very tentative causal explanations of deterrence failures, for we cannot know whether influences at work during failures are also present during putative successes, because, again, we cannot identify cases of successful deterrence. ${ }^{88}$ How can an observer be sure that an allegedly deterred state intended to attack, but was prevented from doing so by its adversary's threats?

${ }^{88}$ Richard Ned Lebow, "Deterrence," p. 30. The implications of these methodological difficulties are severe. The inability to discern deterrence successes from non-events can lead states to the unjustified belief that their actions are what have deterred adversaries from attacking, and to persist in strategies that may make war both more probable and more horrible. See Morgan, Deterrence, p. 57. 
CHAPTER TWO:

\title{
DETERRENCE
}

\begin{abstract}
By arranging it so that we might have to blow up the world, we would not have to. ${ }^{1}$
\end{abstract}

Thomas C. Schelling

Since we ourselves find it difficult to believe that we would actually implement the threat of assured destruction in response to a limited attack on military targets that caused relatively few civilian casualties, there can be no certainty that, in a crisis, prospective opponents would be deterred from testing our resolve. ${ }^{2}$

James Schlesinger

As explained in Chapter One, Optimism stems from the expectation that new nuclear states will adhere to Classical prescriptions and fulfill the tenets of MAD. However, there is little reason to expect that Classical thought will be whole-heartedly embraced by states once they are in possession of nuclear weapons. Indeed, Classical thought has never been thoroughly

${ }^{1}$ Thomas C. Schelling, Arms and Influence (New Haven: Yale University Press, 1966), p. 43.

2 James Schlesinger, Department of Defense Annual Report (1975), quoted in James DeNardo, The Amateur Strategist: Intuitive Deterrence Theories and the Politics of the Nuclear Arms Race (New York: Cambridge University Press, 1995), p. 29. 
accepted even in U.S., and it seems to have been completely ignored by the Soviets.

This chapter will explore the debate between Classicals and AntiClassicals. The discussion will proceed from very general concepts, to the schism between Classicals and Anti-Classicals regarding how best to deter, and to the specific, incompatible policy prescriptions offered by each side. ${ }^{3}$

\section{WHAT IS DETERRENCE?}

Broadly speaking, there are two ways states with incongruent objectives can establish a stable and mutually tolerable modus vivendi. ${ }^{4}$ First, states can attempt to insulate themselves from the harmful effects of their adversaries' actions through negation: attempts to abate the deleterious consequences of an adversary's actions. ${ }^{5}$

Alternatively, states can attempt to prevent their adversaries' from acting in an injurious fashion to begin with - or even to prompt them to act in a desirable way. This is coercion: an attempt to modify an opponent's

${ }^{3}$ On the incompatibility of these prescriptions, see DeNardo, Amateur Strategist, p. 18.

${ }^{4}$ One of these ways may be available when the other is not, and vice versa. See Edward J. Rhodes, Power and MADness: The Logic of Nuclear Coercion (New York: Columbia University Press, 1989), p. 84.

${ }^{5}$ Other authors discuss analogous concepts. Schelling uses brute force, while Rhodes uses direct power. See Schelling, Arms and Influence, p. 3; Rhodes, Power and MADness, p. 84. 
behavior by influencing its decision-making calculus through the use of promised rewards or threatened penalties. ${ }^{6}$ Deterrence refers to the type of coercion that is intended to prevent an undesired action. (Compellance, on the other hand, refers to the type of coercion intended to bring an undesired action to a halt. ${ }^{7}$ ) Though a less ambitious means of self-protection than negation, deterrence (and compellance) may fail where direct power would succeed, because coercion requires that the target state be able to modify its behavior. $^{8}$

The definition of nuclear deterrence that I will employ here is a slightly modified version of Richard Brody's definition of deterrence. Nuclear deterrence

... refers to the attempt by decision makers in one nation or group of nations to restructure the set of alternatives available to decision makers in another nation or group of nations by posing a [contingent] threat to their key values. The restructuring is an attempt to exclude [nuclear] aggression ... from consideration. ${ }^{9}$

${ }^{6}$ Rhodes, Power and MADness, p. 82. See also Daniel Ellsberg, "The Theory and Practice of Blackmail," in Bargaining: Formal Theories of Negotiation, ed: Oran Young (Chicago: University of Illinois Press, 1975), p. 346

${ }^{7}$ Schelling, Arms and Influence, pp. 70-71.

${ }^{8}$ Rhodes, Power and MADness, p. 86.

${ }^{9}$ International Encyciopedia of Social Sciences, vol. 4, s.v. "Deterrence," by Richard Brody, pp. 130-133. For another, similar definition, see Patrick M. Morgan, Deterrence: $A$ Conceptual Analysis (Beverley Hills: Sage Publications, 1977), pp. 63-64.

It is important to acknowledge that for threats to effectively deter, they must be contingent. As Schelling explains, threatening to shoot somebody constitutes neither 
Two other important forms of deterrence that should be explained here are mutual deterrence and extended deterrence. Mutual deterrence exists when two (or more) nuclear-armed states attempt simultaneously to deter one another from attack. (For the remainder of this text, the term deterrence can be considered synonymous with mutual nuclear deterrence, unless otherwise noted.)

Extended deterrence most often refers to attempts by a state to deter attacks on allies. However, deterrence may be thought to be extended in other ways. For example, NATO threatened to attack the Soviets with nuclear

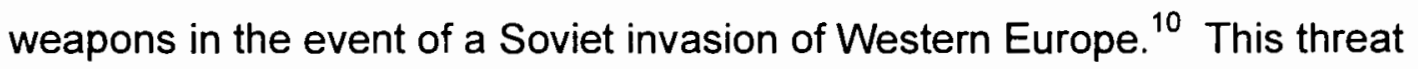
could be considered extended in two ways: it offered protection to Western allies; and the threatened response differed in kind with the provocation (i.e., it was a nuclear response to a conventional attack).

\section{THE COMMITMENT PROBLEM}

States attempting to deter their adversaries from using nuclear weapons or some other provocative act face a commitment problem if - after attached to it. Schelling, Arms and Influence, p. 74.

${ }^{10}$ Jan N. Lodal, "Nuclear Strategy," Daedalus 109 (Fall 1980): 158. 
the provocation occurs - it is no longer in the state's interest to abide by its prior commitment to react as promised..$^{11}$

The commitment problem is particularly acute in the case of nuclear deterrence between states with second-strike capabilities: the ability to mount a vigorous response after absorbing a nuclear attack (or counter-attack). ${ }^{12}$ How can states convince their adversaries that they would respond to a nuclear provocation by striking back, when such a response would surely invite a coup de gràce $?^{13}$ If the leaders of a state are aware that its adversary might not react to a provocation as it has promised, what remains to stop that state from performing that provocative act?

Therefore, for a state effectively to deter another, it is necessary that it establish the credibility of its threat, by fostering the perception in its adversary

11 The commitment problem - more often referred to as the ex ante-ex post dilemma - has been widely acknowledged in the deterrence literature and elsewhere. For discussions, see Albert Wohlstetter, "Nuclear Sharing: NATO and the N+1 Country," in The Dispersion of Nuclear Weapons, ed: R.N. Rosecrance (New York: Columbia University Press, 1964), pp. 194-195; Morgan, Deterrence, pp. 93-94; Ellsberg, "The Theory and Practice of Blackmail," p. 354; Jan N. Lodal, "Deterrence and Nuclear Strategy," Daedalus 109 (Fall 1980): 160; Robert H. Frank, Passions Within Reason: The Strategic Role of Emotions (New York: W.W. Norton \& Co., 1988), p. 243.

${ }^{12}$ Since the late 1950 s, both the U.S. and the Soviet Union had second-strike capabilities. On this period of Soviet vulnerability, see Marc Trachtenberg, "A 'Wasting Asset': American Strategy and the Shifting Nuclear Balance, 1949-1954," International Security 13 (Winter 1988-89): 5-49.

${ }^{13}$ See Rhodes, Power and MADness, p. 119; Lodal, "Nuclear Strategy," p. 167; Ellsberg, "The Theory and Practice of Blackmail," p. 358. Again, the credibility of extended deterrence is even more difficult to bolster. For example, how could the U.S. convince the Soviets that it would risk the immolation of New York to prevent the occupation of West Berlin? 
that there is a significant probability that the threat will be carried out - despite the costs of doing so. ${ }^{14}$ The daunting task of establishing the credibility of nuclear threats is the hurdle faced by nuclear states. The size or sophistication of one's arsenal is insignificant if there is no purpose for which one's weapons can credibly be employed. ${ }^{15}$

As we will see below, Classicals and Anti-Classicals offer their own unique prescriptions for solving the commitment problem. Before examining their solutions, some attention should be devoted to two characteristics of threat-makers that may affect the credibility of their threats: rationality and reputation.

\section{Rationality and Credibility}

As Patrick Morgan points out, there are different definitions of rationality, and there is often confusion about what type of rationality is under discussion. ${ }^{16}$ Either because of this confusion, or due to the perceived

${ }^{14}$ Rhodes, Power and MADness, p. 194. I distinguish credibility from reputation. In this thesis, credibility is an attribute of a threat, independent of its source. In contrast, reputation is an attribute of a threat-making state. The significance of reputation for deterrence is taken up later in this chapter.

${ }^{15}$ Kenneth N. Waltz, "More May Be Better," in Scott D. Sagan and Kenneth N. Waltz, The Spread of Nuclear Weapons: A Debate (New York: W.W. Norton \& Company, Inc., 1995), p. 6.

${ }^{16}$ Morgan, Deterrence, p. 79. 
vapidity of the concept, many reject the notion of rationality entirely. ${ }^{17}$ As

noted in Chapter One, I follow Robert Strotz's definition (with a slight

modification). To be rational, an actor must "choose a plan of [action] for a

future period of time so as to maximize the utility of the plan as evaluated at the present moment."18

There has been a great deal of concern among deterrence theorists regarding the rationality of threats. The assumption has been that the more rational the threat is, the more credible it is. However, this is not always true, and the importance of rationality has often been exaggerated. ${ }^{19}$ Examples of human and organizational irrationality are sufficiently plentiful that it would be foolish to dismiss irrational threats because they seem implausible. ${ }^{20}$

${ }^{17}$ Morgan prefers "sensible" to rational. A sensible decision maker is aware of his own irrationality, the uncertainty around him, the chance of error and accident, and the occasional utility of irrationality. See Morgan, Deterrence, p. 104.

As Harsanyi explains, "the term 'irrational behavior' is rather misleading because it seems to prejudge the issue of whether or not such behavior serves any useful purpose." Concerned that irrational conotes non-purposiveness, Harsanyi rejects the term irrationality, suggesting symbolic instead. He speculates that a "preoccupation with symbolic actions can be explained essentially as an act of desperation: it may simply mean that people have given up all hope of achieving their goals by reality-oriented instrumental activities, and so feel they have nothing to lose by turning to magic, ritual, ideology, and other forms of symbolic behavior." John C. Harsanyi, "Rational-Choice Models of Political Behavior vs. Functionalist and Conformist Theories," World Politics 21 (July 1969): 525.

${ }^{18}$ R. H. Strotz, "Myopia and Inconsistency in Dynamic Utility Maximization," Review of Economic Studies 25 (1955-56): 165, emphasis added. I substituted the more general "action" for Strotz' more economically-oriented "consumption."

${ }^{19}$ As we will see, some threats can be made credible only through feigning irrationality or actually becoming irrational.

${ }^{20}$ Jerome Frank has estimated that seventy-five heads of state in the last four centuries have suffered from "severe mental disturbances." Jerome Frank, quoted in Morgan, 
The impact of rationality varies across circumstances, and the connection between rationality and propensity to use nuclear weapons is therefore ambiguous. ${ }^{21}$ A nuclear response - or even a first-strike - could result from irrational emotionalism, or what psychologists refer to as "hot cognition."22 However, nuclear violence could also result from "cold," rational calculation. $^{23}$

\section{Deterrence, p. 153.}

Military leaders are not immune to psychological pathologies, either. Consider General Horace Wade's remarks about General Thomas Power, head of Strategic Air Command during the Cuban Missile Crisis: "I used to worry about General Power. I used to worry that General Power was not stable. I used to worry about the fact that he had control over so many weapons and weapons systems and could, under certain conditions, launch the force. Back in the days before we had real positive control, SAC had the power to do a lot of things, and it was in his hands, and he knew it." General Horace Wade, quoted in Scott D. Sagan, The Limits of Safety: Organizations, Accidents and Nuclear Weapons (Princeton: Princeton University Press, 1993), p. 150.

${ }^{21}$ Jervis complains that, "When critics talk of the impact of irrationality, they imply that all such deviations will be in the direction of emotional impulsiveness, of launching an attack, or of taking actions that are terribly risky. But irrationality could also lead to a state to passive acquiescence, while a rational grasp of the situation could lead to belligerence." Robert Jervis, "Deterrence Theory Revisited," World Politics 31 (January 1979): 299. On "irrationally timid" leaders, see also Morgan, Deterrence, p. 52.

${ }^{22}$ As Wohlstetter puts it, "Even if cold calculation were to suggest that the balance lay in favor of not responding to Russian aggression, there is obviously a very considerable chance that in the circumstances we would not calculate coldly." Wohlstetter, "Nuclear Sharing," p. 213. On hot cognition, see Irving L. Janis and Leon Mann, Decision Making: A Psychological Analysis of Conflict, Choice, and Commitment (New York: The Free Press, 1977), p. 45; Frank, Passions Within Reason.

${ }^{23}$ As Bull points out, "There are situations which we can readily imagine, and which, though perhaps they do not exist, are not remote from present circumstances, in which 'strategic [i.e., rational] man' himself would choose the initiation of strategic nuclear warfare." Hedley Bull, The Control of the Arms Race (New York: Praeger, 1961), p. 49.

The spiraling violence which culminated in World War I is an excellent example of states engaging in war "not because they saw an 'opportunity' for gain but because they believed the strategic consequences of inaction would be catastrophic." Richard Ned Lebow, "Deterrence: A Political and Psychological Critique," in Perspectives on Deterrence, ed: Paul C. Stern, Robert Axelrod, Robert Jervis and Roy Radner (New York: Oxford University Press, 
Some have argued that if states were fully rational, the U.S. or the Soviet Union ought to have launched a first-strike long ago, confidently expecting that the irrational response would never come. ${ }^{24}$ Paradoxically, despite all of the concern about making one's threats rational, the success of U.S.-Soviet deterrence may have at least partially depended on the occasional irrationality of state decision-making. ${ }^{25}$

\section{Reputation and Credibility}

Another attribute considered a determinant of credibility is the reputation of the threat-maker. ${ }^{26}$ By reputation, I am not referring to intelligence or hard empirical data regarding an adversary's technical capabilities, strategy or objectives. Reputation as used here refers to the perceived character of a state and the leaders of that state, especially as related to their past record of abiding by prior commitments. In order to boost

1989), p. 37. See also Robert Powell, "The Theoretical Foundations of Strategic Nuclear Deterrence," Political Studies Quarterly 100 (Spring 1985): 87; Morgan, Deterrence, p. 92.

${ }^{24}$ Rhodes, Power and MADness, p. 188. Also see Morgan, Deterrence, pp. 94-95. Of course, as has been noted, the opposite is also true: if nuclear war is conceived of as irrational in response to provocation, it remains irrational to respond after the provocation occurs.

${ }^{25}$ Robert Powell, "The Theoretical Foundations of Strategic Nuclear Deterrence," Political Studies Quarterly 100 (Spring 1985): 80 . This point is also repeatedly made by Morgan. He finds it difficult to understand why anyone would apply rational choice theory to the problem of deterrence at all. Morgan, Deterrence, pp. 111-112.

${ }^{26}$ Unlike the factors discussed thus far, reputation is a quality of the threat-maker as opposed to the threat itself. 
the credibility of one's threats, it would be useful to have a reputation for trustworthiness, vindictiveness or even irrationality. ${ }^{27}$ (On the other hand, this advice ought not be taken too far. Erratic behavior by a nuclear state could also invite pre-emption. ${ }^{28}$ )

Some have touted the importance of reputation for deterrence, others have ignored it. ${ }^{29}$ I believe reputation is - at least at this point in the nuclear age - relatively unimportant, for two reasons. First, there have been few opportunities for states to develop clear reputations for nuclear "bravado" or "cowardice" among other states. ${ }^{30}$ Second, it would be foolish to infer from a

${ }^{27}$ As Schelling explains, "it does not always help to be, or to be believed to be, fully rational, cool-headed, and in control of oneself or of one's country." Schelling, Arms and Influence, p. 37. President Nixon, for example, subscribed to "madman theory," and through contrived unpredictablity attempted to bolster the credibilty of U.S. threats. See Seymour M. Hersh, The Price of Power. Kissinger in the Nixon White House (New York: Summit Books, 1983), p. 75.

${ }^{28}$ Kenneth N. Waltz, "More May Be Better," in Scott D. Sagan and Kenneth N. Waltz, The Spread of Nuclear Weapons: A Debate (New York: W.W. Norton \& Company, Inc., 1995), p. 24.

${ }^{29}$ Rosecrance cautions state leaders to consider the implications of their actions, warning that, "Even actions which may not be intended to have international reference will be seen in terms of the bipolar competition." R. N. Rosecrance, "Bipolarity, Multipolarity and the Future," Journal of Conflict Resolution 10 (September 1966): 315.

${ }^{30}$ The U.S. may have earned a reputation either for weakness or benevolence, or some combination of these two qualities, as a result of its non-use of nuclear weapons during the early 1950s. Then again, the U.S. is the only state to have used nuclear weapons against an adversary, so whether that reputation is deserved is questionable. In 1980, during superpower tensions over Afghanistan, the assistant secretary of defese for public information explained on NBC why the Soviets ought to be deterred from moving next against Iran. "The Soviets know that this terrible weapon has been dropped on human beings twice in history and it was an American president who dropped it both times," he said. Richard K. Betts, Nuclear Blackmail and Nuclear Balance (Washington, D.C.: The Brookings Institution, 1987), p. 130.

On reputation, see Rhodes, Power and MADness, p. 105. 
state's non-nuclear behavior how willing that state would be to use nuclear weapons or to run the risk of nuclear war, since the gulf between these realms of action is tremendous.

However, this is not to say that others do not consider the reputation of the threat-maker in their estimates of the credibility of its threats. There was great concern during the 1970 s that because the U.S. had a reputation as being unable to stomach great losses, the Soviets doubted the sincerity of U.S. theats. ${ }^{31}$ For example, Michael Howard argues that reputation does matter, for "credibility depends not simply on a perceived balance, or imbalance, of weapons systems, but on the perceptions of the nature of the society whose leaders are threatening such retaliation." ${ }^{\text {32 }}$

\section{DETERRENCE THEORIES}

Before explaining what deterrence theories are, a moment ought to be spent explaining what they are not, and their limitations. Deterrence theories are applicable only in intensely conflictual relationships, and even when

${ }^{31}$ As Gary Scott points out, this fear may have been unjustified, for the U.S. had developed a reputation as a harsh retaliator.

${ }^{32}$ Michael Howard, "The Forgotten Dimensions of Strategy," Foreign Affairs 57 (Summer 1979): 983. Throughout his article, Howard argues that the U.S. has neglected the long-important social dimension of war, focusing exclusively on the technological. Ibid., pp. 975-986. 
appropriately applied, these theories provide states with no means by which to extricate themselves from such relationships. ${ }^{33}$ "At best," explains Robert Jervis, deterrence theories tell states "how to maintain a hostile and dangerous relationship." ${ }^{34}$ At worst, deterrence theories fail as aids to state leaders attempting to prevent war. ${ }^{35}$

Theories about how states are most effectively deterred from attacking are essentially decision-making theories. The success of deterrence hinges in part on the threat-maker's understanding of the decision-making processes of its adversary. ${ }^{36}$ As Morgan explains,

Analysts of deterrence consistently adhere to the view that to deter is to influence, even manipulate, via threats of retaliation the decision making of a foreign government. It follows that any standard working notion of deterrence flows from assertions and assumptions as to how governments make decisions. Thus in threatening another government to keep it from deciding to attack, it is imperative to have a fairly clear idea of how that government would reach such a decision. Alas, this is an onerous requirement, for students of foreign policy do not agree on how governments make decisions. ${ }^{37}$

\footnotetext{
${ }^{33}$ Robert Jervis, "Deterrence Theory Revisited," World Politics 31 (January 1979):
} 292-295.

34 Ibid., p. 293.

35 John D. Steinbruner, "Nuclear Decapitation," Foreign Policy 45 (Winter 1981-82):

27.

\footnotetext{
${ }^{36}$ Morgan, Deterrence, p. 23.

${ }^{37}$ Ibid., p. 48.
} 
Of course, the overwhelming destructive power of nuclear weapons is thought to pose a threat "so stark and so obvious" that it obviates the need to account for the peculiarities of state decision-making. ${ }^{38}$ Nevertheless, the success rate of deterrence surely improves with the accuracy of the threat-making state's image of its adversary's decision-making.

As noted in the final pages of Chapter One, there is virtually no unequivocal evidence indicating which factors contribute to or undermine nuclear deterrence. The absence of unambiguous data precludes both the creation of a theory of nuclear deterrence through induction (i.e., building from evidence), and the testing of any theory, however generated. ${ }^{39}$ Therefore, deterrence theories are largely deductive bodies of thought, built on rational choice or other such assumptions regarding state behavior. Though, in principle, there is no reason that a theory must be testable or even connected to available evidence, the current state of the competing theories is such that a comparative evaluation of their merits is difficult. ${ }^{40}$

${ }^{38}$ John D. Steinbruner, "Beyond Rational Deterrence: The Struggle for New Conceptions," World Politics 28 (January 1976): 227.

${ }^{39}$ Colin S. Gray, "Strategic Stability Reconsidered," Daedalus 109 (Fall 1980): 137. Please note that I claim only that we lack sufficient evidence to create a theory of nuclear deterrence, not necessarily a general theory of deterrence. However, I am skeptical as to whether conclusions drawn from cases of non-nuclear deterrence can be applied to nuclear deterrence.

${ }^{40}$ Ibid., p. 135. On "potential observability," see James N. Rosenau, Turbulence in World Politics: A Theory of Change and Continuity (Princeton: Princeton University Press, 1990), pp. 27-33. 
The central challenge for deterrence theorists is the commitment problem: in the case of contemporary nuclear deterrence, it could be irrational for states to actually carry out the deterrent threats they made to prevent a certain provocation once it occurs. If state leaders reflect on that fact, they may realize that the deterrent threats they face are hollow, and may no longer be deterred. As we will see below, there are two sorts of solutions to this problem, one of which is championed by Classicals, the other by AntiClassicals.

\section{NERVE AND PAIN}

According to Schelling,

War appears to be, or threatens to be, not so much a contest of strength as one of endurance, nerve, obstinacy, and pain. It appears to be, and threatens to be, not so much a contest of military strength as a bargaining process - dirty, extortionate, and often quite reluctant bargaining on one side or both - nevertheless a bargaining process. ${ }^{41}$

Classicals believe that contests of pain involving nuclear weapons are so painful that they are unwinnable. Therefore, they suggest ways to win the contest of nerve that precede actual warfare, by preventing one's adversary from initiating a contest of pain. In contrast, the Anti-Classicals offer

${ }^{41}$ Schelling, Arms and Influence, p. 7. 
suggestions to improve the chances of prevailing in a contest of pain. By convincing an adversary that one is capable of winning a contest of pain, an adversary would be unlikely to invite such a contest. Powell compares these two antagonistic views:

In the theory based on a spectrum of risk [i.e., nerve], crises are a competition in demonstrating the resolve to run grave risks of an explosive escalation to general nuclear war. The uncertainty of a crisis is primarily about each side's willingness to accept the risk of suffering an unrestricted nuclear attack. In the theory based on a spectrum of violence [i.e., pain], crises are a competition in demonstrating the resolve to suffer future destruction. Here the uncertainty is about . . . each side's willingness to inflict and endure future destruction. ${ }^{42}$

Classicals imagine nuclear war to involve escalation along the spectrum of risk: as each side ups the ante until one state loses its nerve and concedes, or both sides are obliterated in a mutually suicidal denouement. Anti-Classicals however, envision nuclear war as escalation along the spectrum of violence, with opponents reciprocating "tit" for "tat" until either the state with the lowest tolerance for pain concedes, or one or both sides are rendered incapable of continuing to compete.

These visions of nuclear war are not completely separate. Classicals do not necessarily reject the contest of pain view. Rather, they expect that such a competition would quickly escalate beyond the control of the

\footnotetext{
42 Powell, "Theoretical Foundations," pp. 91-92, emphases my own.
} 
participants. ${ }^{43}$ The "winner" would experience too much pain to be truly considered victorious. Likewise, Anti-Classicals recognize that the prelude to a nuclear war might resemble a contest of nerve. However, if neither side conceded, they expect that states will then be able to control the tempo of nuclear war, such that it may be possible for one side to prevail.

In the sections below, the specific solutions to the commitment problem offered by Classicals and Anti-Classicals will be examined.

\section{Mutually Assured Destruction}

MAD doctrine flowed from Classical expectations regarding the conduct and consequences of a U.S.-Soviet nuclear war. First, Classicals expected that carefully calibrated responses to a Soviet provocation would not be possible in the heat of nuclear war. ${ }^{44}$ Escalation was thought to be

${ }^{43}$ This expectation is widely held. See, for example, Scott D. Sagan, "Sagan Responds to Waltz," in The Spread of Nuclear Weapons: A Debate, ed: Scott D. Sagan and Kenneth N. Waltz (New York: W.W. Norton \& Company, Inc., 1995), pp. 131-133; Steinbrunner, "Beyond Rational Deterrence", p. 244. Bull believes that nuclear war could result from escalation from the use of tactical nuclear weapons, or even from conventional warfare. See Bull, Arms Race, pp. 50-56.

Other Classicals, however, express the belief that control can be maintained. See Kenneth N. Waltz, "More May Be Better," in The Spread of Nuclear Weapons: A Debate, ed: Scott D. Sagan and Kenneth N. Waltz (New York: W.W. Norton \& Company, Inc., 1995), pp. 34-37; John J. Weltman, "Nuclear Devolution and World Order," World Politics 32 (January 1980): 192; Joseph S. Nye, Jr., "The Long-Term Future of Deterrence," in The Logic of Nuclear Terror, ed: Roman Kolkowicz (Winchester, Mass.: Allen \& Unwin, Inc., 1987), p. 235.

44 Spurgeon M. Keeny, Jr. and Wolfgang K. H. Panofsky, "MAD Versus NUTS," Foreign Affairs 60 (Winter 1981-82): 287-304. The uncontrollability of nuclear escalation makes limited responses pointless. As Rhodes explains, "A deterrence posture that deters the Soviets from undertaking limited military attacks while failing to discourage a massive Soviet 
unavoidable and uncontrollable. (Some Optimists accept MAD while rejecting the notion of automatic escalation. ${ }^{45}$ Without this expectation of escalation, however, MAD makes little sense.)

Second, due to the inevitability of escalation, Classicals expected that the "winners" of a nuclear conflict would be indistinguishable from the losers. ${ }^{46}$ Without the capability of mounting an overwhelming and incapacitating - or splendid - first-strike, pre-emptive attacks would be unlikely to reduce an opponents' arsenal enough to preclude a counter-attack. ${ }^{47}$ The probability

blow against American society is of dubious utility." Rhodes, Power and MADness, p. 208. Some Classicals, however, have proposed the deployment of limited responses devices so that the U.S. could mount a "flexible response." This is in no way incompatible with MAD, though such policies are criticized by some Classicals as expensive and wasteful. Classicals who believe in the possibility of a "flexible response" are discussed in Lodal, "Nuclear Strategy," p. 156.

${ }^{45}$ Waltz, for example, claims that escalation probably would not occur, because "if a few warheads are fired, all of the countries involved will want to get out of the mess they are in." Waltz, "More May Be Better," p. 34. See also Leonard Beaton and John Maddox, The Spread of Nuclear Weapons (New York: Frederick A. Praeger, Inc., 1962), p. 201.

${ }^{46}$ See for example Kenneth N. Waltz, "The Origins of War in Neorealist Theory," in The Origin and Prevention of Major Wars, ed: Robert I. Rotberg and Theodore K. Rabb (Cambridge, UK: Cambridge University Press, 1988), p. 50; Stanley Sienkiewicz, "Observations on the Impact of Uncertainty in Strategic Analysis," World Politics 32 (October 1979): 108. On the enormous collateral effects of nuclear weapons (and even the reputedly less destructive devices such as neutron bombs) see Keeny and Panofsky, "MAD Versus NUTS," pp. 295-298.

${ }^{47}$ This has never been a possibility for the Soviet Union, and the U.S. lost the ability to mount a splendid first-strike in the late 1950s. As Tractenberg notes, the early 1950 s was "not a period when it was taken for granted that all-out war meant the destruction of whole societies." Trachtenberg, "A 'Wasting Asset'," p. 21. 
that an attempted splendid first-strike would succeed were thought to be terribly slim, because nuclear weapons could easily be made survivable. ${ }^{48}$

Therefore, because nuclear war would spell doom for both the U.S. and the Soviet Union, the Classicals believed that it was clearly is in the interests of both to prevent it. ${ }^{49}$ The Classicals expected that the Soviets would recognize this convergence of interest. ${ }^{50}$ MAD could thus be conceived of as "a relationship between two supposedly like-minded and ultimately . . likeintending adversary-partners. ${ }^{.51}$

Given that nuclear war was expected to result in the destruction of the U.S. and the Soviets, Classicals focused on ensuring that nuclear war was prevented by guaranteeing and making evident that it would be as horrible and as unmanageable as they anticipated. ${ }^{52}$ As mentioned in Chapter One, three tenets of MAD had to be fulfilled if stability was to obtain between

${ }^{48}$ Berkowitz makes a strong argument that the survivability of modern weapons has truly made our world MAD. See Bruce Berkowitz, "Technological Progress, Strategic Weapons, and American Nuclear Policy," Orbis 29 (Summer 1985): 241-258. The problem has shifted from one of ensuring survivability through miniturization and mobility, to one of "maintaining adequate command and control" of these devices. Ibid, p. 249.

${ }^{49}$ Gray, "Strategic Stability Reconsidered," pp. 137-138.

${ }^{50}$ This synergy, or "sympathetic parallelism," is discussed by Gray, "Strategic Stability Reconsidered," p. 144.

51 Ibid., p. 136. Emphasis added.

${ }^{52}$ For an expression of "existential MADness," see Keeny and Panofsky, "MAD Versus NUTS," pp. 303-304. 
adversaries: mutual survivability of nuclear weapons, low probability of nuclear "accidents" on both sides, and mutual abandonment of launch-on-warning. If these requirements were fulfilled, both states would face irresistibly strong disincentives to launch a first-strike, and neither would have reason to fear unauthorized or unprovoked launches. ${ }^{53}$

MAD doctrine required that states achieve second-strike capability, so that an adversary would not be tempted to attempt a splendid first-strike. MAD arranged things such that "even if one slays the other, the latter will manage to retaliate posthumously." ${ }^{54}$ The U.S. and the Soviet Union acheived second-strike capability through the hardening of missile silos, the deployment of hardpoint missile defenses, the use of mobile missile launchers (e.g., railcars, aircraft or submarines), and the decentralization of launch authority. ${ }^{55}$ Second-strike capability reduced each state's fear of a paralyzing

${ }^{53}$ Rhodes, Power and MADness, pp. 189-190.

54 Yehoshafat Harkabi, Nuclear War and Nuclear Peace (Jerusalem: Israeli Program for Scientific Translations, 1966), quoted in Gray, "Strategic Stability Reconsidered," p. 137.

${ }^{55}$ It is essential that it be clear that in the event of political "decapitation," others are willing to execute pre-established responses. See Rhodes, Power and MADness, p. 215. Hardpoint defenses are defenses capable of protecting small, hardened targets, such as missiles. Area defenses are defenses capable of protecting larger targets (e.g., cities) that are not hardened against nuclear attack. See Lodal, "Nuclear Strategy," p. 166; Gray, "Strategic Stability Reconsidered," pp. 147-148. 
first-strike, and also reduced the incentives for them to "use-or-lose" their weapons. $^{56}$

MAD also called for countervalue targeting: the practice of aiming missiles at an adversary's population and industrial centers and away from its nuclear weapons. ${ }^{57}$ Unlike counterforce targeting - the targeting of an adversary's weapons - countervalue targeting ensured the survivability of the adversary's weapons. Countervalue targeting did not require highly accurate missiles. ${ }^{58}$ (While willingly sacrificing accuracy runs contrary to conventional military thought, Classicals argue that weapons effective for deterrence may not be useful in war, and vice versa. ${ }^{59}$ )

${ }^{56}$ Lodal, "Nuclear Strategy," p. 164. "While these incentives would not likely be high enough to be a menace in times of calm, they could be sufficient to create instability in periods of heightened tension and perceived likelihood of war," explains Jervis. Robert Jervis, "Arms Control, Stability and Causes of War," Political Science Quarterly 108 (Summer 1993): 248.

57 The U.S. has never has a purely countervalue posture, and, in reality, MAD allows for a variety of targeting methods, so long as the ability of one's adversary to assure one's one destruction is not undermined. Gray, "Strategic Stability Reconsidered," p. 136.

${ }^{58}$ Precisely targetable missiles were useful for destroying an enemy's missiles before they could be launched, but are not necessary to destroy cities. Indeed, the possession of precisely targetable weapons might be considered by an adversary to be evidence that one was seeking the ability to mount a splendid first-strike, and for this reason they were rejected by MAD.

59 For example, Rhodes explains that, "Militarily effective forces - as distinct from force capable only of senseless destruction - increase psychological and organizational pressures on the opponent and may possibly increase his rational incentives for rushing into war as well." Rhodes, Power and MADness, p. 224. 
Though MAD allowed for the use of hardpoint defenses to ensure the survivability of missiles, the deployment of area defenses was rejected, because these defenses could have mitigated the suffering that would result from a nuclear attack. The adversary of a state on the threshold of developing effective area defenses would also experience pressure to launch a preemptive attack, because a state able to insulate itself from suffering may reduce its disincentives to strike first. ${ }^{60}$ Attempts to defend population and industry were also criticized by Classicals as expensive and impractical. ${ }^{61}$

Understandably, because MAD involved threats to unleash a severe nuclear punishment upon the Soviet Union, Classicals stressed the importance of diminishing the possibility of unprovoked or unauthorized missile launches and abandoning launch-on-warning postures. If there was a significant probability of such launches by one side, the other would

${ }^{60}$ James DeNardo, The Amateur Strategist: Intuitive Deterrence Theories and the Politics of the Nuclear Arms Race (New York: Cambridge University Press, 1995), pp. 24-25. As Nye puts it, "It may be 'better to defend than avenge,' but only if the consequences of trying to defend do not increase the risk of nuclear conflict in the meantime." Nye, "Long-Term Future," p. 242.

${ }^{61}$ Keeny and Panofsky, "MAD Versus NUTS," pp. 299-302. For a survey of the technical impediments to the deployment of effective area defenses, see Lodal, "Nuclear Strategy," pp. 164-172. Classicals also reject area defenses on grounds of expense and feasibility. See Rhodes, Power and MADness, pp. 41-42. Finally, Spurgeon Keeny, Jr. and Wolfgang Panofsky offer a good illustration of how effective a missile defense system would have to be to merit deployment. See Keeny and Panofsky, "MAD Versus NUTS," p. 298. 
experience increased pressure to strike first to reduce the suffering it may consider unpreventable otherwise.

One way to reduce the chances of unprovoked or unauthorized launches - and to limit the destructiveness that could result from such an event - was to limit the size of one's arsenal to the minimum required to destroy the adversary once over. ${ }^{62}$ While Classicals disagreed over precisely how many weapons were necessary to do so, ${ }^{63}$ they did agree that overkill capacity - the possession of weapons beyond those required to destroy one's adversary (or adversaries) once over - was wasteful, increased the chance of "accidents," and indicated to the adversary that one intends to fight and win a nuclear war. ${ }^{64}$

MAD was seen as an ideal solution to U.S. policymakers, for it offered a war-weary U.S. a solution to its post-World War II security problem that did

${ }^{62}$ On the "massive indelicacy" of MAD, see Gray, "Strategic Stability Reconsidered," pp. 140-141. According to Gray, MAD is thought to offer a much-desired exit from the interminable U.S.-Soviet nuclear arms race. "The U.S. defense and arms control community has extreme difficulty accommodating the idea that it is condemned to an endless competition with the Soviet Union." Ibid. See also Morgan, Deterrence, p. 92.

${ }^{63}$ Dr. Herbert York as estimated that a minimal deterrent would be "in the range of 1 , 10, or 100" warheads. Daniel Ellsberg, "Manhattan Project II: To End the Threat of Nuclear War," Harvard Journal of World Affairs (Summer 1992): 11. Nitze would likely offer a higher estimate. During the late 1970s, he questioned whether the U.S. really had overkill capacity at all, due to progressive reductions in the total megatonnage of U.S. forces. See Paul H. Nitze, "Deterring Our Deterrent," Foreign Policy 25 (Winter 76-77): 206-207.

${ }^{64}$ On the diminishing marginal value of nuclear weapons, see Rhodes, Power and MADness, pp. 39-40; Morgan, Deterrence, p. 117; Keeny and Panofsky, "MAD Versus NUTS," p. 293; Waltz, "Origins of War," p. 51. 
not require large military expenditures. ${ }^{65}$ Indeed, Richard Pipes described MAD as "born of a marriage between the scientist and the accountant." 66

\section{MAD and the Commitment Problem}

One of the primary criticisms of MAD was that it was incredible. ${ }^{67}$ MAD required that the U.S. threaten that in the event of a provocation unrestrained punishment might be administered. Punishment - as defined here - refers simply to a threatened reaction to a provocation that is not necessarily proportional. $^{68}$ Punishment may continue even after the provocation ceases, it may be more severe than the provocation, and it may not even resemble the provocation in kind.

However, as their critics pointed out, the Classicals confronted a severe commitment problem. It may be rational ex ante to threaten to punish a provocation, but once the provocation occurs it becomes irrational to live up to

${ }^{65}$ See Richard Pipes, "Why the Soviet Union Thinks It Could Fight and Win a Nuclear War," Commentary 64 (July 1977): 23; Ellsberg, "Manhattan Project II," p. 7.

${ }^{66}$ Pipes, "Fight and Win a Nuclear War," p. 24. Pipes argues that nuclear scientists were predisposed to consider nuclear weapons to be absolute, because of their "strong pacificist convictions" and their "deep guilt" over their participation in the creation of the weapon. Ibid.

${ }^{67}$ Lodal, "Nuclear Strategy," p. 156.

${ }^{68}$ Rhodes, Power and MADness, pp. 90-98. While this distinction between retaliation and punishment has not been widely used, it will allow for greater rigor in our discussion of various threats. 
this promise. During the Cold War, some U.S. policymakers and academics

were concerned that if the Soviets were to take limited hostile action, the U.S.

would lack any credible response. ${ }^{69}$ For example, Paul Nitze doubted the

willingness of the U.S. to respond to a Soviet counterforce attack.

The crucial question is whether a future U.S. president should be left with only the option of deciding within minutes, or at most within two or three hours, to retaliate after a counterforce attack in a manner certain to result not only in military defeat for the United States but wholly disproportionate and truly irremediable destruction to the American people. $^{70}$

Threats to react punitively - that is, to make the severity of one's response wholly independent of the severity of the provocation - were implausible against anything short of an all-out attack. ${ }^{71}$

${ }^{69}$ See DeNardo, Amateur Strategist, p. 28; Gray, "Strategic Stability Reconsidered," p. 151; Nitze, "Deterring Our Deterrent," p. 204.

${ }^{70}$ Nitze, "Deterring Our Deterrent," p. 206. See also Colin S. Gray and Keith Payne, "Victory is Possible," Foreign Policy 39 (Summer 1980): 15.

${ }^{71}$ On the implausibility of punitive threats, see Rhodes, Power and MADness, pp. 140141. Powell, "Theoretical Foundations," p. 77. On "salami tactics," see Schelling, Arms and Influence, pp. 66-67. For some hypothetical, limited scenarios of Soviet aggression, see Keeny and Panofsky, "MAD Versus NUTS," p. 294; Morgan, Deterrence, p. 84; Howard, "The Forgotten Dimensions of Strategy," p. 984.

Huth and Russett conclude that extended deterrence is more likely to work when the extended of deterrence and the recipient share economic ties. "[D]eterrence is more likely to be effective the greater the defender's visible and symbolic stake in the protégé." Paul K. Huth and Bruce Russett, "What Makes Deterrence Work? Cases from 1900 to 1980," World Politics 34 (July 1984): 516. 
For the Classicals, however, nuclear war was intrinsically punitive.

They believed that there was a significant probability that nuclear warfare at any level could escalate into a full-blown exchange. Furthermore, they did not want to reduce the likelihood of escalation, because the possibility of uncontrolled escalation surely gives potential belligerents pause, and hence strengthens deterrence. They wanted to make it clear to even those most resistant to MAD that nuclear war was unwinnable.

Therefore, Classicals suggested that the U.S. attempt to solve the commitment problem by doing two things. First, the U.S. had to use threatsthat-leave-something-to-chance: threats not to embark on some elaborate, predesignated course of action, but to incrementally forfeit control over the situation. ${ }^{72}$ Truly to commit with a one-hundred-percent probability to punish would be foolhardy in our uncertain world, and would hence lack credibility. ${ }^{73}$ According to Classicals, just the possibility that the U.S. would respond to an

${ }^{72}$ As Rhodes explains, a threat-that-leaves-something-to-chance requires both the absence of control and knowledge. First, once the threat is triggered, the promised infliction of pain cannot be withdrawn. Second, the party making the threat cannot be certain that pain will be inflicted, or else the threat ceases to leave anything to chance. Rhodes, Power and MADness, p. 89. See also Jervis, "Deterrence Theory Revisited," p. 300 . Schelling likens the threat to engage in limited war to the threat of "rocking the boat" - exposing one's adversary to the risk of some undesirable outcome. Schelling, Arms and Influence, p. 105.

${ }^{73}$ As Morgan explains, "We do not build automatic doomsday machines because giving such an automatic shape to our fate is irrational in an imperfect world." Morgan, Deterrence, p. 97. 
attack by yielding control over its own behavior would be sufficient to deter a first-strike. ${ }^{74}$

Second, states must also commit themselves to respond by denying themselves the ability to act on the basis of their rational ex post preferences. $^{75}$

State leaders may arrange things so that if provoked, the state would have no choice but to set into motion a series of events beyond its control. ${ }^{76}$ This

${ }^{74}$ As Jervis explains, "it never makes sense to destroy the other side's cities - and invite retaliation in kind - but the ever-present chance of this outcome exercises a most powerful influence." Jervis, "Deterrence Theory Revisited," p. 324. "In a conventional world, a country can sensibly attack if it believes that success is possible," writes Waltz. "In a nuclear world, the would-be attacker is deterred if it believes that the attacked may retaliate." Waltz, "More May Be Better," p. 24. See also Wohlstetter, "Nuclear Sharing," p. 214; Rhodes, Power and MADness, p. 124; DeNardo, Amateur Strategist, pp. 35-36.

Though the argument is frequently made that the slim chance of disaster is enough to deter, Wohlstetter explains, "This line of reasoning parallels Pascal's famous argument that, even if there were only a small probability of eternal damnation, the risk would be excessive. Yet some have risked hellfire." Wohlstetter, "Nuclear Sharing," p. 198.

${ }^{75}$ Rhodes, Power and MADness, p. 109. Such an ostensibly irrational commitment is completely rational if leaders expect to fare better by having made it. Rhodes, Power and MADness, p. 126. Rhodes distinguishes commitment-through-irrationality from commitmentthrough-denial-of-choice: denying oneself the ability to do ex post anything other than what one threatened to do ex ante, regardless of changes in one's preferences over time. This, it seems to me, is merely a type of commitment-through-irrationality in which ex post irrationality is not just probable but certain. Rather than distinguish between the two as different modes of commitment, I make a distinction below between probabilistic and certain threats.

However, leaders already suffering a credibility deficit cannot rationally committhough-irrationality, because the likelihood that their commitment will be mistakenly regarded as bluffing-through-irrationality is too great to make the tactic worthwhile. Ibid., p. 45.

By increasing the probability that it would have no alternative but to carry out its threats ex post, a state can make its threats more credible. Schelling, Arms and Influence, pp. 41-42. As Jervis explains, "Once [the Chicken] model is grasped, several tactics that are contrary to common sense - such as severing communication links, feigning anger, irrationality, or loss of control over militant factions in one's organization - all fall into place." Jervis, "Deterrence Theory Revisited," pp. 291-292. See also Jon Elster, Nuts and Bolts for the Social Sciences (Cambridge: Cambridge University Press, 1989), p. 106. 
denial or modification of choice can be achieved through the use of some mechanism that prevents the state from behaving rationally if provoked. ${ }^{77}$

It would not be technically difficult for an organization as large and complex as the U.S. to commit to act irrationally if provoked, because irrational decision-making can be made contingent on nuclear aggression. ${ }^{78}$ However, Rhodes stipulates that

irrationality [must] not go very deep . . . . Decision centers at the national or theater level would need to be irrational enough to order the use of nuclear weapons, but the military organization at the front would need to remain rational enough to use them effectively. The organization could not malfunction in carrying out the irrational decisions. ${ }^{79}$

Most other deterrence theorists, including Anti-Classicals, expected that the destruction of $C^{3} /$-command, control, communication and

${ }^{76}$ Ellsberg, "Blackmail," p. 356.

${ }^{77}$ Morgan explains that the idea is to appear "just crazy enough to blow us all up." Morgan, Deterrence, pp. 95-96.

This tactic is useful under a wide array of circumstances, because, as Frank explains, "we face important problems that simply cannot be solved by rational action. The common feature of these problems is that to solve them we must commit ourselves to behave in ways that may later prove contrary to our interests." Frank, Passions Within Reason, p. 4.

${ }^{78}$ Rhodes explains that it is possible "to imagine organizations . . . whose normal ability to engage in intelligent calculation on some matter is destroyed by an opponent's failure to yield." Rhodes, Power and MADness, p. 177. Organizational complexity precludes the minimization of the threat of undesired escalation. Jervis, "Causes of War," p. 248. "Thus the possible speed of nuclear war increases the possibility of ex post irrational execution of significant negative sanctions." Rhodes, Power and MADness, p. 138.

${ }^{79}$ Rhodes, Power and MADness, p. 195. 
intelligence - would make a coordinated response difficult, and may preclude even a fumbling response if a decapitating first strike were to succeed. ${ }^{80}$ Rhodes, however, suggested that the U.S. render its $C^{3}$ I vulnerable to nuclear attack while arranging things such that decapitation - or a nuclear attack on any other "appendage" - increased the likelihood of a punitive response. ${ }^{81}$ Strong $\mathrm{C}^{3} \mathrm{I}$, according to Edward Rhodes, "make it more certain that the United States will be able to respond rationally to Soviet aggression, by the same token it will make it more difficult credibly to threaten to carry out an irrational response ..."82 Efforts to ensure ex post self-restraint not only undermined the MAD commitment to respond irrationally, but were technically challenging, and imposed unnecessary financial burdens. ${ }^{83}$

By rendering $C^{3}$ I vulnerable in such a way that a nuclear attack would splinter a state's nuclear command, a state could ensure that the behavior of

${ }^{80}$ Berkowitz, "Technological Progress," p. 255.

${ }^{81}$ On the importance of $\mathrm{C}^{3}$ I, see Steinbruner, "Nuclear Decapitation," p. 19. On the implications of the disruption of $\mathrm{C}^{3} \mathrm{l}$, see Gray and Payne, "Victory is Possible," p. 18.

${ }^{82}$ According to Rhodes, there is no objectively optimal balance between the ability to behave rationally ex post and the ability to deter ex ante, or between the other values in question. Rhodes, Power and MADness, pp. 163, 212. Unlike Rhodes, most Classicals agree with Anti-Classicals that $C^{3}$ I ought to be strengthened. See for example Gray, "Strategic Stability Reconsidered," p. 148 . Weak $C^{3}$ I impels the U.S. to rapidly escalate according to Steinbruner, "Nuclear Decapitation," p. 22.

${ }^{83}$ Regarding expense, see Rhodes, Power and MADness, pp. 205-206. Regarding the disruptive effects of electromagnetic pulse, see Rhodes, Power and MADness, pp. 139 140; Steinbruner, "Nuclear Decapitation," p. 26. 
these newly independent centers would be unpredictable. ${ }^{84}$ For example, the interests of the U.S. National Command Authorities and U.S. forces in West Germany might have diverged in the event of a Soviet armored onslaught against Europe. ${ }^{85}$ Though central decision-makers in Washington might have elected not to use nuclear weapons once their threats to do so failed to deter attack, besieged U.S. personnel in Europe might have opted to even their odds with the nuclear weapons at their disposal. ${ }^{86}$ Even if communication was possible, sanctions threatened by central decision-makers to prevent unauthorized use of nuclear weapons might have been ineffective. ${ }^{87}$ Futhermore, the vulnerability of $C^{3}$ I could allow for the disruption of communication between personnel willing to use nuclear weapons and their leaders. The pre-engineered collapse of a state's command structure during hostilities could actually be ex ante advantageous, bolstering the credibility of

${ }^{84}$ Steinbruner - who values $C^{3} \mathrm{I}$ - warns that fewer than 100 nuclear weapons could cripple U.S. command, control, communication and intelligence. Steinbruner, "Nuclear Decapitation," p. 18. However, as Rhodes explains, rationality ex post can only be won at the expense of credibility. See Rhodes, Power and MADness, p. 164. See also Wohlstetter, "Nuclear Sharing," p. 217.

${ }^{85}$ Rhodes, Power and MADness, p. 183.

${ }^{86}$ Ibid., p. 217.

${ }^{87}$ As Rhodes explains, "It may be that in the event the opponent fails to yield, the central decision center would [or could] no longer carry out the sanctions it can inflict on the secondary center." Ibid., p. 182. 
claims to respond irrationally to provocation, even in cases of extended deterrence.

Rhodes warned that the U.S. must ensure that it would not lose control as a result of a mere international crisis, but only due to those specific actions that its arsenal was intended to deter ${ }^{88}$ The U.S. also needed to communicate to the Soviets what specific action it was committed to respond to. ${ }^{89}$ Otherwise, the U.S. could have encouraged the Soviets to probe the boundaries of permissible behavior. ${ }^{90}$ It was especially imperative to specify what actions would provoke a response, because it would be difficult to refrain from responding to even innocuous probes if one was committed to respond irrationally.

Of course, the U.S. could instead have bluffed, by pretending to have been committed to an irrational, punitive response while aware that it would never respond this way. As a solution to the commitment problem, however, bluffing suffers significant drawbacks. One important difficulty with bluffing was that not all states were able to bluff convincingly. ${ }^{91}$ Open democratic

${ }^{88}$ Ibid., pp. 168, 189.

${ }^{89}$ Schelling, Arms and Influence, p. 48.

${ }^{90}$ Vagueness undermines commitments. If pressed, it may be expected that the committing party will find a "graceful" way out of an ambiguous commitment. Schelling, Arms and Influence, p. 48.

${ }^{91}$ Morgan, Deterrence, p. 85 
states such as the U.S. would have had an especially difficult time successfully lying about how they would respond to nuclear provocation. ${ }^{92}$ Democratically-elected leaders given to frequent, ostentatious commitments to react irrationally to provocation might not be tolerated for long, either. ${ }^{93}$

Obviously, many of MAD's policy prescriptions ran contrary to both military instinct and conventional morality, and necessitated painful sacrifices in other values. ${ }^{94}$ Rhodes' recommendations for rendering $C^{3}$ I vulnerable were not entirely above criticism, either. ${ }^{95}$ It was quite understandable that MAD was an object of controversy.

${ }^{92}$ Rhodes, Power and MADness, p. 133.

${ }^{93}$ Ibid., p. 185.

94 On the trade-offs required by MAD, see Keeny and Panofsky, "MAD Versus NUTS," p. 288; Rhodes, Power and MADness, p. 220; Lodal, "Nuclear Strategy," pp. 173-174; Morgan, Deterrence, p. 121. For example, threatening to lose control increases the risk that an "accident" or some event could precipitate uncontrolled escalation.

On the immorality of MAD, see Fred Charles Iklé, "Can Deterrence Last Out the Century?" Foreign Affairs 75 (January 1973): 267-285; Gray and Payne, "Victory is Possible," pp. 16-17.

${ }^{95}$ Rhodes' suggestions, though ingenious, require that each side in a nuclear standoff attempt to foist rationality upon the other. He explains that one ought not undermine an opponent's ability to be rationally deterred. Rhodes, Power and MADness, p. 208. He also argues that "by threatening the survival of central military control during conflict, U.S. deployments may encourage ex ante decentralization of Soviet decision-making and predelegation of authority, thus increasing the danger of organizational dysfunction in time of crisis." Ibid., p. 219. However, such a configuration is precisely what Rhodes suggests the U.S. adopt itself.

It seems that this policy of fragile $\mathrm{C}^{3} \mathrm{I}$, especially if adopted by both sides, could make nuclear "accidents" worse by paving the way for irrational escalation. 


\section{Nuclear Utilization Target Selection}

Anti-Classicals rejected MAD for a variety of reasons, but two stand out a particularly important. The first reason was that once deterrence failed, the threat to unleash forces that would result in a nuclear holocaust was not credible. The U.S., once provoked, and lacking anything but a suicidal alternative, would likely be self-deterred. ${ }^{96}$ Furthermore, MAD makes difficult the pursuit of a war-fighting strategy once deterrence fails. ${ }^{97}$

Second, they argued that the Soviets did not believe that nuclear weapons were absolute weapons, nor did they believe that nuclear war was unwinnable. ${ }^{98}$ Hence they pursued a strategy antithetical to MAD that was based on preemptive attack, numerical superiority, counterforce targeting and defensive measures. ${ }^{99}$

${ }^{96}$ This was a recurring concern among U.S. policymakers during the Berlin Crises of the Eisenhower and Kennedy administrations. See Betts, Nuclear Blackmail, pp. 83-109.

${ }^{97}$ As Gray puts it, "To ignore the possibility that strategy can be applied to nuclear war is to insure by choice a nuclear apocalypse if deterrence fails." Gray and Payne, "Victory is Possible," p. 26. See also Benjamin Lambeth, Selective Nuclear Options in American and Soviet Strategic Policy (Rand Corporation, R-2034-DDRE, December 1976), p. 14.

${ }^{98}$ The Soviet view that nuclear weapons were not special was dismissed by the U.S. in the late 1940s as sour grapes. However, in September 1949 the Soviets detonated its own nuclear weapon, and as Pipes explains, "Disconcertingly, [the Soviets'] attitude to nuclear weapons did not change, at any rate not in public." Pipes, "Fight and Win a Nuclear War," $p$. 28.

Pipes also argues that the Soviets believe that their society could weather a nuclear war. Ibid, p. 21.

${ }^{99}$ Pipes, "Fight and Win a Nuclear War," pp. 31-34. According to Nitze, the Soviets during the 1970s were amassing survivable counterforce and countervalue weaponry, the former intended for use in a first-strike, the latter to hold hostage an impotent US. Nitze, 
Anti-Classicals devised Nuclear Utilization Target Selection (NUTS) as an alternative doctrine intended to deter Soviet aggression and also to provide the U.S. with a war-fighting a strategy in the event that deterrence fails. ${ }^{100}$ In order to deter the Soviets - who were thought to have believed that they could win a nuclear war - Anti-Classicals argued that it was necessary to deny them the ability to win a nuclear conflict at any level of intensity. ${ }^{101} \mathrm{~A}$ nuclear war-fighting strategy was necessary to accomplish this task, but AntiClassicals feared that U.S. policymakers and academics accepted MAD by default, unwilling (or perhaps even unable) to seriously contemplate nuclear war. $^{102}$

Like MAD, NUTS doctrine consisted of three key tenets: first, deny the adversary any prospect of victory at any level of conflict without escalating to

"Deterring Our Deterrent," pp. 197-198. He explained that "they wish to be able, after a counterforce attack, to maintain sufficient reserve megatonnage to hold U.S. population and industry hostage in a wholly asymmetrical relationship." Ibid, p. 208.

${ }^{100}$ See Keeny and Panofsky, "MAD Versus NUTS," p. 289. Bull claimed - a decade or so before NUTS coelsced in the minds of U.S. strategists and policymakers - that deterrence theories are "concerned not to affect the outcome of war ..." Bull, Arms Race, p. 45. This is clearly not true, since NUTS seeks to deter war precisely by affecting its potential outcome.

${ }^{101}$ On tailoring one's threats, see Morgan, Deterrence, p. 138.

102 "A dominant belief that nuclear forces have failed if they are ever used is hardly likely to stimulate officials to think very realistically about command stability problems in a nuclear war environment," explains Gray. Gray, "Strategic Stability Reconsidered," p. 149. Furthermore, Pipes claims that in the US, the use of force is considered evidence of failure. Pipes, "Fight and Win a Nuclear War," p. 25. Therefore, it seems logical that the U.S. emphasized prevention. 
the highest level; second, make likely the adversary's defeat at any of these levels; and third, make possible the limitation of damage to oneself. ${ }^{103}$ NUTS clearly represented a radical departure from Classical thought. Unlike MAD, NUTS doctrine allowed for the possibility of nuclear conflict at levels below unmitigated punitive warfare, and hence also allowed for the possibility of victory in a nuclear war. NUTS also embraced area defenses, which were forbidden under MAD doctrine.

NUTS was based not on punishment, but rather on retaliation: the infliction of pain upon an opposing state so long as it continued to inflict pain upon one's own state. ${ }^{104}$ Retaliation is reciprocal: the threatened response would cease as soon as the provocation ends, would qualitatively resemble the provocation, and, most importantly, would be roughly proportional in terms of severity. ${ }^{105}$ Due to their proportionality, retaliatory threats tend to be more credible than punitive threats. ${ }^{106}$

${ }^{103}$ These tenets have been derived from a set of three Soviet-specific recommendations made by Gray and Payne. See Gray and Payne, "Victory is Possible," pp. 26-27. (Admittedly, the first and second tenets could be collapsed into one.)

${ }^{104}$ Rhodes, Power and MADness, pp. 90-98.

${ }^{105}$ Schelling claims that if the behavior prompting punishment and the threatened punishment are somehow connected, the credibility of the deterrent threat increases. Schelling, Arms and Influence, pp. 88-89.

${ }^{106}$ Lodal, "Nuclear Strategy," p. 163. 
The first and second tenets of NUTS doctrine require the achievement of escalation dominance: the ability to best an adversary in most - if not every - relevant category of weapons and defense-related technology. ${ }^{107}$ Anti-Classicals support the creation of "an array of limited options" so that the U.S. could respond proportionally and more credibly to provocations of various intensities. ${ }^{108}$ A diverse range of weapons - including tactical nuclear landmines, highly-accurate Multiple Independently-Targetable Reentry Vehicles (MIRVs), and even Anti-Submarine Warfare (ASW) technologies were allowed under NUTS. The wider the array, the more options were available from which the U.S. could chose an appropriate, credible and proportional response. Not only do the Anti-Classicals support diversified arsenals, but they believe these weapons should be numerous, as well. ${ }^{109}$

${ }^{107}$ On escalation dominance, see Lodal, "Nuclear Strategy," p. 162. Some Classicals are not adamantly against limited measures, and others support the a "flexible response" arsenal. Gray and Payne criticize flexible response Classicals for neglecting "to take proper account of the fact that the United States would be initiating a process of competitive escalation that it had no basis for assuming could be concluded on satisfactory terms." Gray and Payne, "Victory is Possible," p. 18.

${ }^{108}$ Robert Powell, "Theoretical Foundations," p. 78.

${ }^{109}$ Kull explained away this pursuit of overkill capacity as illogical. "Psychologists have found that when people face a threat to which they cannot effectively respond, they tend to generate the illusion that there is some meaningful action they can take to reduce this threat." Steven Kull, "Nuclear Nonsense," Foreign Policy 58 (Spring 1985): 51.

Morgan explains that the expansion of one's overkill capacity was a sensible reaction to the possibility that the other side believed advantages still matter. Morgan, Deterrence, $\mathrm{p}$. 134. 
Unlike MAD, NUTS did not forbid the deployment of weapons that were vulnerable to a first-strike. While the Classicals feared that the possession of such weapons would betray a willingness to strike first, it is precisely for this reason that Anti-Classicals valued these weapons. ${ }^{110}$ They were indicative of the confident belief that "victory is possible."

As the third tenet of NUTS doctrine suggests, both hardpoint and area defenses were allowed. Anti-Classicals believed that deterrence would be strengthened if one's weapons, critical industries and population could be shielded from attack. ${ }^{112}$ Without defensive capabilities, trading proportional blows would simply lead to MAD in slow motion, or, as Colin Gray describes it,

${ }^{110}$ Nitze, "Deterring Our Deterrent," p. 210.

${ }^{111}$ This is the title of an important contribution to the Anti-Classical literature: Gray and Payne, "Victory is Possible." Some Classical agree with the value of symbolism. Lodal, whom I would regard as a Classical, supports defenses even while admitting that they would have no real impact on the consequences of a nuclear war. Lodal believes that the world is MAD, but recognizes that the Soviets do not see this truth. He supports the deployment of an active defense system because he believes it would communicate resolve to the Soviets. He also believes that it would also be a more efficient way to ensure retaliatory capacity, rather than building more weapons. Lodal, "Nuclear Strategy," pp. 168-172.

${ }^{112}$ Rhodes discusses a type of threat he calls denial: an attempt to deter an opponent by threatening negation. Rhodes, Power and MADness, pp. 90-98. Denial occupies the hazy borderline between coercion and negation discussed above. The obvious possession of direct power sufficient to deny an opponent the fruits of a particular action may deter that action. Classicals have drawn a largely artificial distinction between defense and deterrence, and this distinction has led to the erroneous belief that threats of denial cannot deter. See Schelling, Arms and Influence, pp. 78-79; Waltz, "More May Be Better," pp. 3-4. 
"suicide on the installment plan."113 NUTS also accepts the fortification of $C^{3} I$, contrary to Rhodes' Classical prescriptions. ${ }^{114}$

Anti-Classicals did not anticipate that the measures called for by NUTS would unduly antagonize or provoke the Soviets. As Gray explains, "Soviet political and military thinkers would be most unlikely . . . to view programs intended to provide active and passive defense of the American homeland as anything other than common sense."

Classicals responded to NUTS by reiterating the dangers of undermining the survivability of an adversary's nuclear arsenal, and by pointing out the expense and ineffectiveness of the technologies required to do so. They also point out that NUTS would be unlikely to enjoy popularity within the U.S.. ${ }^{116}$ However, the most serious problem with NUTS, from the Classical perspective, was that it ignored the danger of escalation. ${ }^{117}$

${ }^{113}$ Colin S. Gray, quoted in Rhodes, Power and MADness, p. 35.

114 Successful, proportional retaliation requires lines of communication to be available. Rhodes, Power and MADness, p. 104.

${ }^{115}$ Gray, "Strategic Stability Reconsidered," p. 148.

${ }^{116}$ Kull, "Nuclear Nonsense," p. 47.

${ }^{117}$ Keeny and Panofsky charged that the doctrine "inevitably encourages the illusion that somehow nuclear weapons can be applied in selected circumstances without unleashing a catastrophic series of consequences." Keeny and Panofsky, "MAD Versus NUTS," p. 290. 


\section{CONCLUSION}

There is no way to determine whether MAD, NUTS or both were correct. Were the Soviets deterred from moving against Western Europe by Eisenhower's MAD-esque New Look, or by the slightly more NUTS-ish approaches of later administrations? Were U.S. officials deterred from challenging the Soviets' vital interests by their strategic doctrine? To know for certain, we would have to know that on some occasion U.S. or Soviet officials authorized to order such a move would have done so had it not been for the prospect of nuclear retaliation or punishment. Furthermore, the U.S. has never adhered to an ideal form of either doctrine, but it has rather pursued a mixed doctrine. Therefore, it is difficult to know to which doctrine we owe our survival, if either.

In the next chapter this discussion of MAD and NUTS will continue, though emphasis will shift from the specifics of each doctrine to their interaction. It will be argued there that, based on the U.S.-Soviet experience, it seems that MAD best deters Classicals, whereas NUTS best deters AntiClassicals. Furthermore, it will be argued that Classicals facing Anti-Classical adversaries are more likely to shift to NUTS than the reverse, because AntiClassical thought seems to be more deeply rooted in traditional military thought and intuition. 
For this reason (and others), I argue in Chapter Three that the first danger of a nuclearized world is that the view that nuclear weapons are useful for purposes other than deterrence may prevail among new nuclear states. In addition, I argue that four other dangers will grow as the spread of nuclear weapons continues: parochialism and myopia, assymetrical proliferation and preventative war, nuclear use as a result of an accident, and catalytic war. 


\section{CHAPTER THREE:}

\section{FIVE REASONS FOR PESSIMISM}

With their immense destructive power, nuclear weapons are bound to make people uneasy. Decades of fuzzy thinking in high places about what deterrence is, how it works, and what it can and cannot do, have deepened the nuclear mailaise. ${ }^{1}$

Kenneth Waltz

Throughout the prescriptive literature, the idea that different people might legitimately understand deterrent stability in different ways is simply given no quarter. ${ }^{2}$

James DeNardo

The final debate regarding the danger of proliferation is to be resolved in this chapter. In the sections below I will describe five dangers, each of which make likely that the proliferation of nuclear weapons will increase the probability of the use of these weapons.

${ }^{1}$ Kenneth N. Waltz, "Nuclear Myths and Political Realities," American Poltical Science Review 84 (September 1990): 731.

2 James DeNardo, The Amateur Strategist: Intuitive Deterrence Theories and the Politics of the Nuclear Arms Race (New York: Cambridge University Press, 1995), p. 39. 
First, as the population of nuclear states grows, so too will the number of states pursuing Anti-Classical doctrines. Just as the U.S. did while deterring the Soviet Union, Classically-oriented states confronting AntiClassical adversaries may experience pressures to abandon MAD, thus causing Anti-Classical thought to spread. (The problem of doctrinal incompatibility may be particularly acute for new nuclear states facing multiple adversaries with different doctrinal orientations. There would be a danger that while successfully countering one threat, a state may actually antagonize its other adversary.)

Second, even assuming that the people within new nuclear states are completely rational, their decisions may nevertheless result in destabilizing deployment choices, which may diminish the likelihood that future crises will not escalate.

Third, nuclear proliferation will likely be an uneven process. If one side of an inter-state rivalry were to acquire nuclear weapons, it may be tempted to use these weapons to compel its adversary to perform certain acts, or to abandon its quest for nuclear weapons.

Fourth, a major nuclear accident during a crisis could precipitate nuclear escalation. Nuclear proliferation will increase the probability of such accidents. Furthermore, as the number of nuclear states increases, the distances between these states decrease, and some of them may pursue 
launch-on-warning postures to attenuate their perceived vulnerability to sudden attack. Such postures increase the likelihood that accidents could escalate into nuclear violence.

Fifth and finally, as the number of nuclear states increases, so does the likelihood of catalytic warfare. The greater the number of nuclear states, the more difficult it will become to ascertain culpability.

\section{CREEPING ANTI-CLASSICAL THOUGHT}

The Optimists expect that new nuclear states will do two things: first, to acknowledge that nuclear weapons have no use but to deter, and to consequently embrace MAD; second, to actualize the ideals of MAD by adhering to the doctrine's three tenets.

As we have seen, the Soviets did neither, much to the Classicals' chagrin. In this section, I will argue that there is no reason to expect that new nuclear states will adhere to the MAD doctrine, either. Even if guided by leaders who subscribe to MAD, new nuclear states may still be unable to adhere to the doctrine's tenets. More problematic is the fact that these leaders may reject MAD in favor of other doctrines which allow for the use of nuclear weapons for purposes more diverse than mere deterrence.

This section is divided into a number of subsections. Some subsections focus on technical impediments to the actualization of MAD; 
others examine the reasons new nuclear states may be unwilling to adhere to $M A D$, even when technically capable of doing so.

\section{The Instinctual Appeal of Anti-Classical Thought}

The deterrence debate was left unresolved in Chapter Two, and it will not be resolved here. (It would surely be a remarkable milestone in the history of strategic thought if it were otherwise.) As had been repeatedly noted, there is very little evidence against which to test the expectations of Classicals and Anti-Classicals. Indeed, it is impossible to know with certainty whether either doctrine worked as it was intended to: MAD purely for deterrence, or NUTS for both deterrence and for defeating the Soviets in a nuclear war. ${ }^{3}$

This epistemological obstacle does not, however, impede my argument that Anti-Classical thought - characterized by a belief that nuclear weapons are more useful than the Classicals admit - will proliferate in a nuclearized world. Indeed, the very fact that the deterrence debate is logically irresolvable actually bolsters my claim, because choices among doctrines will be informed not by reason, but by instinct and intuition. ${ }^{4}$

${ }^{3}$ Again, it is fortunate for humankind that that some of the necessary evidence (i.e., examples of nuclear deterrence failures) is unavailable.

${ }^{4}$ Selten suggests that, "A strategy is not necessarily the result of conscious reasoning. A player guided by routine learning only also follows a strategy. Presumably our motivational 
At the instinctual level, Anti-Classical thought will likely be preferred to Classical thought. Wohlstetter contrasts the counter-instinctual character of

MAD with the more traditional character of NUTS in the passage below.

... the victim's ability to force his own destruction is quite a different thing from a promise to do direct and extensive damage to the aggressor. It is rather more like the method of lying down on the railroad tracks or fasting until death, used (sometimes successfully) by the nonviolent resisters. It is doubtful that it could be counted upon against a totalitarian opponent. And it is likely to wear heavily on the nerves of any but a nation of saints and heroes. ${ }^{5}$

Ensuring that one's own populations are vulnerable to attack while refraining from targeting the adversary's nuclear weaponry is a challenging thing to do for any prolonged period of time.

Evidence of doctrinal preferences is scant and of questionable validity. However, in an important study, James DeNardo gathered evidence that strongly suggests that there are actually several different families of thought regarding deterrence, whose members are united by their common weapons preferences. ${ }^{6}$ Furthermore, these outlooks occur with the same frequencies

system is inherited from our animal ancestors. The power of imagination and reasoning is a later addition to our biological heritage. . This means that rationality is in the service of a rather unsophisticated higher author." Reinhard Selten, quoted in DeNardo, Amateur Strategist, p. 42.

${ }^{5}$ Albert Wohistetter, "Nuclear Sharing: NATO and the N+1 Country," in The Dispersion of Nuclear Weapons, ed: R.N. Rosecrance (New York: Columbia University Press, 1964), p. 199.

${ }^{6}$ DeNardo, Amateur Strategist, pp. 128-147. 
among samples of U.S. "amateurs" (i.e., graduate students) as they do among U.S. strategic "experts" (i.e., RAND, TRW and Northrop analysts).

Consider the preference data presented in Table 3-1 below. The three main row headings are technologies shunned by MAD: the precise, vulnerable MIRVed MX missile, ${ }^{7}$ Strategic Defense Initiative (SDI) anti-missile systems; and Anti-Submarine Warfare (ASW) technology. The three column headings are preferrences: NOs prefer without exception not to build these technologies; IFFs - according to DeNardo - "follow the maxim 'If they have the weapon, we're going to have it too; otherwise, we don't want it."'; ${ }^{8}$ the YESes prefer to build under most circumstances. ${ }^{9}$

${ }^{7}$ The MX missile lends itself well to splendid first-strikes. See DeNardo, Amateur Strategist, pp. 25-26.

${ }^{8}$ lbid., p. 91.

${ }^{9}$ These preferrence types are described in ibid., pp. 89-96. 
TABLE 3-1 Weapons Preferences

\begin{tabular}{|l|l|c|c|c|}
\cline { 3 - 5 } \multicolumn{2}{c|}{} & NO & IFF & YES \\
\hline \multirow{2}{*}{ MX } & Amateurs & $14 \%$ & $45 \%$ & $38 \%$ \\
\cline { 2 - 5 } & Experts & $24 \%$ & $46 \%$ & $26 \%$ \\
\hline SDI & Amateurs & $14 \%$ & $41 \%$ & $41 \%$ \\
\cline { 2 - 5 } & Experts & $15 \%$ & $53 \%$ & $30 \%$ \\
\hline ASW & Amateurs & $12 \%$ & $43 \%$ & $44 \%$ \\
\cline { 2 - 5 } & Experts & $20 \%$ & $52 \%$ & $25 \%$ \\
\hline
\end{tabular}

SOURCE: James DeNardo, The Amateur Strategist: Intuitive Deterrence Theories and the Politics of the Nuclear Arms Race (Cambridge, U.K.: Cambridge University Press, 1995), p. 94., table 5.1.

As Table 3-1 makes apparent, more of DeNardo's survey respondents - amateurs and experts alike - exhibited Anti-Classical YES preferences than Classical NO preferences with respect to these technologies.

\section{Soviet Resistance to MAD}

The resistence of the Soviets to Classical thought made it nearly impossible for the U.S. to sustain adherence to MAD. The doctrine seemed to many Americans to be the most logical, cost-effective method of deterrence. 
Unfortunately, the "mutual" aspect of MAD is criticial to its success. Unless the Soviets eventually accepted the doctrine themselves - which they did not - the stability of deterrence could be jeoparized. ${ }^{10}$ As Pipes explains, "There is something innately destabilizing in the very fact that we consider nuclear war unfeasible and suicidal for both, and our chief adversary views it as feasible and winnable for himself." 11

Nevertheless, Classicals were so convinced of the objective truth of MAD that they expected that the Soviets would come around to their way of thinking sooner or later. ${ }^{12}$ If the Soviets did not immediately appreciate the inescapability of MAD, Classicals argued that they must be persuaded of it. For example, in the 1980s, Steven Kull suggested that the U.S. "play it straight" by maintaining that nuclear war is unwinnable, and attempting to educate the Soviets of that fact. ${ }^{13}$

${ }^{10}$ For example, the Soviets could make limited moves against Western interests, or even a series of them, confident the the U.S. would be unwilling to "end the world" to stop them. Anti-Classicals argue that the Soviets do not subscribe to Classical deterrence. DeNardo, Amateur Strategist, p. 32.

"Richard Pipes, "Why the Soviet Union Thinks It Could Fight and Win a Nuclear War," Commentary 64 (July 1977): 34.

${ }^{12}$ Ibid., p. 21. Pipes also claims that one of MAD's "leading characteristics is a scorn for Soviet views on nuclear warfare."

${ }^{13}$ Steven Kull, "Nuclear Nonsense," Foreign Policy 58 (Spring 1985): 48 . Kull argued that political barriers prevented the U.S. from pursuing NUTS. To justify military spending to match the Soviets, Kull claimed that politicians must convince their constituents that the U.S. was at a disadvantage. However, presenting the U.S. as "weak and vulnerable" runs contrary to NUTS. Ibid, p. 46. 
The U.S. did "play it straight," twenty years before Kull suggested it do so. During the 1960 s, the U.S. enjoyed a substantial numerical edge over the Soviets. At this time the U.S. unilaterally capped its ICBMs at approximately 1,000 and simultaneously dismantled its air defenses. "The expectation was that as soon as the Russians felt themselves equal to the United States in terms of effective deterrence, they would stop further deployments," explains Pipes.

However, this expectation was proven wrong. In the 1970s, the everenlarging Soviet arsenal and the ever-mounting evidence that the Soviets refused to see the world the way the Classicals wanted them to led to intensified and often acrimonious debate among Classicals and their critics regarding how best to react. ${ }^{14}$ Classicals insisted that the U.S. continue to "play it straight," and to try to convince the Soviets that nuclear war was unwinnable.

Anti-Classicals were strongly opposed to this suggestion, and instead argued that if the U.S. was to deter the Soviets, U.S. strategists had to take the Soviet perspective in account. ${ }^{15}$ Moreover, the Anti-Classicals argued that

${ }^{14}$ On the Soviet rejection of sufficiency, see Pipes, "Fight and Win," p. 25; and Colin S. Gray, "Strategic Stability Reconsidered," Daedalus 109 (Fall 1980): 149.

${ }^{15}$ Pipes' contempt for the argument is the most striking. "How ironic that the very people who have failed so dismally to persuade American television networks to eliminate violence from their programs, nevertheless feel confident that they can talk the Soviet 
the winnability of nuclear war was irrelevant. Even if the leaders of a state were certain that nuclear war would escalate into an unmitigated holocaust, a doctrine based on such an expectation - as MAD was - would be unlikely to deter leaders who did not share this expectation. ${ }^{16}$

Pipes ascribed the Soviets' confidence in its ability to be victorious in a nuclear war to its unique definitions of success and failure.

[C]learly a country that since 1914 has lost, as a result of two world wars, a civil war, famine, and various "purges," perhaps up to 60 million citizens, must define "unacceptable damage" differently from the United States, which has known no famines or purges, and whose deaths from all the wars waged since 1775 are estimated at 650,000 - fewer casualties than Russia suffered in the 900-day siege of Leningrad in World War II alone. ${ }^{17}$

leadership into eliminating violence from its political arsenal!" he chides. Pipes, "Fight and Win," p. 26.

${ }^{16}$ For a discussion of perception theory, see Quester, "Cultural Barriers," p. 99 . As Morgan explains, deterrence successes result from the "fortunate conjuction" between the leadership of the attacking and deterring states. Patrick M. Morgan, Deterrence: A Conceptual Analysis (Beverley Hills: Sage Publications, 1977), p. 51. DeNardo agrees, claiming that, "What deters must depend on how real political actors think and reason about strategy - and who controls decisions - not on an autonomous 'logic' that seems right to the theorist." DeNardo, Amateur Strategist, p. 39. "The military system into which nuclear weapons would be fitted would vary in expense and elaboration with the countervailing measures of the enemy." R. N. Rosecrance, "Stability and Nuclear Diffusion," in The Dispersion of Nuclear Weapons, ed: R. N. Rosecrance (New York: Columbia University Press, 1964), p. 299.

${ }^{17}$ Pipes, "Fight and Win," p. 34. For an interesting article that illustrates the sensitivity of affluent states to the costs of warfare, see Edward N. Luttwak, "Toward Post-Heroic Warfare," Foreign Affairs 73 (May-June 1995): 109-122. 
He argued that the prospect of a MAD countervalue attack was not as terrifying to the Soviets as the U.S. believed it to be. Due to lower rates of urbanization, "all of the USSR's multimillion cities could be destroyed without trace or survivors, and, provided that its essential cadres had been saved, it would emerge less hurt in terms of casualties that it was in 1945." ${ }^{18}$ Furthermore, the Soviets also believed they could reduce their losses through active and passive defensive measures. ${ }^{19}$

The Anti-Classicals argued that MAD would be interpreted by the Soviets as a sign that the U.S. lacked the will to fight a nuclear war, and perhaps even to respond to a provocation. ${ }^{20}$ The pursuit of MAD by the U.S. could be perceived to be an attempt to rationalize a small nuclear arsenal, a lack of defensive capabilities, and a lack of civil defense preparedness. ${ }^{21}$

${ }^{18}$ Pipes, "Fight and Win," p. 34. Whenever the U.S. considered shifting to a counterforce posture, such discussions would "throw Soviet generals into a tizzy of excitement. It [i.e., counterforce targeting] clearly frightens them far more than the threat to Soviet cities posed by countervalue strategic doctrine. Ibid., p. 33.

${ }^{19}$ Pipes claims that the only reason Soviets accepted ABM limitations was because they ran into technical difficulties trying to develop them themselves. ABM limitations provided the Soviets with a means to ensure that the U.S. was not able to build them first. Ibid., p. 33.

${ }^{20}$ This interpretation was not exclusive to the Soviets. Howard argued that Western leaders would find recourse to nuclear war more difficult than their Soviet counterparts. Michael Howard, "The Forgotten Dimensions of Strategy," Foreign Affairs 57 (Summer 1979): 984.

${ }^{21}$ The notion that MAD is a convenient excuse for the West to ignore tough strategic questions. For example, Howard suspects that MAD rationalized the abandonment of civil defense preparations in the U.S. See Howard, "Forgotten Dimensions," p. 985. 
More generally, MAD could be viewed as the product of minds unable to cope with the prospect of nuclear war.

It was also unlikely, according to the Anti-Classicals, that the Soviets could have been persuaded to shift doctrines, for three reasons. First, as previously noted, MAD was counter-intuitive, as it "involved preventing wars rather than winning them, securing sufficiency in decisive weapons rather than superiority, and even ensuring the potential enemy's ability to strike back." ${ }^{22}$ It was thus difficult even for the U.S. to accept and faithfully adhere to. ${ }^{23}$ The Soviets' approach was far more traditional and entrenched, with roots in prenuclear military strategy, Marxism and even Russian culture. ${ }^{24}$

Second, because of its counter-intuitive nature, MAD was uninspiring to other states. As Jan Lodal explains, "No matter how cogent the argument that Soviet counterforce weapons confer no real military advantage, political leaders throughout the world are unlikely to agree. Rather, they will react in more traditional military terms, concluding that the Soviet preponderance of

${ }^{22}$ Pipes, "Fight and Win," p. 24.

${ }^{23}$ Quester attributes U.S. Anti-Classicism to a combination of moral concerns and intellectual inertia, but also to fears of a Soviet first strike. Quester, "Cultural Barriers," pp. 8384. The U.S. acquired counterforce capabilities, contra-MAD. Jan N. Lodal, "Deterrence and Nuclear Strategy," Daedalus 109 (Fall 1980): 156. Howard rejects MAD and claims that, "The interest displayed by Soviet writers in the conduct of such a war, which some writers in the West find so sinister, seems to me no more than common sense." Howard, "Forgotten Dimensions," p. 982.

${ }^{24}$ Pipes, "Fight and Win," pp. 25-26. 
raw military force would eventually prevail. ${ }^{25}$ Therefore, the world perception of the US-Soviet balance may have favored the Soviets; while this perception would not affect the outcome of a nuclear standoff, or a nuclear war, it did impact other realms of superpower competition.

Third, adversaries rarely educate one another, at least in the lessons intended. While it may be possible to convince allies of the errors of their ways, it is more difficult to persuade an adversary to change doctrines. ${ }^{26}$ The Soviets would interpret overt attempts at persuasion as trickery - an attempt to convince it to deviate from a doctrine that promises victory. Such an attempt could - in the context of intense superpower rivalry - be viewed as evidence that the Soviet strategy would be effective.

Therefore, if the Soviets were not about to embrace MAD, the AntiClassicals argued that the U.S. must pursue NUTS, which would provide more impressive evidence to the Soviets of U.S. "commitment and readiness for

${ }^{25}$ Lodal, "Nuclear Strategy," p. 163.

${ }^{26}$ Gray, "Strategic Stability Reconsidered," p. 151. U.S. tutelage helped to ensure that the British arsenal was safe and unprovocative to the Soviets. The French, however, were less willing to accept U.S. assistance. In its early years, French nuclear weapons were highly vulnerable and suited to a surprise first-strike. On nuclear sharing with Britain, see Bruce Berkowitz, "Proliferation, Deterrence, and the Likelihood of War," Journal of Conflict Resolution 29 (March 1985): 133. On the French case, see ibid., pp. 127-128. Wohlstetter explains, "Even at the time that Britain and later France decided to become nuclear powers, there was little evidence that the distinction between a first- and second-strike capability was understood." Wohlstetter, "Nuclear Sharing," p. 193. 
self-denial"27 Anti-Classicals argue that rather than attempting to understand the adversary's outlook, Classical deterrence theorists have falsely assumed that each sides' outlook is identical. ${ }^{28}$ If the Soviets believed that numerical or megatonnage superiority beyond overkill capacity mattered, then the U.S. had to convince them that it could match them in these respects, even if U.S.

leaders believed parity above overkill capacity was superfluous. ${ }^{29}$ It was also considered necessary to match them in other respects, as well.

\section{Anti-Classical Thought and New Nuclear States}

Soviet "obtuseness" is critical, for if the Soviet Union was unwilling or unable to embrace $M A D$, there seems little justification for the expectation that all new nuclear states will do so. ${ }^{30}$

Obviously, because the Soviet Union ceased to exist in 1991, die-hard Classicals could argue that eventually — had the state itself endured - it

\footnotetext{
${ }^{27}$ Howard, "Forgotten Dimensions," p. 977 . On the significance of will, see also Morgan, Deterrence, p. 142.

${ }^{28}$ Richard Ned Lebow, "Deterrence: A Political and Psychological Critique," in Perspectives on Deterrence, ed: Paul C. Stern, Robert Axelrod, Robert Jervis and Roy Radner (New York: Oxford University Press, 1989), p. 41.

${ }^{29}$ Betts argues that the Soviet perception of U.S. superiority may have led them to back down during the 1962 Cuban Missile Crisis. Richard K. Betts, Nuclear Blackmail and Nuclear Balance (Washington, D.C.: The Brookings Institution, 1987), p. 115.

${ }^{30}$ On Soviet "obtuseness," see George H. Quester, "Cultural Barriers to an Acceptance of Deterrence," in The Logic of Nuclear Terror, ed: Roman Kolkowicz (Winchester, MA: Allen \& Unwin, 1987), pp. 98-99.
} 
would have accepted MAD. Perhaps this is true. Nevertheless, the Soviets did manage to resist MAD for forty years, which stands as a testament either to a stunning imperviousness to logic, or to the diversity of strategic thought.

The latter interpretation has recently been provided some empirical support by DeNardo. Serendipitously, he gathered survey data from nuclear amateurs and experts before, during and after the collapse of the Soviet Union. He was surprised when his expectation that strategic preferences would be modified by such a momentous political event was not confirmed. The families of thought seem to be almost wholly independent of external factors, and stubbornly resilient in the face of external influences. ${ }^{31}$

As we have seen, however, strategic doctrines are interdependent. It appears that states that foreswear MAD create pressures on their adversaries to follow suit. (There may also be demonstration effects beyond bilateral deterrence relationships. As Nye explains, "nuclear doctrines and deployments that stress the military usefulness of nuclear weapons may help bolster deterrence, but they also tend to make nuclear weapons look more attractive to others." ${ }^{32}$ ) If two adversarial nuclear states are unable to

${ }^{31}$ Ibid., pp. 292-297

32 Joseph S. Nye, Jr., "NPT: The Logic of Inequality," Foreign Policy 59 (Summer 1985): 128. 
reconcile their doctrines, they may be unable to deter one another from provocative behavior.

\section{Revisionism, Desperation and the Utility of Nuclear Weapons}

"No one has figured out how to use nuclear weapons except for deterrence. Is a small and weak state likely to be the first to do so?" asks Waltz. ${ }^{33}$ Another query might be posed in response: "Who better than a small and weak state?" Might not a small and weak state - hoping to somehow ameliorate its condition - adopt a doctrine which allows for the use of hardwon nuclear weapons? Why should it be expected that the United States, a "satisfied world power with a fundamentally defensive strategic mission," would be more interested than small and weak states in finding uses for its nuclear weapons beyond deterrence $?^{34}$ As Jervis puts it,

... a state which is satisfied with the status quo and is optimistic about its future prospects will seek to preserve the peace and may refrain from striking even in the face of crisis instability. By contrast, a state which is highly dissatisfied and/or which believes that its position is

${ }^{33}$ Kenneth N. Waltz, "More May Be Better," in The Spread of Nuclear Weapons: A Debate, ed: Scott D. Sagan and Kenneth N. Waltz (New York: W.W. Norton \& Company, Inc., 1995), p. 39.

${ }^{34}$ This description of the of U.S. is Gray's. See Gray, "Strategic Stability Reconsidered," p. 140. For more on revisionist states and nuclear deterrence, see Morgan, Deterrence, p. 150. Though a powerful state, the Soviet leaders were dissatisfied with the historical progress toward Communism. The prospect of peaceful co-existence with the capitalist West was anathema. See Gray, "Strategic Stability Reconsidered," p. 142. 
likely to deteriorate badly if current trends continue can rationally strike even when the offense only has a slight advantage. ${ }^{35}$

As noted in Chapter Two, "Committing oneself to stand firm works only if the other can retreat." ${ }^{\prime 36}$ For the U.S. and the Soviet Union, retreat was - if never desirable - at least possible. ${ }^{37}$ A tactical retreat did not necessarily deny either superpower the prospect of prevailing on the next occasion, and certainly did not threaten their status as the world's superpowers.

Other states do not have (or as importantly, perceive themselves to be without) the luxury of such flexibility. Trapped in intolerable circumstances, desperate states may consider nuclear weapons a means of escape. ${ }^{38}$ Rather than using these weapons merely for deterrence, they may attempt to use them for compellance, so that they may secure certain benefits that may

${ }^{35}$ Robert Jervis, "Arms Control, Stability and Causes of War," Political Science Quarterly 108 (Summer 1993): 250. 308.

${ }^{36}$ Robert Jervis, "Deterrence Theory Revisited," World Politics 31 (January 1979):

${ }^{37}$ Jervis claims that statesmen rarely, if ever, preclude all possibilities for retreat. Jervis, "Deterrence Theory Revisited," p. 303. Knowing this, truly desperate states may have an advantage.

${ }^{38}$ Lebow, "Deterrence," pp. 34-35. Lebow uses the example of Japan's attack on Pearl Harbor. As Fetter explains, "Many of the new missile states are not happy with the status quo, and may look upon their newly acquired capabilities for mass destruction as instruments of intimidation and change." Steve Fetter, "Ballistic Missiles and Weapons of Mass Destruction," International Security 16 (Summer 1991): 30. 
alleviate their desperation. ${ }^{39}$ Bull argues that, "There are a variety of circumstances in which an act of desperation might appear the most 'rational' solution." ${ }^{40}$

The U.S. and other satisfied, status quo states may have difficulties deterring desperate nuclear states. It has been argued that deterrence is strengthened by the reasonable expectation that the defender's resolve is greater than that of the attacker. ${ }^{41}$ However, resolve is not purely a function of one's status as a defender or an attacker. Paul Huth and Bruce Russett suggest that resolve is "a function of the interests at stake and of 'inherent' resolve (that is, risk-proneness). ${ }^{.42}$ States facing desperate conditions may thus be presumed to be more resolute than MAD-oriented status quo powers such as the US.

${ }^{39}$ As Weltman explains, "If, in fact, the redistribution of wealth or of opportunity is the goal of the new states en bloc, that goal is not reachable without some mechanism to compel those who are relatively well off now to accept significant relative deprivations." John J. Weltman, "Nuclear Devolution and World Order," World Politics 32 (January 1980): 183.

${ }^{40}$ Hedley Bull, The Control of the Arms Race (New York: Praeger, 1961), p. 50.

${ }^{41}$ Waltz, "More May Be Better,"6.

${ }^{42}$ Paul K. Huth and Bruce Russett, "What Makes Deterrence Work? Cases from 1900 to 1980," World Politics 34 (July 1984): 502. Of course, resolve can be feigned in order to enhance the credibility of one's threat, as discussed in Chapter Two. "Inherent resolve" is a state-level attribute that cannot be gauged through the scrutinization of the international political structure. 
Imagine, for instance, a scene in which a grenade-wielding bank robber enters and bank and hands the teller a note. The note reads something like: "Give me $\$ 5000$, or l'll blow us both up!"43 As Daniel Ellsberg explains,

The teller might well reason: "If I were standing out there, I would never . . . drop the grenade, no matter what happened." But his next thought is bound to be: "I would never be standing out there with a grenade in the first place." The very presence of these people in the bank, pushing homicidal notes through the window in full presence of customers and guards, is very impressive warning to the teller not to rely on inferring their payoffs and behavior patterns from his own. ${ }^{44}$

Like bank robbers, desperate and revisionist states seem to have the upperhand by dint of the apparent desperation and irrationality of their actions. The very fact that an incredible threat is expressed could paradoxically bolster its perceived credibility - especially when the threatened party has no evidence that the bank robber is a liar.

Jervis makes the same point by illustrating an overlooked problem with the Chicken model of deterrence used by the Classicals. He argues that the model can be misleading with respect to conflict between status quo and desperate or revisionist states. The Chicken game assumes that two cars are

${ }^{43}$ The $\$ 5000$, a modest demand, was drawn from Ellsberg's description of a wave of such bank heists in New York City during the 1950s. See Daniel Ellsberg. "The Theory and Practice of Blackmail," in Bargaining: Formal Theories of Negotiation, ed: Oran Young (Chicago: University of lilinois Press, 1975), pp. 343-363.

${ }^{44}$ Ellsberg, "Blackmail," p. 360. 
on a collision course from the start, but Jervis points out that the desperate or revisionist driver in fact initiates the game, and the status quo driver is - to borrow a phrase from Ellsberg - a "reluctant duelist." ${ }^{45}$ The player who first demonstrates a willingness to even play Chicken may enjoy a "first-mover" advantage in terms of credibility.

Revisionist states, which seek deeper changes in the international political and economic order, may also attempt to use nuclear weapons to achieve their ends. As Rajni Kothari explains, "Changes in the global structuring of power and resources do not follow nice principles of equity or participation but require effective disturbance of the status quo through the acquisition of significant power by those outside the prevailing oligarchy. ${ }^{146}$ Nuclear weapons could provide outsider states with the power necessary to effect such changes.

However, revisionist states must bear a heavy the burden of proof. ${ }^{47}$ Jervis points that most states are likely to have endured the status quo for some

${ }^{45}$ Jervis, "Deterrence Theory Revisited," p. 297. See also Daniel Ellsberg, "Theory of the Reluctant Duelist," American Economic Review 46 (December 1956): 909-923.

${ }^{46}$ Rajni Kothari, "Sources of Conflict in the 1980's," Adelphi Papers 134 (Spring 1977), quoted in Weltman, "Nuclear Devolution," p. 184.

${ }^{47}$ Betts, Nuclear Blackmail, p. 132 
time. The revisionist state must demonstrate that the situation has become intolerable. $^{48}$

The situation is more complicated when we look beyond a single instance of attempted compellance by a desperate or revisionist state. It may be rational to concede to a single demand by such a state, but one concession could invite greater and more numerous demands from others. As Jervis explains, in any given conflict between a status quo and a revisionist state, "[w]hat the aggressor can gain is not limited to the specific issue, but includes an increased chance of prevailing in future attempts to alter the status quo. The status-quo power, by contrast, gains only a temporary respite. $^{.49}$

Therefore, the resolution of the status quo power facing compellant threats issued by a desperate or revisionist state may be greater than initially expected. If the status quo power believes that one concession will invite

48 Jervis, "Deterrence Theory Revisited," pp. 298-299.

${ }^{49}$ Ibid., pp. 298-299. As Gilpin explains, "It is possible, despite much current speculation to the contrary, that mutual deterrence may serve ultimately to inhibit the dominant power from defending the status quo rather than preventing the rising power from seeking to change." Robert Gilpin, War and Change in World Politics (New York: Cambridge University Press, 1981), p. 216.

Fears of gradual erosion of hegemony has led the U.S. "to deter all changes in the status quo," for fear of appearing to vacillate. Jervis, "Deterrence Theory Revisited," p. 322. 
others, it may decide to call the bluff of the threat-maker. ${ }^{50}$ (However, the threat-maker may make covert threats, hence allowing the status quo power to save face.)

One may wonder how a truly desperate state could develop or obtain a nuclear weapon. As nuclear weapons proliferate, opportunities for theft also increase. Hence, even poor states may have opportunities to acquire these weapons. Second, states can become desperate after they have developed or obtained these weapons.

\section{The Interaction Between Doctrine and Capabilities}

MAD largely demands that technology serve political ends. The pursuit of technologies such as area defenses, ASW, and precise missiles must be forsaken to maintain the clarity of the mutual hostage relationship between nuclear adversaries.

The Optimists may be guilty of putting the cart before the horse in this case. ${ }^{51}$ This influence of technology on strategic thought is especially vivid in the case of the co-evolution of nuclear doctrine and technology. As DeNardo

50 Jervis observes that revisionist often falsely assume that conciliation by a status quo state indicates that future demands will likewise be met with conciliation. Jervis, "Deterrence Theory Revisited," pp. 304-305.

${ }^{51}$ As Bull explains, capabilities do not merely follow intentions, but shape them, as well. Bull, Arms Race, p. 7. 
explains, the Classical expectation regarding technology has little basis in historical fact.

The trouble was that neither the Soviet Union nor the United States showed much resistance to new weapons technologies, however, dangerous or destabilizing they might be. After the A-bomb came the $\mathrm{H}$-bomb, miniaturized bombs, rapid delivery launchers, precision guidance systems, MIRVs, cruise missiles, electronic warfare, exotic space weapons, stealth and more. About the only systems that didn't get built were those that didn't work or that cost too much . . . ${ }^{52}$

Furthermore, these weapons and technologies were not only built, but they were provided justification by Anti-Classicals and by military strategists. ${ }^{53}$

The evolution of the U.S. Navy's strategic thought provides a good example. When inaccurate delivery systems rendered the U.S. incapable of anything but the pulverization of the Soviet Union with imprecise weapons, the Navy espoused MAD. However, when more accurate and specialized weapons became available, the Navy opted for NUTS. ${ }^{54}$ A sort of "sour grapes" effect seems to have operated in cases such as this. The Navy, as well as the other services, supported whatever doctrine justified the purchase of the hottest new technologies.

52 DeNardo, Amateur Strategist, pp. 1-2. Many would argue that even those systems that did not work and that cost too much were built.

${ }^{53}$ On this point, see Spurgeon M. Keeny, Jr. and Wolfgang K. H. Panofsky, "MAD Versus NUTS," Foreign Affairs 60 (Winter 1981-82): 289; Morgan, Deterrence, p. 213.

${ }^{54}$ Quester, "Cultural Barriers," p. 85. 
Likewise, post facto justifications were offered for the growth of the U.S. nuclear arsenal. As Morgan explains, "After 1945, the destructiveness of the most powerful weapons grew enormously, the total potential destruction at the president's command went up, yet the amount of destructive capability deemed necessary to deter the USSR rose apace. ${ }^{.55}$

Thorstein Veblen is said to have remarked, "Invention is the mother of necessity. ${ }^{n 6}$ The fact that U.S. defense requirements increased with U.S. destructive capabilities seems to confirm Veblen's view. The implications of this problem are somewhat grim. MAD, which assumes that technology will serve doctrine, may be shunned by new nuclear states in favor of doctrines in which there is a place for technologies they are able to buy or develop. ${ }^{57}$

${ }^{55}$ Morgan, Deterrence, p. 213. Though he shares the Classicals' faith that secondstrike capability is readily achievable, Sienkiewicz recognizes that an implication of the irresolvability of the deterrence debate is "the impossibility of finding a conclusive analytical basis for determining "how much is enough." Stanley Sienkiewicz, "Observations on the Impact of Uncertainty in Strategic Analysis," World Politics 32 (October 1979): 96. Wohistetter claims that "French military theorists overestimated the number of Russian missiles required to destroy sheltered missiles, miscalculating their accuracy by factors no lower than 5 and sometimes as high as 25." Wohlstetter, "Nuclear Sharing," pp. 193-194.

${ }^{56}$ Veblen, quoted in Alfred E. Kahn, "The Tyranny of Small Decisions: Market Failures, Imperfections, and the Limits of Econometrics," in Economic Theories of International Politics, ed: Bruce Russett (Chicago: Markham Publishing Co., 1968), p. 529.

${ }^{57}$ Pipes, "Fight and Win," p. 30. 


\section{The Interaction Between Doctrine and Adversary Capabilities}

In the previous subsection it was argued that advances in a state's nuclear capabilities could reshape that doctrine in such a way that the new capabilites will find functional niches. In this subsection a related problem will be examined: when states are made vulnerable by their adversaries' technological advances, they may not be able to restore survivability. Instead, they may adopt contra-MAD, launch-on-warning force postures to alleviate the vulnerability of their weapons, and they may confront "use-it-or-lose-it" pressures during intense crises with other nuclear states.

If military technological development stopped tomorrow, all nuclear states may eventually be able to deploy survivable nuclear forces and to adhere to MAD if they so choose. ${ }^{58}$ Unfortunately, faster, more precise and more difficult to detect weapons will in all likelihood continue to be developed, rendering once survivable weapons vulnerable to crippling first-strikes.

Of course, it is always possible to hide a few bombs, and this possibility may be sufficient to deter weak nuclear states from attacking. ${ }^{59}$ However, the likelihood that such a small deterrent would actually prevent an attack

${ }^{58}$ On the staticity of MAD, see ibid.

${ }^{59}$ Waltz ridicules the notion that the U.S. would be able to defend itself against nuclear attack. He claims to have heard the suggestion theat "the Soviets can always hide warheads in bales of marijuana, knowing that we cannot keep them from crossing our borders." Waltz, "Nuclear Myths," p. 742. 
depends also on the relative benefits of aggression. A risk-tolerant state - as many feared the Soviet Union to be - may be willing to absorb the damage of a few bombs as the price for a nuclear victory, as may some new nuclear states.

Optimists' expectations that new nuclear states will deploy survivable nuclear forces are doubtful for two reasons. First, the U.S. and the Soviet Union not only deployed new weapons systems when the Classicals considered them unnecessary, but many of these systems were also vulnerable to first-strikes. Second, both the U.S. and the Soviets sought weapons, technologies and strategies with which they could threaten the survivability of their opponent's nuclear forces.

Today, the survivability of Russian nuclear forces is highly questionable, demonstrating that a once formidable arsenal can - over time be rendered vulnerable by economic and technological stagnation. ${ }^{60}$ Russian military observers estimate that both their land-based mobile weapons and their submarines are highly vulnerable to U.S. attacks. ${ }^{61}$ 53.

${ }^{60}$ On interaction, see Wohlstetter, "Nuclear Sharing," p. 196; and Bull, Arms Race, p.

${ }^{61}$ Bruce G. Blair, Global Zero Alert for Nuclear Forces (Washington, D.C.: The Brookings Institution, 1995), p. 65. 
A recent historical example provides evidence both that the survivability of nuclear forces is often questionable, and that opponents are willing to deploy weapons that threaten the survivability of their (potential) adversary's nuclear forces. U.S. submarine launched Trident $D-5$ s pose a significant threat to the survivability of Soviet nuclear forces. These highly accurate missiles can eliminate all but a few fortified sites within Russia, and could do so very quickly. From the Norwegian Sea, a Trident D-5 aimed at Moscow would arrive in fifteen minutes. (Russia's launch-on-warning policy requires at least a twenty minute warning. ${ }^{62}$ ) Soon, submarines armed with Trident D-5s will be stationed on the west coast of the United States. Once deployed, the U.S. would be able to strike every possible target within the former Soviet Union in under twenty minutes. ${ }^{63}$

Russia is particularly sensitive to the threat posed by the Trident D-5s because the strength of their own submarine forces is rapidly deteriorating. "Shortages of manpower, spare parts, and maintenance have curtailed sea patrols and mobile land missile operations out of garrison. Almost all submarines have been confined to port, where some are routinely geared for

${ }^{62}$ Ibid., pp. 61-62. The fact that Russia has a launch-on-detection policy, again contrary to the advise of the Classicals, will be taken up later in this chapter.

${ }^{63}$ Ibid., p. 63. 
launch on warning to mitigate their acute vulnerability," explains Blair. ${ }^{64}$ Thus, $^{1}$ at precisely the moment when U.S. is acquiring the capability of mounting a splendid first-strike, the vulnerability of Russian land- and sea-based nuclear forces is increasing.

Based on the US-Soviet (and now the US-Russian) cases, it seems unrealistic to expect that all new nuclear states will abstain from the production of weapons that threaten the survivability of their adversary's arsenal, and that they will be capable of enhancing the survivability of their arsenals in the face of countervailing advances in their adversary's weapons capabilities.

An additional problem related to vulnerability is the overcentralization of a state's $C^{3}$ I. As discussed in Chapter Two, a state concerned with preserving the credibility of its threat to retaliate certainly ought to decentralize the decision-making authority to launch to some degree compatible with the prevention of unauthorized launches. ${ }^{65}$ However, states may nevertheless opt to centralize $\mathrm{C}^{3} \mathrm{I}$ to such a degree that it is possible for an adversary to launch

\section{Ibid., p. 64.}

${ }^{65}$ If a single individual alone holds the authority to order a retaliatory strike, he or she may be killed in the first-strike, or may lack the will to retaliate despite threats ex ante. By decentratizing the authority to launch a retaliatory strike, a state enhances the credibility of its threats to retaliate, because it is unlikely that all of those capable of launching will either be killed or will lack the will follow through on prior threats. 
a decapitating first-stike, thereby eliminating those who wield launch authority in a single, focused blow. The Soviets' penchant for political centralization certainly carried over into the design of its $\mathrm{C}^{3} \mathrm{I}$, and the leaders of new nuclear states may also jealously guard their own launch authority. ${ }^{66}$ Russian forces remain under highly centralized control, increasing the chances that a wellplanned decapitating first-strike might succeed. ${ }^{67}$

\section{MAD in a Nuclearized World}

In this section, I have argued that MAD may not prevail in a nuclear world for a number of reasons. First, MAD is thought to be ineffective against Anti-Classical doctrines. Therefore, Classical states attempting to deter AntiClassical adversaries will either have do abandon MAD, or convince their adversaries to embrace it. Because states may cling more tightly to AntiClassical doctrines than to counter-intuitive Classical doctrines, it may be expected that Classical states will more often shift to NUTS than will AntiClassicals shift to MAD.

${ }^{66}$ Gray and Payne characterize the Soviet posture as one of "gross overcentralization." Colin S. Gray and Keith Payne, "Victory is Possible," Foreign Policy 39 (Summer 1980): 21. On this point, see also John D. Steinbruner, "Nuclear Decapitation," Foreign Policy 45 (Winter 1981-82): 19.

${ }^{67}$ Blair, Global Zero Alert, p. 15. 
Second, new nuclear states may face desperate conditions, or may desire changes in the international political and economic order. Such states are more likely to embrace doctrines which emphasize the utility of nuclear weapons for these extra-deterrence purposes.

Third, the superpowers showed little resistence to new weapons technologies. MAD, however, requires that certain technologies be rejected. Rather than reject weapons that were incongruent with nuclear doctrine, nuclear doctrine was modified in such a way that new weapons technologies were provided functional niches.

Fourth, doctrines are not only influenced by one's own technology, but by one's adversary's, as well. Specifically, if a state's arsenal is rendered vulnerable, it may adopt a launch-on-warning force posture, contrary to MAD.

\section{PAROCHIALISM AND MYOPIA}

Adherence to MAD requires both farsightedness and solidarity on the part of actors within states. Leaders, military services and defense industries must refrain from actions that promise short-term payoffs yet undermine the long-term stability of MAD

Nevertheless, as Waltz's opening quotation above suggests, the U.S. could not sustain its adherence to MAD. Furthermore - as Waltz's quote also suggests - the Optimists are ill-equipped to account for "irrational" deviations, 
because Realists assume that states are a unitary, self-regarding, rational entities. Therefore, its actions are expected to be motivated by a desire to benefit the state as a whole. ${ }^{68}$

Reality is, however, more complicated than Realist theory allows, for once you crack open the "billiard ball" of the state, it is apparent that the costs and benefits of state behavior are distributed unevenly among sub-state level groups. Indeed, some state policies may be embarked upon precisely because they benefit particular sub-state level groups capable of influencing state policy.

Explanations of this counter-doctrinal behavior can only be found by considering the divergence of interests between the state and the sub-state level groups and individuals that support the development of Anti-Classical technologies. Though weapons do not alone cause war, "certain kinds and levels of deployments of armaments may be more likely to give rise to the decision to go to war than others." ${ }^{69}$ Waltz argues that states need only a

${ }^{68}$ See Edward J. Rhodes, Power and MADness: The Logic of Nuclear Coercion (New York: Columbia University Press, 1989), p. 114. Even Waltz admits, "I have not tried, but surely some neorealist is capable of producing a theory of the state. It would reveal, among other things, one that we already know: The state in fact is not a unitary and purposive actor." Kenneth N. Waltz, "Reflections on Theory of International Politics: A Response to My Critics," in Neorealism and Its Critics, ed: Robert Keohane (New York: Columbia University Press, 1986), p. 339

${ }^{69}$ Bull, Arms Race, p. 12. 
small deterrent, yet concedes, "That both nevertheless continue to pile weapon upon unneeded weapon is a puzzle whose solution can only be found within the United States and the Soviet Union." 70

Speaking about deterrence, Waltz suggests that states are more willing to take risks when the consequences of failure are distant and easily endurable. ${ }^{71}$ I would extend the idea of proximity of gain or pain to Waltz's notion of "sensitivity to costs." States and state leaders are surely sensitive to costs, but they are more sensitive to proximate costs than to distant and avoidable or deferrable costs. ${ }^{72}$

The proximity of expected costs and benefits of any given action can be measured along two dimensions. First, the payoffs of action can be distributed across time. ${ }^{73}$ Simply knowing whether an actor is rational or not does not provide one with sufficient knowledge to make accurate predictions

${ }^{70}$ Kenneth N. Waltz, "The Origins of War in Neorealist Theory," in The Origin and Prevention of Major Wars, ed: Robert I. Rotberg and Theodore K. Rabb (Cambridge, UK: Cambridge University Press, 1988), p. 51. Emphasis added.

${ }^{71}$ Waltz, "More May Be Better," p. 7.

72 Sensitivity to costs may vary within wide ranges. Wolf points out that in the late 19 th century Paraguay lost $85 \%$ of its population in a war against stronger adversaries. Francisco Solano Lopez, the ruler of Paraguay, declared war first on Brazil and later on Argentina, which refused to allow his troops cross its territory. The Triple Alliance, consisting of Brazil, Argentina and Uruguay, crushed Paraguay in 1870. Barry Wolf, When the Weak Attack the Strong: Failures of Deterrence (Santa Monica, CA: RAND Corporation, N-3261-A, 1991), pp. 3-7.

${ }^{73}$ Indeed, this seems to be what Waltz is referring to. 
as to whether that actor would seek immediate benefits instead of greater benefits in the future. Nor does knowledge of actor rationality allow one to predict with confidence that the actor would prefer small costs in the present to larger costs in the future. ${ }^{74}$

Second, payoffs can also be distributed across space, or persons. Again, knowing that an actor is rational provides no insights as to how that actor weighs costs and benefits falling on others as a result of its actions. Therefore, to accurately predict the behavior of rational actors, one must have have knowledge of the rate at which he, she or it discounts (or inflates) payoffs across both time and persons. ${ }^{75}$

States often fail to realize their interests because sub-state actors often have interests that are not neatly compatible with those of the organization to which they belong. What may not be so good for the group may be great for some of the group's individual members. What may be harmful to the group as a whole may be disastrous for some of the group's individual members.

\footnotetext{
${ }^{74}$ Simon explains that "the mere assumption of rationality provides little basis for the prediction of behavior. To be of much use, that assumption must be supplemented by considerable empirical knowledge about the decision maker." Jeffrey D. Simon, "Misunderstanding Terrorism," Foreign Policy 67 (Summer 1987): 295.

${ }^{75}$ On rationality and altruism, see Robert $\mathrm{H}$. Lieshout, Between Anarchy and Hierarchy: A Theory of International Politics and Foreign Policy (Aldershot, U.K.: Edward Elgar Publishing, Ltd., 1995), pp. 47-50.
} 
Sub-state actors could, of course, support the development of AntiClassical weaponry because they are true Anti-Classicals. However, certain sub-state actors - including military services and defense industries - may support such developments for a combination of two additional reasons: first, the real gains from such developments will be concentrated upon the group itself, whereas the hypothesized penalties will be distributed among others; second, the expected gains from such developments will be immediate, and the hypothesized penalties distant in the future.

Parochialism may contribute to the deployment of weapons systems and technologies that are incompatible with the avowed doctrine of the state. When we adopt the Realistic conception of the state as a unitary actor, it makes no sense that technologies like Trident D-5s or "Brilliant Pebbles" would be sought or even deployed. From a Classical perspective, these technologies seem contrary to the interests of the state as a whole. However, when we peer within the state at the sub-state actors that influence the policies of the state as a whole, we can offer more meaningful explanations of Anti-Classical behavior than Waltz's "fuzzy" thinking.

Furthermore, the harm from such doctrinal deviations is not proximate in time. Many social scientists have observed the human tendency to discount the future. Generally, people prefer a payoff now over a payoff later, 
even if the more distant payoff is greater. ${ }^{76}$ Strotz characterizes this as an "intertemporal tussle," fought between the decision-maker in the present and the same decision-maker in the future, as if the two were separate actors. ${ }^{77}$ In the 18 th century, Hume described humans as "more frequently ... seduced from his great and important, but distant, interests, by the allurement of present, though often very frivolous temptations. ${ }^{.78}$

There are numerous examples of organizations facing the intertemporal tussle. $^{79}$ Indeed, organizations may actually be more inclined to discount the future. ${ }^{80}$ This tendency certainly holds true with respect to defense-related decision-making. As Morgan explains, state leaders "are badly equipped to

${ }^{76}$ R.H. Strotz, "Myopia and Inconsistency in Dynamic Utility Maximization," Review of Economic Studies 23 (1955-1956): 177-178.

${ }^{77}$ Ibid., pp. 165-180.

${ }^{78}$ David Hume, Essays, Moral, Political and Literary (Indianapolis: Liberty Classics, 1985), p. 38, quoted in Robert H. Lieshout, Between Anarchy and Hierarchy: A Theory of International Politics and Foreign Policy (Aldershot, U.K.: Edward Elgar Publishing Ltd., 1995), p. 34. Hume's prognosis is grim. "This great weakness is incurable in human nature," he lamented. Ibid.

${ }^{79} \mathrm{~A}$ balanced budget amendment would provide a mechanism by which the U.S. in the present could resist the temptation to overspend, therefore benefiting the U.S. in the future. (This is not an endorsement of such an amendment; it is merely a description in terms of Strotz' intertemporal tussle.)

${ }^{80}$ For a model of myopic organizational behavior, see Michael D. Cohen, James $G$. March, and Johan P. Olsen, "A Garbage Can Model of Organizational Choice," in Decisions and Organizations, ed: James G. March (Oxford: Basil Blackwell, 1988), pp. 294-334. 
resist the long-run pressures to deploy, generated by research and development programs and the organizations they serve. ${ }^{n 11}$

Stanley Sienkiewicz warns that, "We must ... take care that our own strategic weapons programs not prove to be counterproductive to our objectives in the longer run.. ${ }^{82}$ He explains that "nonrational factors influence (and some argue, dominate), the development and deployment of the American forces." One such nonrational factor is the presence within the U.S. of a "highly competent, highly competitive scientific-engineering-marketing establishment dedicated to the task of developing more effective military technologies." ${ }^{13}$

This would explain much of the "fuzzy" thinking displayed by the United States and the Soviet Union with regard to their nuclear weapons policies. In the long term, the development and deployment of an effective area defense system may be destabilizing. In the short term, however, support for such a program by a leader may strengthen him or her politically, and the awarding of contracts for research and development could provide a conduit for political patronage.

\footnotetext{
${ }^{81}$ Morgan, Deterrence, p. 209.

${ }^{82}$ Sienkiewicz, "Uncertainty," p. 108.

83 Ibid., p. 101.
} 


\section{A Note on Myopia and Anticipation}

Another problem myopic states must confront are failures to anticipate their adversaries' actions. Understandably, states usually concerning themselves only with deterring those challenges that seem possible. ${ }^{84}$ However, as Jervis explains, "Case studies often reveal failures of imagination on the part of would-be deterrers: they cannot think of all the possible ways open to the other to change the status quo - even ways that in retrospect seem obvious. ${ }^{185}$ For example, when the Soviets placed nuclear missiles in Cuba in 1962, the U.S. found itself unprepared for possibility of an attack from the south, and has to jury-rig a detection system. ${ }^{86}$

New nuclear states will not be less capable of anticipating methods their adversaries may use to alter the status quo. However, anticipation is likely to become more difficult as the number of new nuclear states increases. States may find themselves confronting two or more potential adversaries,

84 Jervis, "Deterrence Theory Revisited," p. 307.

${ }^{85}$ Ibid., p. 307.

${ }^{86}$ This hastily arranged system was also prone to mishaps. See Scott D. Sagan, The Limits of Safety: Organizations, Accidents and Nuclear Weapons (Princeton: Princeton University Press, 1993), p. 122. 
and will have to anticipate and prepare for contingencies involving one adversary without threatening others.

\section{ASYMMETRICAL PROLIFERATION \\ AND PREVENTATIVE WAR}

As Wohlstetter explains, "the view that widespread diffusion will be stabilizing assumes that the prototype relation among the many powers will be mutual deterrence. ${ }^{87}$ However, proliferation is an uneven process, and it is likely that nuclear imbalances may result, as was the case when the U.S. developed the first nuclear weapons and used them against Japan. ${ }^{88}$ Unilateral deterrence is stable only if the state possessing nuclear weapons is a status quo state, as in the case of US-Soviet deterrence in the late 1940s and early $50 \mathrm{~s}^{89}$ Otherwise, unstable military balances often precipitate calls for preventative war. $^{90}$

The Optimists generally discount the likelihood of preventative strikes, because their futility seems obvious. Waltz asks, "would one country strike so hard as to destroy another country's potential for future nuclear development?

${ }^{87}$ Wohlstetter, "Nuclear Sharing," p. 203.

${ }^{88}$ See Intriligator and Brito, "Nuclear Proliferation," p. 248. See also Bull, Arms Race, p. 148.

\footnotetext{
${ }^{89}$ Morgan, Deterrence, p. 89

${ }^{90}$ Bull, Arms Race, pp. 38, 50-51.
} 
If it did not, the country struck could resume its nuclear career." ${ }^{91}$ Indeed, preventative strikes may in fact convince states seeking nuclear arms of their importance in a hostile world. ${ }^{92}$

Nevertheless, this is precisely what happened in 1981, when Israeli bombers destroyed Saddam Hussein's embryonic nuclear program at Osiraq. Israel struck the blow while surely aware that the destruction of one nuclear facility would not forever prevent the determined state from eventually developing nuclear weapons.

In the U.S. case, the idea of preventative war found ample advocacy among prominent intellectuals, as well as civil and military leaders in the period just following World War II. ${ }^{93}$ Richard Betts observes a "facile inclination to introduce vague nuclear threats" by the U.S. during the first two decades of the Cold War. ${ }^{94}$ Disarmament ultimata were discussed by New York Times science correspondent William Laurence. ${ }^{95}$ British philosopher and mathematician Bertrand Russell shifted from supporting such ultimata in

${ }^{91}$ Waltz, "More May Be Better," p. 18.

92 Ibid.

${ }^{93}$ Marc Trachtenberg, "A 'Wasting Asset': American Strategy and the Shifting Nuclear Balance, 1949-1954," International Security 13 (Winter 1988-89): 7.

${ }^{94}$ Betts, Nuclear Blackmail, p. 213. The Soviet were more willing to back off than the US. Ibid., p. 214.

95 Trachtenberg, "A 'Wasting Asset'," p. 7. 
1946 to advocating outright preventative war two years later. ${ }^{96}$ Winston Churchill and physicist Leo Szilard were also advocates of preventative war during this period. ${ }^{97}$

The possibility that the West's "window of opportunity" would be lost was much discussed among U.S. civil and military leaders. ${ }^{98}$ Secretary of the Navy Francis Matthews, in a 1950 speech, urged the U.S. to be the world's first "aggressors for peace." ${ }^{99}$ Even Eisenhower contemplated preventative war. ${ }^{100}$ According to Marc Tractenberg, "even as late as 1959, Eisenhower was still wondering whether America 'should start fighting now' instead of 'waiting to go quietly down the drain."'101

One of the most colorful expressions of preventative sentiment was made by General Orvil Anderson - commanding officer at the Air War College in the early 1950s and a frequent advocate of preventative warfare. "Give me

${ }^{96}$ Ibid., p. 8. Bertrand Russell's two positions can be seen in the Bulletin of the Atomic Scientists 2 (October 1946): 19-21 and in the New York Times, November 21, 1948, p. 4, respectively.

${ }^{97}$ Churchill was for "bringing matters to a head," before the Soviets developed their own weapons. Trachtenberg, "A 'Wasting Asset'," pp. 8-9.

98 Ibid., p. 6.

99 It has been claimed that his Matthews' speech was a "trial balloon," and actually represented the thought to Secretary of Defense Louis Johnson. Ibid., p. 20.

100 Ibid., p. 39.

${ }^{101}$ Ibid., p. 44. 
the order to do it, and I can break up Russia's five A-bomb nests in a week ...." he boasted. "And when I went up to Christ - I think I could explain to Him that I had saved civilization." 102

There are reasons to be skeptical of such "big talk." We can never know whether Russell or even General Anderson would have actually given the order to launch a first-strike against a Soviet Union with few or no nuclear weapons. Sagan, Kull and other Pessimists who rely heavily on statements such as those mentioned above can never be certain that the individuals who advocated preventative war when occupying role or situation $X$ would do the same in role or situation $Y{ }^{103}$ Specifically, would military leaders continue to advocate preventative war if they became political leaders? Though he entertained the idea, Eisenhower — himself former military leader — rejected preventative war when he was president. This is a flaw in much of the

${ }^{102}$ Anderson quoted in ibid., p. 10.

${ }^{103}$ For example, Wolf makes much of Qadhdhafi's claim that had Libya possessed ICBMs during the 1986 U.S. attack on Tripoli, he would have retaliated against New York. Barry Wolf, When the Weak Attack the Strong: Failures of Deterrence (Santa Monica, CA: RAND Corporation, N-3261-A, 1991), p. 2. If Qadhdhafi was in possession of ICBMs capable of striking New York City in 1986, the U.S. would probably have been more hesitant to raid Tripoli to begin with.

Though he does not inflate its significance, Betts mentions that Thomas Schelling proposed during a 1961 crisis simulation that the U.S. fire a nuclear warning shot over a sparsely populated region of the Soviet Union. Betts, Nuclear Blackmail, p. 100. Perhaps Schelling made the suggestion because he felt that it was his job to do so, or perhaps he gambled more in simulations than in real crises. There is little one can infer from the mere advocacy of such actions.

On role constraints, see Morgan, Deterrence, p. 71; and Erik Yesson, "Strategic Makebelieve and Strategic Reality," International Security 14 (Winter 1989-90): 188-189. 
Pessimist literature: they too quickly assume that deeds follow directly from words, just as Optimists assume that in a nuclear world state actions follow their rational interests.

Nevertheless, this advocacy of preventative war in the U.S. and Britain stemmed from real apprehension of the possibility of Soviet acquisition of nuclear weapons. New nuclear states may have more cause for alarm than the U.S. did if the sources of conflict with their nuclear weapons-seeking rivals are not only ideological, but ethnic or religious.

\section{CASCADING ACCIDENTS AND CRISES}

As long as nuclear weapons exist, the danger of accidents related to them cannot be entirely eliminated. No one, however, expects that an accident alone could precipitate even a limited nuclear war. Neither the U.S. nor former Soviet (nor even Russian) nuclear forces are so highly automated that weapons could be launched without a deliberate action taken by a small group.

Rather, the danger is that a serious accident - such as a false launch detection or an accidental detonation - could occur during an intense international crisis, causing one side or the other to "stumble over the 
brink." 104 Unfortunately, it is precisely during crises, when states may be preparing themselves for the possibility of war, when one might most expect an accident to occur. States must ensure positive control during crises, so that launch crews could respond quickly if ordered to do so. However, there is a tension between positive control and negative control: the ability of state leaders to prevent unauthorized use. ${ }^{105}$

It is not difficult to construct plausible scenarios in which some conspiracy of factors - malfunctioning detection systems, distorted satellite imagery, communication breakdowns, accidental detonations, stray aircraft and perceived vulnerabilty - could lead to a pre-emptive attack during an intense crisis. The chance of such an unlikely conjunction increases as nuclear weapons proliferate.

\section{A Brief History of Nuclear Weapons Accidents and Near Accidents}

Waltz dismisses the danger of nuclear war sparked by accidents. "All nuclear countries live through a time when their forces are crudely designed. All countries have so far been able to control them," he argues. ${ }^{106}$ Indeed,

${ }^{104}$ On accidents during crises, see Sagan, Limits of Safety, pp. 236-237. See also Bull, Arms Race, pp. 50-51.

105 Steinbruner, "Nuclear Decapitation," pp. 23-24.

${ }^{106}$ Waltz, "More May Be Better," p. 20. 
new nuclear states should not be expected to be any more careless with their nuclear weapons than have the U.S. and the Soviet Union. ${ }^{107}$ However, as we will see below, this provides little basis for Optimism.

Information regarding nuclear weapons accidents or near accidents in the former Soviet Union and other nuclear states is - as one would expect scarce. ${ }^{108}$ It was reported that during a test launch in the autumn of 1986 a Soviet SLBM strayed 1,500 miles off course and landed within China. ${ }^{109}$ Nevertheless, the Soviets are thought to have minimized the likelihood of unauthorized launches, due largely to the centralization of launch authority. (The Soviets in effect minimized the likelihood of accidents by increasing their own vulnerability to a decapitating first-strike.)

Contrary to Optimistic expectations, launch-on-warning remains a central feature of Russian nuclear strategy. ${ }^{110}$ Soviet computer simulations led Moscow to be deeply concerned about the prospect of "decapitation and

${ }^{107}$ Aaron Wildavsky, a prominent risk theorist, has argued that "richer is safer." It may be expected that new nuclear states will be less wealthy than the U.S., Britain, France or the former Soviet Union. See Sagan, Limits of Safety, p. 51

${ }^{108}$ For a discussion of the scanty evidence of British, French and Chinese nuclear accidents, see Milton Leitenberg, "Nuclear Weapons and 50 Years of International Political History: Risks, Dangers, Threats, Crises, Proposals and Considerations of Use," (Unpublished manuscript, August 7, 1995), pp. 12-14.

${ }^{109}$ Ibid., p. 12. See also "Missile Mishaps," Arms Control Today 16 (October 1986): $21-22$.

${ }^{110}$ Blair, Global Zero Alert, p. 15. 
total paralysis of the Soviet strategic forces," and this concern has not attenuated since the collapse of the Soviet Union. ${ }^{111}$ Only recently has Russia attempted to shift to a more Classical launch-on-attack posture, which the Russians refer to as the "dead hand."112

In recent years, the Russians have reduced centralization to compensate for their perceived vulnerability to U.S. attack. As Blair explains, "Deployment of Russian forces in vulnerable silos is being abandoned, even though their safeguards are the strongest, in favor of mobile ICBM and submarine deployments with weaker safeguards."113

Although civil launch authority could be circumvented by top military officials, the possibility that renegade Russian missile crews could launch an unauthorized attack is thought to be very low. ${ }^{114}$ From Moscow, authorities can prevent launches by transferring control over missiles to others, or by overriding missile crews themselves. Russian silos are also equipped with sensors to detect unauthorized access and that disable the missiles they house. If all else fails, crews are authorized to disable missiles during lift-off

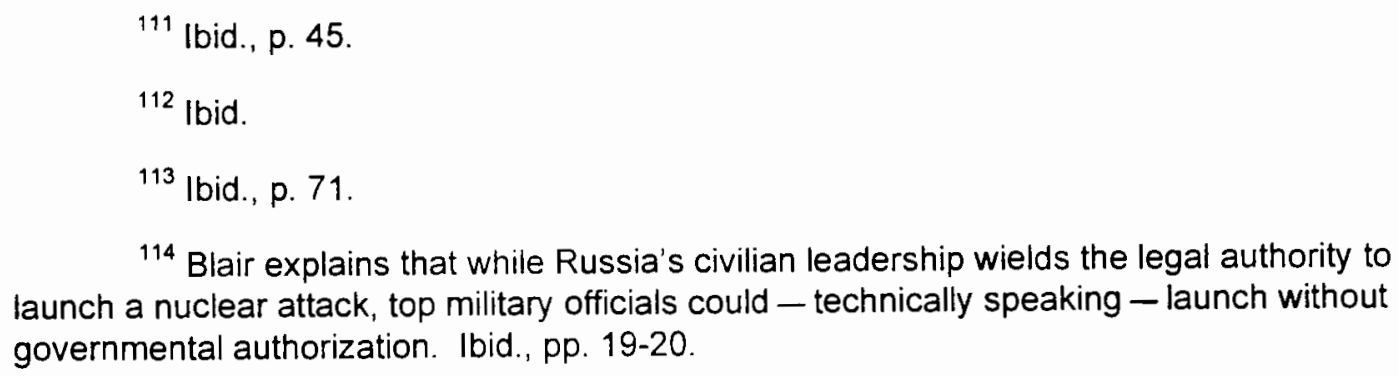

${ }^{114}$ Blair explains that while Russia's civilian leadership wields the legal authority to launch a nuclear attack, top military officials could - technically speaking - launch without governmental authorization. Ibid., pp. 19-20. 
with machine guns. ${ }^{115}$ Russian missile submarines are under less control; their nuclear bombs and cruise missiles are under the least control. ${ }^{116}$

There is little evidence of false launch detections by the Soviets or the Russians. It is known, however, that in 1995 the launch of a scientific rocket by Norway prompted an emergency teleconference among Russian civil and military leaders. ${ }^{117}$ The rocket was apparently mistaken for an inbound missile.

Sagan's investigations of the history of U.S. nuclear operations have revealed many more examples of accidents and near accidents. A partial list of incidents that could have conceivably resulted in false attack detections or accidental detonations is listed below.

- August 23, 1962. A B-52 strayed within a few hundred miles of the Soviet Union as a result of navigational error. It was ordered to alter its course by Alaskan ground control. ${ }^{118}$ Sagan claims that the bomber was almost certainly within range of Soviet interceptors based on the Chukotski peninsula. ${ }^{119}$ (Alarmingly, this event was

${ }^{115}$ Ibid., p. 16.

${ }^{116}$ On missile submarines, see ibid. Though safeguards prevent Russian bomber crews from using the weapons without authorization or against unauthorized targets, the devices - if stolen - could be dropped from other aircraft and against any targets. Ibid., p. 17.

${ }^{117}$ Ibid., p. 47.

${ }^{118}$ Sagan, Limits of Safety, pp. 74-76.

${ }^{119}$ Ibid., p. 74. 
not reported to civil authorities. ${ }^{120}$ )

- January 17, 1966. As a result of a mid-air collision during the refueling of a B-52 over Palomares, Spain, four hydrogen bombs fell to earth. The conventional explosives in two of the bombs detonated, and one bomb was later recovered intact 12 miles off the Spanish coast. ${ }^{121}$

- January 21, 1968. A B-52 carrying four nuclear weapons crashed seven miles from Thule Air Base, Greenland. The conventional explosives detonated, scattering radioactive debris across the ice. $^{122}$

- November 9, 1979. The playing of a practice tape led to the false detection of an SLBM decapitation strike against the US. ${ }^{123}$ The President's special "doomsday plane" (the National Emergency Airborne Command Post, or "Kneecap") was scrambled, though President Carter was not aboard. ${ }^{124}$

- June 3, 1980. SAC detected a massive SLBM/ICBM attack against the US. The false detection - which was not verified by other monitors - was the result of the failure of a 64 cent computer

${ }^{120}$ Ibid., p. 76.

121 Ibid., p. 178. See also "U.S. Nuclear Weapons Accidents: Danger in Our Midst," The Defense Monitor 10 (May 1981): 10. Leitenberg reports that during the early years of the U.S. nuclear program, bombs could detonate inadvertently as a result of impact. The U.S. Atomic Energy Commission held a series of tests confirming this possibility from 1955 through 1958. See Leitenberg, "Nuclear Weapons," p. 14.

122 "U.S. Nuclear Weapons Accidents: Danger in Our Midst," The Defense Monitor 10 (May 1981): 10-11. Sagan has developed a plausible counterfactual scenario around this incident. B-52s were equipped with "dead man's" switches, so that if the crew were killed during a mission, and if the bomber descended below a certain altitude, the bombs would be armed and dropped. Sagan speculates that the bombs could have detonated, setting of blast detectors near Thule Air Base. At the time of the incident, communications to Thule had been severed. There would have been no way for military leaders in the U.S. to determine whether Thule had been destroyed. Sagan, Limits of Safety, pp. 187-188.

${ }^{123}$ Sagan, Limits of Safety, pp. 228-230.

${ }^{124}$ The plane, however, was launched after NORAD declared the warning false, revealing a problem with communications. Ibid., pp. 243-244. 
chip. $^{125}$

While these examples simply attest to the fact that accidents can

happen, more alarming are the incidents listed below which occured during the most tense superpower crisis of the Cold War: the 1962 Cuban Missile Crisis.

- October 25, 1962. A small bear was mistaken for a Soviet saboteur at Duluth Sector Direction Center. A security guard shot at the intruder, and sounded the Center alarm, which was linked to other nearby bases. At Volk Field in Wisconsin, the alert Klaxon rather than the sabotage alarm sounded, and pilots rushed to their nuclear-loaded F106A interceptors. An officer had to drive a car onto the runway and flash his headlights to prevent their take-off. ${ }^{126}$

- October 26, 1962. At 4:00 AM, a test launch was conducted at Vandenburg Air Force base. ${ }^{127}$ It had been scheduled before the Cuban Missile Crisis had begun. Sagan explains that Soviet launch detection was primitive at the time, so Soviet intelligence agencies maintained networks of covert observers in the vicinity of many U.S. military bases, and it was their duty to report hostile activity. ${ }^{128}$ If such observers were stationed near Vandenburg, the Soviets may have known of the launch.

- October 27, 1962. A U-2 strayed off course over the Arctic, again potentially threatening the Soviets for the second time that year. ${ }^{129}$

\footnotetext{
${ }^{125}$ Ibid., pp. 230-233.

${ }^{126}$ Ibid., pp. 99-100.

${ }^{127}$ Ibid., p. 79.

${ }^{128}$ Ibid., p. 80.

129 Ibid., pp. 135-138.
} 
Betts explains that President Kennedy was concerned, because "Moscow might have been expected to read this as a possible final reconnaissance for a U.S. nuclear strike." 130

- October 28, 1962. Radar operators warned Strategic Air Command in Omaha of an attack on Florida. The detection of the inbound missile, turned out to have resulted from the running of radar test software. ${ }^{131}$ (SAC was obliged to scramble bombers in the event of such a detection, yet did not. ${ }^{132}$ )

Sagan also recounts a bizarre incident that may have been an attempt to spark a nuclear crisis between the U.S. and the Soviet Union in late 1962. Soviet Colonel Oleg Penkovsky had been a CIA informant, and he promised his American contacts that he would warn Washington of an impending nuclear attack via the transmission of a unique phone signal. Shortly after the resolution of the Cuban Missile Crisis, Penkovsky's clandestine activities were detected by the KGB. He was tried for treason and sentenced to death.

Remarkably, Washington received the Penkovsky signal after his capture. Sagan speculates: "[K]nowing that he was going to be placed on trial

${ }^{130}$ Betts, Nuclear Blackmail, pp. 121-122. Betts reports that in a letter to Kennedy, Khrushchev later mentioned the stray $U-2$, and the possibility that the plane could be mistaken for a bomber.

While this incident was considered potentially dangerous due to the timing of its occurance, overflights of the Soviet Union by U-2s and SR-71s were common throughout the Cold War, as were incursions into U.S. airspace. See Leitenberg, Nuclear Weapons, pp. 2021.

\footnotetext{
${ }^{131}$ Sagan, Limits of Safety, pp. 130-131.

132 Ibid., p. 154.
} 
and executed, [Penkovsky] could have decided to let the KGB unknowingly initiate a false warning message that an attack was imminent, in the hope that an American military response would be forthcoming. That would be his final revenge on the Soviet system."133

\section{Implications of "Close Calls" for New Nuclear States}

Sagan notes the "Catch-22" problem of inferring the likelihood of accidents from near accidents, or bizarre incidents such as the Penkovsky affair. These incidents could just as easily be cited as evidence of organizational success as they could be interpreted to be dire warnings of imminent organizational failure. ${ }^{134}$

However, Sagan — following the pioneer of "normal accidents" theory Charles Perrow - argues that the validity of the more sanguine interpretation of near accidents rests on the belief that organizations are able to learn from failures, and even from imagined, potential failures. ${ }^{135}$ Unfortunately, human

${ }^{133}$ Ibid., p. 146-148, quote from 148. Sagan admits that Penkovsky's signal alone, after the Cuban Missile Crisis had ended, would be very unlikley to prompt a U.S. launch. lbid., p. 148-149.

134 Ibid., p. 51-52.

135 "Normal accidents" theory holds that organizations that are characterized by interactive complexity and interactive linearity are more prone to accidents than are organizations that do not have these qualities. For descriptions of these characteristics, see Charles Perrow, Normal Accidents: Living With High-Risk Technologies (New York: Basic Books, 1984), p. 78. Also see Sagan, Limits of Safety, p. 32. 
pride poses a formidable obstacle to organizational learning. Organizations are loath to admit mistakes, and when they must make such admissions, powerful members typically attribute blame on members lower in the organizational hierarchy. ${ }^{136}$

Organizations are often reluctant to even consider the possibility of errors. As Sagan explains, "in the politicized environment of a conflicted organization, some highly unpalatable accident scenarios, especially those that clearly place blame on certain individuals or subunits, will not be addressed because to do so would require that those responsible implicitly acknowledge that such events are possible."137

The custodians of the nuclear weaponry of new nuclear states cannot be expected to be any more willing to admit errors, or even to take measures to prevent embarassing hypothetical errors. One problem that nuclear states old and new will face in a nuclearized world is increased sensitivity to false attack detections and accidental detonations. The greater the number of nuclear states, the more proximate each nuclear state is to another. ${ }^{138}$ The

${ }^{136}$ The common attribution of blame for accidents on "operator error" is probably an organizational defense mechanism. All too frequently, the operators are no longer available for comment after the accidents for which they are blamed have occured. On the biased interpretation of accidents, see Sagan, The Limits of Safety, pp. 41-42.

${ }^{137}$ lbid., p. 41.

${ }^{138}$ See Waltz, "More May Be Better," p. 11; Fetter, "Ballistic Missiles," p. 29. 
obvious danger is that states may have insufficient warning time to mount a response, and launch-on-warning may be adopted as the prospect of splendid first-strikes become possible. ${ }^{139}$

The new nuclear states cannot be expected to be better able than other states to avoid crises, either. For example, India and Pakistan approached the brink of war in 1990 over Kashmir. ${ }^{140}$ The deputy director of the CIA at the time described the event as "the most dangerous nuclear situation we have ever faced since l've been in the U.S. government."141

After a violent police crackdown on pro-independence demonstrators in Kashmir in January 1990, the Pakistanis began training and equipping Kashmiri Muslims. Muslim-led demostrations continued until April, and hundreds more protestors were killed. India deployed 200,000 troops to Kashmir, ostensibly to assist in maintaining order within Kashmir if necessary. ${ }^{142}$ Indian armored forces also were positioned 50 miles from the

${ }^{139}$ As we have seen, this has been the Russian response to their perceived vulnerability to a sudden U.S. attack. 56-69

${ }^{140}$ Seymour M. Hersh, "On the Nuclear Edge," The New Yorker, March 29, 1993, pp.

${ }^{141}$ Former Deputy Director of the Central Intelligence Agency Richard J. Kerr, quoted in ibid., p. 56.

${ }^{142}$ See Leitenberg, Nuclear Weapons, p. 98. 
Pakistani border, with the capability of invading Pakistan and dividing the country down the middle. ${ }^{143}$

In response, Pakistan leveled explicit nuclear deterrent threats against India. In the spring of 1990 , the U.S. intercepted a Pakistani military communique. "Precisely what was obtained could not be learned," reports Seymour Hersh, "but one American summarized the information as being, in essence, a warning to India that if 'you move up here' - that is, begin a ground invasion into Pakistan — 'we're going to take out Delhi."' 144 The message also authorized the assembly and preparation of Pakistan's nuclear weapons, although subsequent reports indicate that Pakistan's weapons were not loaded on their F-16s. ${ }^{145}$

Due in some measure to U.S. diplomatic intervention, the crisis was successfully defused. ${ }^{146}$ Nevertheless, this example illustrates that even smaller nuclear powers cannot avoid crises any better than the superpowers did. Indeed, the 1990 Kashmir Crisis seems to have been more dangerous

${ }^{143}$ Hersh, "Nuclear Edge," p. 64. See also See Leitenberg, Nuclear Weapons, p. 98.

${ }^{144}$ Hersh, "Nuclear Edge," p. 64.

${ }^{145}$ See Leitenberg, Nuclear Weapons, p. 98.

${ }^{146}$ President Bush did not cite this diplomatic success as evidence of his administration's foreign policy prowess, however. The nuclear standoff was embarassing to the US, because a blind eye was turned to Pakistan's nuclear program during the 1980s in exchage for their anti-Soviet stance during the occupation of Afghanistan. See Hersh, "Nuclear Edge," p. 57. 
even than the 1962 Cuban Missile Crisis, which is widely regarded as the point at which the U.S. and the Soviet Union were closest to war.

\section{CATALYTIC WAR}

The fifth problem, which seems unique to a world of many nuclear powers, is catalytic warfare. ${ }^{147}$ Typically Optimistic, Waltz believes the possibility of catalytic war may actually moderate the behavior of new nuclear states. "A nuclear Libya ... would have to show caution, even in rhetoric, lest it suffer retaliation in response to someone else's anonymous attack on a third state," he assures. ${ }^{148}$ (One could respond by asking, "Who would be willing to retaliate against a Libya with second-strike capabilities and a demonstrated willingness to cause nuclear violence, on the behalf of the victims of alleged Libyan malfeasance?")

Even if the "likely suspects" can be expected to demonstrate caution, there are reasons for concern nonetheless. First, preventing a state from provoking war between two or more other states would be difficult, because a state even considering such a venture would certainly not make its intentions

147 See Bull, Arms Race, pp. 50-51; Leonard Beaton and John Maddox, The Spread of Nuclear Weapons (New York: Frederick A. Praeger, Inc., 1962), p. 204; Wohistetter, "Nuclear Sharing," p. 204.

${ }^{148}$ Waltz, "More May Be Better," p. 12. 
known. ${ }^{149}$ Second, the greater the number of nuclear states, the greater the doubts regarding culpability. ${ }^{150}$ Third, if stealth and cruise missile technology were also to proliferate - and there is no reason to expect that they will not the spread of this technology would "raise hazards for all nuclear countries. The criterion of anonymity for any one state is the ascription of 'authorship' to others." 151

\section{SUMMARY}

In this chapter five separate dangers endemic to a nuclearizing world have been examined. As a result of creeping Anti-Classical thought, many new nuclear states may adopt the view that nuclear weapons are useful for purposes other than deterrence - contrary to the Optimists expectations. Parochialism and myopia may cause actors within these new nuclear states particularly the military and the defense industries - to rationalize weapons developments that run contrary to the avowed strategic doctrine of the state as a whole. Asymmetrical proliferation may generate pressures to engage in

${ }^{149}$ On the difficulty of identifying the perpetrators of an act intended to cause a catalytic war, see Jeffrey D. Simon, "Misunderstanding Terrorism," Foreign Policy 67 (Summer 1987): 112-113; and Fetter, "Ballistic Missiles," p. 30.

${ }^{150}$ Rosecrance, "Nuclear Diffusion," p. 311.

${ }^{159}$ Ibid., p. 305. 
preventative war. Serious nuclear weapons accidents could cascade into outright nuclear conflict - especially as the increasing proximity of nuclear states to one another creates incentives to adopt launch-on-warning force postures. Finally, as the number of nuclear states increases, so too does the likelihood that a third state could successfully and anonymously instigate war between its rivals.

In the next chapter, possible solutions to these problems, and to the underlying problem of nuclear proliferation, will be briefly considered. 


\title{
CHAPTER FOUR:
}

\section{REDUCING THE DANGERS}

\begin{abstract}
Absolute security from war and defeat has never been enjoyed by sovereign states living in a state of nature, and is foreign to all experience of international life. A great deal of public thinking about international relations is, however, absorbed in the pursuit of this fantasy. The solutions and recommendations produced by this kind of thinking are remote from the range of alternatives or spectrum of possible actions from which governments are able to choose. These solutions do not concern the problems with which the world is actually confronted, but concern the arbitrary dismantling or reconstruction of the world, in such a way that these problems would not arise: a reconstruction to be achieved by acts of will, constitutions for world governments, declarations, the abolition of war, gestures, research, therapies and cures. They represent, in my view, a corruption of thinking about international relations, and a distraction from its proper concerns. The fact is that we are where we are, and it is from here that we have to begin. ${ }^{1}$
\end{abstract}

Hedley Bull

What can be done to reduce or slow nuclear proliferation, or to ameliorate the five proliferation-related dangers examined in Chapter Three? In this chapter, a variety of counter-proliferation measures will be briefly surveyed. The Optimists' accusation that the Pessimists are motivated by

${ }^{1}$ Hedley Bull, The Control of the Arms Race (New York: Praeger, 1961), p. 27. 
ethnocentrism will also be considered, and some remarks will also be made about the more general problems associated with continuous technological innovation and the future of deterrence theory.

\section{CAN PROLIFERATION BE REVERSED, STOPPED, OR SLOWED?}

When possible measures by which the proliferation of nuclear weapons can be countered are imagined, they can fall into a number of categories. These measures can be either hierarchical (i.e., imposed by a powerful supreme authority) or anarchical (i.e., arising spontaneously or intentionally from the interaction between sovereign states). Solutions may also aim at reducing the supply of nuclear weapons, or at reducing the demand for them. In the subsections below, these categories of counter-proliferation solutions will be examined.

\section{The Problem With Hierarchical Measures}

Some analysts recommend hierarchical measures to the problem of proliferation, achieved through the formation of a supra-state organization possessed of the ability to prevent states from or punish them for having nuclear weapons. Such an entity would presumably have an arsenal of 
nuclear weapons for itself, and would be capable not only of halting proliferation, but of rolling it back.

Though such an arrangement is not entirely beyond the bounds of possibility, it does so test these boundaries that - from a practical perspective - discussions of it amount to a waste of time and ink. As Bull and the Realists correctly remind us, solutions must begin with the state system. States will not soon relinquish their sovereignty to a global nuclear police entity.

\section{Anarchical Supply-Oriented Measures}

Anarchical supply-oriented counter-proliferation measures to the problem of proliferation range from unilateral attempts by a state to prevent others from acquiring nuclear weapons to bilateral or multilateral agreements between states to reduce their arsenals or abandon nuclear weapons altogether. Generally, these measures can be pursued via conflict, cooperation or some mix of both. They do not, however, require a transferal of sovereignty to a supra-state entity. ${ }^{2}$

${ }^{2}$ According to Waltz, a sovereign state "decides for itself how it will cope with its internal and external problems, including whether or not to seek assistance from others and in doing so to limit its freedom by making commitments to them." Kenneth N. Waltz, "Political Structures," in Neorealism and Its Critics, ed: Robert Keohane (New York: Columbia University Press, 1986), p. 90. 
There have been proposals for an international law banning nuclear weapons. ${ }^{3}$ At this point, this is an interesting but pointless exercise of the imagination. As Weltman puts it, "to assume that all the actors in the system can be made to come to a universal negative decision beggars the imagination - especially when they have before them the examples of a number of states which have quite obviously come to the opposite conclusion about the requirements of their own self-interest." ${ }^{4}$

Of course, supply can be reduced even in the absence of a super-state authority. Nuclear states may on occasion voluntarily abandon nuclear weapons, or may be prevented from acquiring them by other states. South Africa, for example, decommissioned its nuclear forces in $1990 .^{5}$ Iraq's nuclear ambitions have been temporarily dashed by extensive observation and interference by United Nations personnel. Bilateral and multilateral arms limitation agreements could also diminish the supply of nuclear weapons.

${ }^{3}$ See for example Stephen Kinzer, "World Court Weighs Legality of Atomic War," New York Times, November 20, 1995, p. A7.

4 John J. Weltman, "Nuclear Devolution and World Order," World Politics 32 (January 1980): 193. Bull rejects total disarmament not only on the grounds of being "impracticable," but because it is impossible. In his view, human society has an innate capacity for organized violence. See Bull, Arms Race, p. 34.

${ }^{5}$ For more on the story of South Africa's nuclear experience, see J.W. de Villiers, Roger Jardine and Mitchell Reiss, "Why South Africa Gave Up the Bomb," Foreign Affairs 72 (November-December 1993): 98-109. 
However, weapons miniaturization is also making arms control verification nearly impossible. ${ }^{6}$ Furthermore, states that voluntarily or involuntarily reduce their arsenals still possess the knowledge and industrial bases necessary to build these weapons again if they were required. ${ }^{7}$ Nye explains that "it would be impossible to abolish nuclear knowledge without burning all books and all scientists."

The prospects for supply-oriented measures do not look promising, because reductions in supply (the mere number of nuclear weapons at present) do not diminish potential supply (the number of nuclear weapons that could be available in the future). However, as we will see below, while such measures may not inhibit future nuclear proliferation, they do diminish the likelihood of cascading accidents in the present.

${ }^{6}$ Bruce Berkowitz, "Technological Progress, Strategic Weapons, and American Nuclear Policy," Orbis 29 (Summer 1985): 250-254. Indeed, he argues that "because of the theoretical accuracies of modern strategic weapons, the ability to verify compliance with arms control limits may now be inherently incompatible with the need to maintain a survivable strategic force." Ibid, p. 252.

${ }^{7}$ As Beaton and Maddox put it, "The spread. . . is undesirable and dangerous. It is also irreversible; once a country has reliable and tested nuclear weapons it has a potentiality which no renunciation can entirely remove." Beaton and Maddox, The Spread of Nuclear Weapons, p. 205. Bull concurs, explaining that, "A nation's war potential does not reside merely in its 'armaments', but in the whole complex of its economic and demographic resources, strategic position, technological and industrial skill, military experience and ingenuity, morale, commitments and more besides ..." Bull, Arms Race, p. 35.

${ }^{8}$ Joseph S. Nye, Jr., "The Long-Term Future of Deterrence," in The Logic of Nuclear Terror, ed: Roman Kolkowicz (Winchester, MA: Allen \& Unwin, Inc., 1987), p. 240. 


\section{Anarchical Demand-Oriented Measures}

Unfortunately, unlike the case of most other commodities, the demand for nuclear weapons seems highly inelastic to supply. In an anarchical order, there are incentives to acquire nuclear weapons both when supply is low and when it is high. ${ }^{9}$ Therefore, supply-oriented measures are unlikely to depress demand; some such measures, under some circumstances, may actually increase demand. ${ }^{10}$

However, by reducing demand, corresponding reductions in the supply of nuclear weapons may be more easily achieved. ${ }^{11}$ Unfortunately, demandoriented measures would likely be difficult, for they would involve to alleviating the tensions and conflicts among states to such a degree that recourse to violence is not considered a viable option. When there is room for compromise in inter-state disputes, demand-oriented measures might

${ }^{9}$ When supply is low, to be among the few in possession of nuclear weapons is better than to be at the mercy of another state. When supply is high, to be among the few without nuclear weapons is also undesirable. Compelling justifications for possession can be found at any level of supply.

${ }^{10}$ The aforementioned example of Iraq is a prime example of this difficulty. One cannot help but suspect that United Nations efforts to prevent Iraqi acquisition of weapons of mass destruction only increases their desire for these weapons. The U.N. - nor anyone else - interferes too much in the affairs of the U.S., Russia, China, Britain, France or other nuclear powers.

${ }^{11}$ For an example of a demand-oriented approach, see Daniel Ellsberg, "Manhattan Project II: To End the Threat of Nuclear War," Harvard Journal of World Affairs (Summer 1992): 1-16. 
succeed. However, other inter-state conflicts have become so bitter, and linked to so many issues, that it may be nearly impossible to reduce the demand for nuclear weapons (or other weapons of mass destruction) on either side. $^{12}$

The demand for nuclear weapons could also be slowed if effective defensive measures were developed. As Richard Rosecrance explains, "Counteraction [i.e., defenses] will not only affect the destabilizing impact of weapons diffusion, it will also reduce the incentives for further diffusion." ${ }^{13}$ However, the likelihood that such defenses would be sufficiently effective - or affordable - appear slim.

\section{How Far Will Nuclear Weapons Spread?}

Even though supply-and demand-oriented measures do not appear to be promising at present, it is unlikely that nuclear weapons will spread to

${ }^{12}$ For decades, the U.S. has positioned forces between North and South Korea to deter an attack by the North. The same sort of long-term commitment may prove necessary to prevent warfare in Bosnia.

Though their relations are not as hostile as those between the Muslims and the Serbs in Bosnia, or the North and South Koreans, the conflict between Turkey and Syria provides a good example of issue-linkage. The Turks are damming the Tigris and Euphrates rivers, diminishing flow into Syria. The Syrians, however, provide support for Kurdish separatists operating in eastern portions of Turkey. A solution to this conflict would require that both activities cease, or at least diminish to an acceptable degree.

${ }^{13}$ R. N. Rosecrance, "Stability and Nuclear Diffusion," in The Dispersion of Nuclear Weapons, ed: R. N. Rosecrance (New York: Columbia University Press, 1964), p. 309. 
every state. A few states, or course, may be not desirous of these weapons, despite the Optimists' salesmanship. Other states may forego nuclear weapons in favor of other, comparably horrific weapons. ${ }^{14}$ In the unlikely event that effective defenses are developed, the spread may also cease.

As proliferation continues, a formidable political obstacle to the continued spread of nuclear weapons may arise. As Berkowitz has argued, the size of the Nuclear Club may grow to include enough states that they could collectively halt proliferation — and thus preserve their nuclear advantages over those excluded from the Club. ${ }^{15}$ He anticipates that the spread will slow sometime around that half-way mark. (Unfortunately, he also argues that a half-nuclearized world is the most dangerous of all worlds, because the opportunities of conflict among nuclear and non-nuclear states would at that point be greatest. ${ }^{16}$ )

${ }^{14}$ For a comparison of the damage that could be wrought by missiles armed with nuclear warheads or anthrax spores, see Steve Fetter, "Ballistic Missiles and Weapons of Mass Destruction," International Security 16 (Summer 1991): 6. Just as nuclear weapons produce fallout and lingering after-effects, anthrax spores can survive for decades in the soil. Ibid, p. 26.

${ }^{15}$ Bruce Berkowitz, "Proliferation, Deterrence, and the Likelihood of War," Journal of Conflict Resolution 29 (March 1985): 134.

${ }^{16}$ Ibid., pp. 133-134. In Chapter One, I classified Berkowitz as an Optimist, because he argues that a nuclearized world would be a safe world. However, at this point in time, as the world approaches the half-way point, he is basically Pessimistic. After this point, he argues that nuclear states ought to facilitate further proliferation, though he predicts that this will not occur. 
Of course, it is impossible to accurately forecast the extent to which nuclear weapons will proliferate. Though Berkowitz's argument is intriguing, there may be no means by which Club members can prevent their fellows from sharing technology with outsiders. Where proliferation ends depends on who is left out in the cold, and whether they have allies among the nuclear states who would rather see them armed with nuclear weapons than to extend their deterrent to include them.

Therefore, at whatever point the spread ceases, the non-nuclear states may be expected to be composed of two groups. First, some non-nuclear states may enjoy security without nuclear weapons, through alliances or the possession of other destructive or defensive capabilities. Second, "pariah" states, with no allies among the nuclear states, may be prevented from developing or acquiring weapons of their own by the interference of these states.

One may legitimately wonder not only how far proliferation will spread, but how far proliferation ought to spread. Usually two views of arms control predominate. First is the view that arms control should seek disarmament; "that it is the business of arms control to bring about a world radically different from our own. .."17 The second view is that a balance of power is the best

${ }^{17}$ Bull, Arms Race, p. 62. 
mechanism by which to promote peace, but that arms control is largely irrelevant, because such balances are robust and naturally-occurring.

Third is the view, held by Bull and myself, that while the balance of power is the best mechanism by which to promote peace, balances must be consciously maintained. In this view, the proper ends of arms control should be to support the balance, to minimize the number of armaments required to balance, and to restrict the deployment of armaments that threaten to upset the balance or to accelerate arms races. ${ }^{18}$ In this view, the optimal number of nuclear weapons is not zero or any other fixed amount, but the minimum necessary to achieve stable balances between potential rivals.

\section{CAN PROLIFERATION-RELATED PROBLEMS BE SOLVED ANYWAY?}

Today, existing nuclear states lack the will to prevent the further spread of nuclear weapons. If proliferation cannot be completely impeded for the foreseeable future, might the five problems discussed in Chapter Three be solvable anyway? In the subsections below, possible measures to attenuate the five problems stemming from proliferation are considered.

${ }^{18}$ Ibid. 


\section{Creeping Anti-Classical Thought}

As discussed in Chapter Three, the Classicals believe that states can be educated of the virtues of MAD. This may be possible, though it would be difficult to do so given the appeal of the idea that nuclear weapons are useful, that defenses are desirable, and that rendering one's adversary vulnerable is a worthy goal. Classical lessons would be far more likely to be absorbed if the mentor was a close ally of the tutored state.

Of course, advocacy of this educational measure presumes that MAD is indeed preferable to NUTS in some objective sense. I spent a great deal of time the two previous chapters challenging this notion. As Bull explains, "Deterrence is a psychological, not a military, relationship, and what military capacity is necessary to maintain it will depend on the changing character and intentions of the opponent." ${ }^{\text {"19 }}$ While a world of MAD states may seem preferable to a world populated by NUTS states, in the interim there may be occasions in which improvements in deterrence stability are achieved by coaxing a state into abandoning MAD to better deter a NUTS adversary.

Over the long run, hostile pairs of states may co-evolve from NUTS to $M A D$, as they build trust through non-use and seek to reduce the costs of deterring one another. Then again, one side or the other may fail to refrain

\footnotetext{
${ }^{19}$ Bull, Arms Race, p. 105.
} 
from using nuclear weapons. Such an event would have a demonstration effect beyond the immediate deterrence relationship to other states, the nature of which would depend on the outcome of use. ${ }^{20}$ As Fred Iklé explains, "The strategic order among the major nuclear powers is fragile precisely because it rests so heavily on beliefs and untested theories. As soon as these beliefs are confronted with compelling evidence to the contrary, the strategic order will start to break up."21

Furthermore, if it is in the parochial interest of powerful sub-state level actors in either side of the deterrence relationship to "gear up" for NUTS, such gradual co-evolution to MAD would also be slowed if not completely derailed.

\section{Parochialism and Myopia}

The problem of parochialism and myopia, stemming from the frequent divergence of individual and collective interests, and between short- and longterm interests, are not easily rectified. A possible solution may be greater civil

\footnotetext{
${ }^{20}$ If a nuclear use escalated into a mutual suicide for two Anti-Classical states, the lesson drawn by other states would likely be that MAD is the superior doctrine. However, if deterrence broke down between two MAD-oriented states, NUTS may gain adherents.

Other outcomes may provide no clear lessons. For example, if nuclear hostilities erupted between states pursuing contrary doctrines, it would offer no evidence of the superiority of either doctrine, other than to demonstrate that MAD is not as universallyappealing as some Classicals suggest.

${ }^{21}$ Fred Charles Iklé, "The Second Coming of the Nuclear Age," Foreign Affairs 75 (January-February 1996): 123.
} 
governmental regulation (i.e., not military authority) over defense industries, so that research and development could follow policy rather than - as it occasionally seems to do - lead it.

Unfortunately, I doubt that this measure would succeed in diminishing the severity of the problem of parochialism and myopia. Ad hoc rather than continuous weapons research and development could slow military technological progress relative to progress in states with less regulation of their defense industries, and increase production costs. Therefore, there would be pressures to again unbridle the defense industry. Furthermore, regulation would have to extend to nearly every frontier of technological development, for breakthroughs on a variety of fronts (e.g., aeronautics, artificial intelligence, lasers) could yield military applications that may run contrary to a state's avowed strategic doctrine. Finally, civil governmental authorities may be no worse at regulating the defense industry than the market - but they may be no better, either. It is conceivable that such authorities could use their positions to fulfill their own parochial and myopic interests to the detriment of the long-term strategic needs of the state as a whole.

To ensure that a state's strategic doctrine does not become a plastic set of rationalizations for every new weapon technology, the architects and advocates of the doctrine must succeed at convincing military and defense 
industry officials that it is sound, and that deviations from it are dangerous.

This would be a more difficult task for the advocates of MAD than those of NUTS, because the latter doctrine is not only more appealing, but it also allows for just about every weapons technology under the sun. Therefore, true believers in NUTS in the military and in the defense industry consider themselves able to satisfy their instincts, their parochial interests, and their state's interests simultaneously.

\section{Asymmetrical Proliferation and Preventative War}

To solve the problem of asymmetrical proliferation, states may be forced to assist states made vulnerable by the nuclearization of their rivals. One obvious way to provide such assistance is to give them nuclear weapons technology, so that they would be able to deter attacks upon themselves. ${ }^{22}$ Unfortunately, while it may solve this problem, this solution exacerbates the four other proliferation-related problems. ${ }^{23}$

\footnotetext{
${ }^{22}$ Michael D. Intriligator and Dagobert L. Brito, "Nuclear Proliferation and the Problem of War," Public Choice 37 (1981): 251.

${ }^{23}$ Actually, managed proliferation may be a useful method of ensuring that tutored states pursue MAD. However, to assume this is an advantage is also to assume that MAD is truly the superior doctrine. As mentioned earlier, in some cases stability may be best served by encouraging a nuclear pupil to pursue NUTS when its adversary is of the Anti-Classical persuasion.

One might also argue that nuclear mentoring may actually reduce the danger of accidents. However, while it may allow older nuclear states to ensure that the arsenals of new nuclear states are designed in a safe and unprovocative manner, the new nuclear state's arsenal cannot be expected to be any safer than its mentor's. As we have seen, the nuclear
} 
Another solution may be for nuclear states to extend their deterrent over their vulnerable allies. However, extended deterrence suffers from a lack of credibility, and vulnerable states may not be satisfied if their security rests on the empty threats of another. Furthermore, older nuclear states may resist extending their deterrence for fear of being drawn into a conflict, or of having their reputations tarnished if they back out of their commitments.

A tentative conclusion of a deterrence study by Huth and Russett is that extended deterrence is more successful among trading partners. They argue that "an important contribution to effective deterrence may emerge from the achievement of a goal that is usually sought for other purposes maintaining and strengthening the ties of mutual interest among nation-states in an open global economic system."24

It makes sense that extended deterrence threats would be more successful when employed to protect a partner in whom one has a vested interest of some sort. If states attempt to mitigate the dangers of

operations of the older nuclear states have been far from perfect. Additionally, proliferation diminishes the distance between nuclear states, increases the pressure to adopt launch-onwarning, and hence increases the risk that a serious accident could escalate into a nuclear exchange.

${ }^{24}$ Paul K. Huth and Bruce Russett, "What Makes Deterrence Work? Cases from 1900 to 1980," World Politics 34 (July 1984): 524. 
asymmetrical proliferation through extended deterrence, they ought to ensure that they increase visible ties with their nuclear protectorates.

\section{Nuclear Use as a Result of a Cascading Accident}

As mentioned in the discussion of supply-oriented counter-proliferation measures above, the best means to diminish the likelihood of cascading accidents would be to render all or some portion of one's nuclear arsenal incapable of launching on a mere moment's notice. As Sagan illustrates, increasingly complicated measures to ensure safety will not be perfect, and while accidents may occur less often, they may be more difficult to remedy. Furthermore, regardless of the sophistication of one's safety measures, the pride of the custodians of a state's nuclear arsenal may cause them to resist admitting that accidents have occurred, or could occur. It is difficult to devise safety measures to prevent mishaps that are not even considered.

Unfortunately, such "stand-down" measures - such as decoupling warheads from missiles or merely retargeting them on unpopulated areas are the least likely to be pursued in the cases where it is most desirable that they would be. Again, the best means to solve this problem is the most challenging: to address the underlying sources of conflict, so that states can step back from the brink. 


\section{Catalytic War}

The fifth danger, catalytic war, is also difficult to remedy. Through the use of "nuclear forensics," investigators may be able to track down the instigators of such an event with a combination of satellite and human intelligence. However, bringing catalysts to justice is little consolation to their victims. To prevent the occurrence of catalytic war, it would be necessary that its potential practitioners be aware of the ability of investigators to establish their culpability.

Of course, such post facto detective work may not be possible. Indeed, depending upon the meticulousness of their plans, the catalysts may leave no evidence to indicate that the war was instigated by a third party. The best and most difficult way to avoid catalytic war, or any war for that matter, is to ameliorate the hostile relations among states so that none feels compelled to resort to arms - ostentatiously or even anonymously.

\section{ETHNOCENTRISM: A RESPONSE}

As the reader may recall from Chapter One, some of the leading Optimists have accused the Pessimists of being motivated - consciously or not - by ethnic prejudice. Though I chose not to address this charge in that chapter, I would be remiss not to take an occasion to comment on it before concluding. 
The Optimists must advance such accusations because they cannot otherwise account for the fact that reasonable observers of nuclear proliferation could come to conclusions dissimilar to their own. Moreover, the Optimists seem blind to their own "epistemocentric" biases. Though attempting to illustrate that unfounded prejudices may impinge on reason is laudable, the Optimists' charge is coupled with an implicit valorization of their own way of thinking. Who is to say that the Optimists have struck upon the correct way of thinking about deterrence and proliferation?

The irony and arrogance of their argument is striking. Essentially, the Optimists accuse their critics of having underestimated the ability of leaders in new nuclear states to attain the level of cognitive sophistication and lucidity of thought they enjoy themselves. By so doing, they reveal their own conceit that theirs is the only correct way of thinking about matters of nuclear deterrence.

Indeed, Classical deterrence theory itself could be fairly called ethnocentric, because it assumes that everyone thinks like Western strategists, or ought to. However, just as Soviet strategic thought was rooted in the experience of the Russian people, so too was strategic thought in the U.S. based on the unique American experience. As Jervis explains,

Like most theories of international relations developed by the Americans and West Europeans, it is grounded in the experience, culture, and values of the West; deterrence theorists usually assume 
that while countries differ in the goals they seek, they see the world in the same way. Others may hold a strategic doctrine that lags behind that of the United States, but they will eventually come around to the "correct" way of seeing things. ${ }^{25}$

Though directed specifically at Wohlstetter, DeNardo's criticism seems applicable to Classicals who maintain that there is some logic of deterrence that they have discovered and that others will, too.

[Classicals] implicitly assume that deterrence has an inherent logic, apparent by reflection alone, and rationally compelling to all (perhaps after some instruction). To defend his prescriptions for designing nuclear forces, [for example,] Wohlstetter appeals to universal principles, not to empirical evidence that describes how people actually think and reason about deterrence. Of course, contrary opinions necessarily violate the universal principles. They are dismissed as 'confused. 26

It is the presence of this "confusion" above all else that seems to undermine the Optimists' argument. So long as states behave in a "confused" way by failing to adhere to the tenets of MAD, there seems to be much less reason for Optimism regarding the spread of nuclear weapons.

\footnotetext{
${ }^{25}$ Robert Jervis, "Deterrence Theory Revisited," World Politics 31 (January 1979): 296.

${ }^{26}$ James DeNardo, The Amateur Strategist: Intuitive Deterrence Theories and the Politics of the Nuclear Arms Race (New York: Cambridge University Press, 1995), p. 38. In fairness to the Optimists, there is little data to work with. DeNardo skirts the problem by examining the strategic beliefs of people not directly involved in the formulation of deterrence policy.
} 


\section{TECHNOLOGY AND DETERRENCE}

Before concluding, two important points ought to be made. First, nuclear weapons, though capable of inflicting damage on a enormous scale and with unprecedented speed, are not "absolute" weapons. More nightmarish weaponry already exists, and more undoubtedly lies on the horizon. The problem humanity faces is not nuclear weapons, but continuous technological innovation in a conflict-riven global environment. ${ }^{27}$ Humankind must reduce the number and intensity of conflicts before weapons become so small, destructive and cheap that they cannot be kept out of the hands of those willing to use them. Some conflicts may not be solvable, and in these cases balances must be sought between the potential (or actual) belligerents. In some cases it may be possible to achieve a balance at low levels of destructive power; in others, however, it may first be necessary to bolster the weaker side to pave the way for such mutual reductions. ${ }^{28}$

27 "The chief theme of studies of strategy and arms control is not the nuclear explosive (or any particular weapon or weapons system), but military technology, and the problem of war in a society whose most distinctive feature is the tendency to continuous and accelerating innovation." Bull, The Control of the Arms Race, p. 96.

${ }^{28} \mathrm{My}$ admission that in come cases in may be necessary to equip weak and threatened states with nuclear weapons does not undermine my thesis that the spread of nuclear weapons is dangerous as ought to be avoided. Nuclear sharing is a short-term fix; while it may diminish the likelihood of nuclear blackmail or preventative war, it increases the four other dangers discussed. The long-term fix, on the other hand, would entail achieving a stable balance between adversaries, then attempting to reduce the level of destructive power at which the balance is established. 
Second, deterrence theory has long been focused on the behavior of unitary rational actors; few innovations have been made. ${ }^{29}$ The rationalirrational dichotomy is considered by all a gross simplification of reality. As Morgan suggests, "observing that there are varying degrees and kinds of irrationality would mean designing threats accordingly." ${ }^{30}$ Increased attention ought to be devoted to how various types of personalities and decisionmaking bodies assess risk and react to different type of threats. ${ }^{31}$

${ }^{29}$ The lack of innovation should not be interpreted as a sign that deterrence theory is fully developed, just as the lack of nuclear warfare should be taken to indicate that the theory is correct. Better to innovate now than to wait for deterrence theory to fail. As Steinbruner puts it, "In principle, our society ought to spare no effort to drive understanding of the problem of nuclear defense to the very limits of human comprehension; but we are hardly doing that." John D. Steinbruner, "Beyond Rational Deterrence: The Struggle for New Conceptions," World Politics 28 (January 1976): 224.

${ }^{30}$ This point is emphasized throughout Patrick M. Morgan, Deterrence: A Conceptual Analysis (Beverley Hills: Sage Publications, 1977).

31 Ibid., p. 157. 


\section{BIBLIOGRAPHY}

Allison, Graham T. Essence of Decision: Explaining the Cuban Missile Crisis. Boston: Little and Brown, 1971.

Allyn, Bruce J.; Blight, James G.; Welch, David A. "Essence of Revision: Moscow, Havana, and the Cuban Missile Crisis." International Security 14 (Winter 1989-90): 136-172.

Aron, Raymond. "The Anarchical Order of Power." Daedalus 124 (Summer 1995): 27-52.

Beaton, Leonard; Maddox, John. The Spread of Nuclear Weapons. New York: Frederick A. Praeger, Inc., 1962.

Berkowitz, Bruce. "Proliferation, Deterrence, and the Likelihood of War." Journal of Conflict Resolution 29 (March 1985): 112-136.

- "Technological Progress, Strategic Weapons, and American Nuclear Policy." Orbis 29 (Summer 1985): 241-258.

Betts, Richard K. Nuclear Blackmail and Nuclear Balance. Washington, D.C.: The Brookings Institution, 1987.

Blair, Bruce G. Global Zero Alert for Nuclear Forces. Washington, D.C.: The Brookings Institution, 1995.

Blaker, James. "Coping With the New 'Clear and Present Danger' From Russia." Arms Control Today 25 (April 1995): 13-16.

Boulding, Kenneth E. "What Power Do Nuclear Weapons Give Their Possessors? The Basic Instability of Deterrence." In After the Cold War: Questioning the Morality of Deterrence, pp. 99-110. Edited by Charles W. Kegley, Jr. and Kenneth L. Schwab. Boulder: Westview Press, 1991.

Brodie, Bernard. The Absolute Weapon: Atomic Power and World Order. New York: Harcourt Brace, 1946.

Brown, Seyom. International Relations in a Changing Global System: Toward a Theory of the World Polity. Boulder: Westview Press, 1992. 
Bueno de Mesquita, Bruce; Riker, William H. "An Assessment of the Relative Merits of Selective Nuclear Proliferation." Journal of Conflict Resolution 26 (June 1982): 293-306.

Bull, Hedley. The Control of the Arms Race. New York: Praeger, 1961. . "International Theory: The Case for the Classical Approach." World Politics 18 (April 1966): 361-377.

"Rethinking Non-Proliferation." International Affairs 51 (January 1975): 175-189.

The Anarchical Society: A Study of Order in World Politics. 2nd ed. New York: Columbia University Press, 1995.

Buzan Barry; Jones, Charles; Little, Richard. The Logic of Anarchy: Neorealism to Structural Realism. New York: Columbia University Press, 1993.

Cohen, Michael D.; March, James G.; Olsen, Johan P. "A Garbage Can Model of Organizational Choice." In Decisions and Organizations, pp. 294-334. Edited by James G. March. Oxford: Basil Blackwell, 1988.

DeNardo, James. The Amateur Strategist: Intuitive Deterrence Theories and the Politics of the Nuclear Arms Race. New York: Cambridge University Press, 1995.

de Villiers, J.W.; Jardine, Roger; Reiss, Mitchell. "Why South Africa Gave Up the Bomb." Foreign Affairs 72 (November-December 1993): 98-109.

Ellsberg, Daniel. "Theory of the Reluctant Duelist." American Economic Review 46 (December 1956): 909-23.

"The Theory and Practice of Blackmail." In Bargaining: Formal Theories of Negotiation, pp. 343-63. Edited by Oran Young. Chicago: University of Illinois Press, 1975.

. "Manhattan Project II: To End the Threat of Nuclear War." Harvard Journal of World Affairs (Summer 1992): 1-16.

Elster, Jon. Nuts and Bolts for the Social Sciences. Cambridge, U.K.: Cambridge University Press, 1989. 
Fetter, Steve. "Ballistic Missiles and Weapons of Mass Destruction." International Security 16 (Summer 1991): 5-42.

Frank, Robert H. Passions Within Reason: The Strategic Role of Emotions. New York: W.W. Norton \& Co., 1988.

Gallois, Pierre Marie. The Balance of Terror. Boston: Houghton-Mifflin, 1961.

Gilpin, Robert. War and Change in World Politics. New York: Cambridge University Press, 1981.

Gray, Colin S. "Strategic Stability Reconsidered." Daedalus 109 (Fall 1980): 135-54.

Gray Colin S.; Payne, Keith. "Victory is Possible." Foreign Policy 39 (Summer 1980): 14-27.

Haggard, Stephen. "Structuralism and Its Critics: Recent Progress in International Relations Theory." In Progress in Postwar International Relations, pp. 403-437. Edited by Emanuel Adler and Beverly Crawford. New York: Columbia University Press, 1991.

Hamilton, Lawrence C.; Hamilton, James D. "Dynamics of Terrorism." International Studies Quarterly 27 (March 1983): 39-54.

Harkabi, Yehoshafat. Nuclear War and Nuclear Peace. Jerusalem: Israel Program for Scientific Translations, 1966.

Harsanyi, John C. "Rational-Choice Models of Political Behavior vs.

Functionalist and Conformist Theories." World Poltics 21 (July 1969): 513-30.

Hersh, Seymour M. The Price of Power: Kissinger in the Nixon White House. New York: Summit Books, 1983. 69. "On the Nuclear Edge." The New Yorker, March 29, 1993, pp. 56-

Howard, Michael. "The Forgotten Dimensions of Strategy." Foreign Affairs 57 (Summer 1979): 975-986.

Hume, David. Essays, Moral, Political and Literary. Indianapolis: Liberty Classics, 1985. 
Huth, Paul K.; Russett, Bruce. "What Makes Deterrence Work? Cases from 1900 to 1980." World Politics 34 (July 1984): 496-526.

Iklé, Fred Charles. "The Second Coming of the Nuclear Age." Foreign Affairs 75 (January-February 1996): 119-28.

Intriligator, Michael D.; Brito, Dagobert L. "Nuclear Proliferation and the Problem of War." Public Choice 37 (1981): 247-260.

Janis, Irving L.; Mann, Leon. Decision Making: A Psychological Analysis of Conflict, Choice, and Commitment. New York: The Free Press, 1977.

Jervis, Robert. "Deterrence Theory Revisited." World Politics 31 (January 1979): 289-324. "Arms Control, Stability and Causes of War." Political Science Quarterly 108 (Summer 1993): 239-53.

Kahn, Alfred E. "The Tyranny of Small Decisions: Market Failures, Imperfections, and the Limits of Econometrics." In Economic Theories of International Politics, pp. 522-37. Edited by Bruce Russett. Chicago: Markham Publishing Co., 1968.

Karp, Aaron. "Ballistic Missiles in the Third World." International Security 9 (Winter 1984-85): 166-195.

Keeny, Spurgeon M., Jr.; Panofsky, Wolfgang K. H. "MAD Versus NUTS." Foreign Affairs 60 (Winter 1981-82): 287-304.

Kegley, Charles W., Jr.; Wittkopf, Eugene R. American Foreign Policy: Pattern and Process, 3rd ed. New York: St. Martin's Press, 1987.

Kinzer, Stephen. "World Court Weighs Legality of Atomic War." New York Times, November 20, 1995, p. A7.

Kothari, Rajni. "Sources of Conflict in the 1980's." Adelphi Papers 134 (Spring 1977).

Kramish, Arnold. "The Emergent Genie." In The Dispersion of Nuclear Weapons, pp. 261-73. Edited by R.N. Rosecrance. New York: Columbia University Press, 1964.

Kull, Steven. "Nuclear Nonsense." Foreign Policy 58 (Spring 1985): 28-52. 
Lambeth, Benjamin. Selective Nuclear Options in American and Soviet Strategic Policy. Santa Monica, CA: RAND Corporation, R-2034DDRE, December 1976.

Lebow, Richard Ned. "Deterrence: A Political and Psychological Critique." In Perspectives on Deterrence, pp. 25-51. Edited by Paul C. Stern, Robert Axelrod, Robert Jervis and Roy Radner. New York: Oxford University Press, 1989.

Leitenberg, Milton. "Nuclear Weapons and 50 Years of International Political History: Risks, Dangers, Threats, Crises, Proposals and Considerations of Use." 7 August, 1995. (Mimeographed.)

Lieshout, Robert H. Between Anarchy and Hierarchy: A Theory of International Politics and Foreign Policy. Aldershot, U.K.: Edward Elgar Publishing Ltd., 1995.

Lodal, Jan N. "Deterrence and Nuclear Strategy." Daedalus 109 (Fall 1980): 155-175.

Luttwak, Edward N. "Toward Post-Heroic Warfare." Foreign Affairs 73 (MayJune 1995): 109-122.

Mearsheimer, John J. "Back to the Future: Instability in Europe After the Cold War." In The Cold War and After: Prospects for Peace, pp. 141-92. Edited by Sean M. Lynn-Jones and Steven E. Miller. Cambridge: MIT Press, 1993.

Morgan, Patrick M. Deterrence: A Conceptual Analysis. Beverley Hills: Sage Publications, 1977.

Nitze, Paul H. "Deterring Our Deterrent." Foreign Policy 25 (Winter 76-77): 195-210.

Nye, Joseph S., Jr. "NPT: The Logic of Inequality." Foreign Policy 59 (Summer 1985): 123-31.

. "The Long-Term Future of Deterrence." In The Logic of Nuclear Terror, pp. 233-50. Edited by Roman Kolkowicz. Winchester, Mass.: Allen \& Unwin, Inc., 1987.

. Understanding International Conflict: An Introduction to Theory and History. New York: HarperCollins College Publishers, 1993. 
Perrow, Charles. Normal Accidents: Living With High-Risk Technologies. New York: Basic Books, 1984.

Pipes, Richard. "Why the Soviet Union Thinks It Could Fight and Win a Nuclear War." Commentary 64 (July 1977): 21-34.

Powell, Robert. "The Theoretical Foundations of Strategic Nuclear Deterrence." Political Studies Quarterly 100 (Spring 1985): 75-96.

Quester, George H. "Cultural Barriers to an Acceptance of Deterrence." In The Logic of Nuclear Terror, pp. 82-109. Edited by Roman Kolkowicz. Winchester, MA: Allen \& Unwin, Inc., 1987.

Rapoport, David C. "Fear and Trembling: Terrorism in Three Religious Traditions." American Political Science Review 78 (September 1984): 658-77.

Rhodes, Edward J. Power and MADness: The Logic of Nuclear Coercion. New York: Columbia University Press, 1989.

Riker, William H. "Political Science and Rational Choice." In Perspectives on Positive Political Economy, pp. 163-181. Edited by James E. Alt and Kenneth A. Shepsle. Cambridge, U.K.: Cambridge University Press, 1990.

Rosecrance, R. N. "Stability and Nuclear Diffusion." In The Dispersion of Nuclear Weapons, pp. 299-318. Edited by R. N. Rosecrance. New York: Columbia University Press, 1964.

"Bipolarity, Multipolarity and the Future." Joumal of Conflict Resolution 10 (September 1966): 314-27.

Rosenau, James N. Turbulence in World Politics: A Theory of Change and Continuity. Princeton: Princeton University Press, 1990.

Rousseau, Jean Jacques, The Social Contract and Discourses. Translated by G.D.H. Cole. New York: E.P. Dutton and Co., 1950.

Sagan, Scott D. The Limits of Safety: Organizations, Accidents and Nuclear Weapons. Princeton: Princeton University Press, 1993.

"More Will Be Worse." In The Spread of Nuclear Weapons: A Debate, pp. 47-92. Edited by Scott D. Sagan and Kenneth N. Waltz. New York: W.W. Norton \& Company, Inc., 1995. 
"Sagan Responds to Waltz." In The Spread of Nuclear Weapons: A Debate, pp. 115-36. Edited by Scott D. Sagan and Kenneth $\mathrm{N}$. Waltz. New York: W.W. Norton \& Company, Inc., 1995.

Schelling, Thomas C.; Haperin, Morton. Strategy and Arms Control. New York: Twentieth Century Fund, 1961.

Schelling, Thomas C. Arms and Influence. New Haven: Yale University Press, 1966.

Schmookler, Andrew Bard. The Parable of the Tribes: The Problem of Power in Social Evolution. Albany: State University of New York Press, 1995.

Selten, Reinhard. "Bounded Rationality." Journal of Institutional and Theoretical Economics 146 (December 1990): 649-658.

Sienkiewicz, Stanley. "Observations on the Impact of Uncertainty in Strategic Analysis." World Politics 32 (October 1979): 90-110.

Simon, Jeffrey D. "Misunderstanding Terrorism." Foreign Policy 67 (Summer 1987): 104-20.

Singer, J. David. "The Political Origins of International War: A Multifactorial Review." In Aggression and War: Their Biological and Social Bases, pp. 202-19. Edited by Jo Groebel and Robert A. Hinde. Cambridge: Cambrige University Press, 1989.

Smart, Ian. "The Great Engines: The Rise and Decline of a Nuclear Age." International Affairs 51 (October 1975): 544-53.

Snyder, Jack L.. "Rationality at the Brink: The Role of Cognitive Processes in Failures of Deterrence." World Politics 30 (April 1978): 345-65.

Steinbruner, John D. "Beyond Rational Deterrence: The Struggle for New Conceptions." World Politics 28 (January 1976): 223-45. 28.

"Nuclear Decapitation." Foreign Policy 45 (Winter 1981-82): 16-

Strotz, R.H. "Myopia and Inconsistency in Dynamic Utility Maximization." Review of Economic Studies 23 (1955-1956): 165-180. 
Trachtenberg, Marc. "A 'Wasting Asset': American Strategy and the Shifting Nuclear Balance, 1949-1954." International Security 13 (Winter 198889): 5-49.

"U.S. Nuclear Weapons Accidents: Danger in Our Midst." The Defense Monitor 10 (May 1981): 1-12.

Von Neumann, John. "Can We Survive Technology?" Fortune, June 1955, pp. 106-108, 151-152.

Wagner, R. Harrison. "Nuclear Deterrence, Counterforce Strategies, and the Incentive to Strike First." American Political Science Review 85 (September 1991): 727-49.

Waltz, Kenneth N. Man, the State, and War. New York: Columbia University Press, 1954.

"Laws and Theories." In Neorealism and lts Critics, pp. 27-46. Edited by Robert Keohane. New York: Columbia University Press, 1986.

"Reductionist and Systemic Theories." In Neorealism and Its Critics, pp. 47-69. Edited by Robert Keohane. New York: Columbia University Press, 1986.

"Political Structures." In Neorealism and Its Critics, pp. 70-97. Edited by Robert Keohane. New York: Columbia University Press, 1986.

"Anarchic Orders and Balances of Power." In Neorealism and Its Critics, pp. 98-130. Edited by Robert Keohane. New York: Columbia University Press, 1986.

"Reflections on Theory of International Politics: A Response to My Critics." In Neorealism and Its Critics, pp. 322-45. Edited by Robert Keohane. New York: Columbia University Press, 1986.

"The Origins of War in Neorealist Theory." In The Origin and Prevention of Major Wars, pp., 39-52. Edited by Robert I. Rotberg and Theodore K. Rabb. Cambridge, U.K.: Cambridge University Press, 1988. 
"Nuclear Myths and Political Realities." American Political Science Review 84 (Semptember 1990): 731-45.

"More May Be Better." In The Spread of Nuclear Weapons: A Debate., pp. 1-46. Edited by Scott D. Sagan and Kenneth N. Waltz. New York: W.W. Norton \& Company, Inc., 1995.

"Waltz Responds to Sagan." In The Spread of Nuclear Weapons: A Debate., pp. 93-114. Edited by Scott D. Sagan and Kenneth N. Waltz. New York: W.W. Norton \& Company, Inc., 1995.

Weltman, John J. "On the Obsolescence of War: An Essay in Policy and Theory." International Studies Quarterly 18 (December 1974): 395416.

"Nuclear Devolution and World Order." World Politics 32 (January 1980): 169-93.

Wendt, Alexander E. "The Agent-Structure Problem in International Relations Theory." International Organization 41 (Summer 1987): 335-70.

Wentz, Walter B. Nuclear Proliferation. Washington, D.C.: Public Affairs Press, 1968.

Wohlstetter, Albert. "Nuclear Sharing: NATO and the N+1 Country." In The Dispersion of Nuclear Weapons., pp. 186-221. Edited by R.N.

Rosecrance. New York: Columbia University Press, 1964.

. "Technology, Prediction and Disorder." In The Dispersion of Nuclear Weapons., pp. 274-89. Edited by R.N. Rosecrance. New York: Columbia University Press, 1964.

Wolf, Barry. When the Weak Attack the Strong: Failures of Deterrence. Santa Monica, CA: RAND Corporation, N-3261-A, 1991.

Yesson, Erik. "Strategic Make-believe and Strategic Reality." International Security 14 (Winter 1989-90): 182-93. 